\title{
THE KODAKISTAN EDUCATION PROGRAM RESOURCE MANUAL
}

\author{
VOLUME II: Activities
}

Internationl Rescue Committee

Peshawar, Pakistan

1993 
Suggested Games, Activities and Learning Materials

\section{INTRODUCtion to Part V}

II. Suggested Games, activities and learning Materials

- Classroom Management Ideas $\quad 3$

Ideas for Display 9

- Educational Games and Toys 11

- Language Development 27

- Mathematics 45

- Art and Craft 93

$\begin{array}{ll}\text { Materials for Art/Craft } & 107\end{array}$

- Physical Education $\quad \cdot \quad 109$

$\begin{array}{ll}\text { Sand and Waterplay } & 117\end{array}$

- Music 119

$\begin{array}{ll}\text { Making Musical Instruments } & 124\end{array}$

$\begin{array}{ll}\text { - } & \text { Science } \\ & 129\end{array}$

- Islamiat 148

- Health Education 154

- Nursery 156

- Citizenship Education 164

III. BIBLIOGRAPIIY 
PART V

SUGGESTED GAMES, ACTIVITIES AND LEARNING MATERIALS 


\section{INTRODUCTION TO PART V \\ SUGGESTED GAMES, ACTIVITIES AND LEARNING MATERIALS}

The final section of the KEP Resource Manual - Pant $V$ : Suggested Games, Activities and Learning Materials is a collection of ideas for the kodakistan teacher to implement in the classroom. Some are activities for the whole group, things to do with individual children, small group activities or games and exercises children can undertake independently. Other activities include things to make for children to play with and learn from, or things to better organize the classroom.

Part $V$ has been divided into sections which reflect the kodakistan curriculum: Language, Mathematics, Art and Craft and so on, as well as some additional topic areas like Educational Toys and Classroom Management Ideas. Keep in mind that the divisions are of necessity somewhat arbitrary. That is, a specific activity can often fall into more than one category. For example, listening activities are part of language development skills as well as Music activities. A Mathematics activity can be combined with physical exercise and it becomes appropriate for Physical Education, yet still promotes number concepts. The divisions have been created as a means to organize the numerous activities and facilitate finding appropriate activities for a particular skill. However, do not be confined by the categories - they are not intended to limit how the kodakistan teacher implements any of the suggestions.

\section{There are several points to keep in mind when using and selecting particular activities:}

- Do not feel bound to activities as they are described. The suggested activity represents only one possibility. Alter the activity or game to suit your needs: an independent activity can be altered to accommodate a large group; an advanced activity can be simplified to be appropriate for younger children; use different materials if certain resources are not available, etc.

- Use these recommendations as a way to spark more ideas. Record adaptations and new activities you have developed and share them with KEP for future manuals or to share with other teachers.

- It is useful to try out the activities before using it in the classroom, especially art and craft activities. Try them out with co-teachers, on your own children, or on your own. It is particularly useful to learn through actually doing. The kodakistan teacher will have a better understanding of what the children learn from the activity.

- what skills are being developed?

- what are possible problems or trouble spots?

- how can you plan for these?

- is the activity too easy or too difficult?

- how can it be made more appropriate for the age group?

Trying out activities in advance helps you plan more effectively and give you the confidence to carry out the activity well, as you are now familiar with it. 


\section{Introduction}

- Some of the activities include a list of questions to ask the children. Add your own ideas to the list. Remember to adapt any of the activities to the abilities of the age group in your class - some questions may be too difficult (or too simple) for some groups of children. Be flexible - use what is relevant and appeals to you!

- After making a game or toy, follow through with making an appropriate storage box that is clearly labeled for children to recognize the activity and know where to put it away when they are finished playing.

- Painting a toy or learning material is often recommended but not essential. If the kodakistan is pressed for funds, or particular items are not available - substitute it with less expensive items that you have access to.

- It is important for children to learn culturally relevant activities - do not hesitate to tailor activities and ideas to make them more appropriate for Afghan children.

- As a general rule, begin with easy games for children. All learners, regardless of age, like to succeed! Also, do not force a child to do something she or he is not ready to do. Let them proceed according to their own inner timetable. Remember to respect each child's individuality and value their accomplishments - whether they are slower to learn or more clever, than the other children. Children develop at their own rate and not all children can be expected to be capable of the same skills at the same time.

- And finally, the most important thing is not the actual toys, but how they are used and played with. This concept goes hand in hand with remembering that the aim is not simply to do an activity, but to develop skills and facilitate learning. For example, the aim of an art activity is not to cut and paste and make a pretty picture - although this is an additional benefit - it is to develop creativity, teach about color or perhaps develop their fine motor skills as they learn to handle pencils and scissors. The process is key. Do not lose sight of this objective by thinking only about the product.

How children learn, rather than what is most important to their development. How they learn will shape the way they learn and think in the future. The best education is one which is designed to help children become optimistic problem solvers children who are able to approach a variety of problems and situation with conficlence and self assurance even when failure is possible.

Reminder about Safety: Always keep in mind the issue of satety when undertaking an activity or making learning materials for children. For example, make sure none of the materials you are using are poisonous, such as lead paint; any wooden objects should be sanded well to avoid splinters and sharp corners; do not use objects which are small enough for very young children to swallow easily. 
Part V: Suggested Games, Activities and Learning Materials

\section{Classroom Management Ideas Ideas for Display}




\section{Ideas for Classroom Storage}

- Label materials, toys and resources in the classroom so that it is easy for young children to put things back in the correct place. Labels using both words and pictures can be used. The same label can be placed on the box or container in which the activity/game is stored and also below the shelf space that the box belongs. For example, a picture of a puzzle and the word puzzle can be put on a label. The label is glued to the box that holds the jigsaw puzzles. The identical label is attached to the shelf marking where the jigsaw puzzle belongs.

Containers storing materials can be labeled in the same way. The pencil box has a picture of a pencil, the button box a button, the jar of marbles a marble. Be sure to use words as well, even if

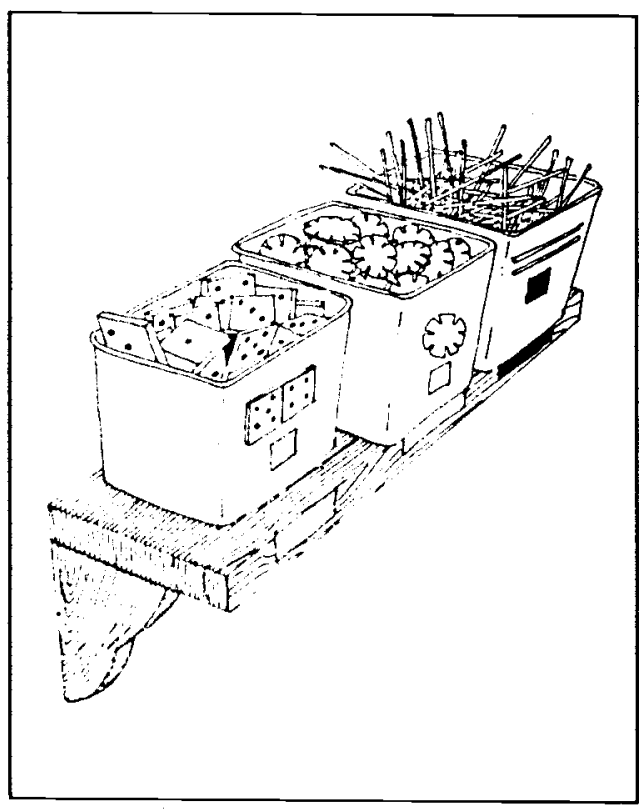
the children can not yet read. It will reinforce the concept that words have meaning and represent things. They will also become familiar with the letters of the alphabet. Color coding activities by subject can also help organize the classroom and make it easy for children. For example, all math activities are labeled red, language blue, art materials green and so on.

- Some ideas for useful storage containers include plastic ice cream containers, yogurt containers and any other sturdy plastic. For large items, plastic rubbish pails with lids are very effective, particularly if they are colorful. Plastic cullery trays are good for small items, such as rods, beads, small building materials etc. Remember to label all these containers with the respective items kept in them.

- Making mobiles are a good and attractive way of displaying children's work, supporting a theme that is being studied in the kodakistan - such as, the environment, animals, transport, etc. There are many ways to make mobiles. One is to use thing wire or coat hanger wire and bend it to make a loop. Cut-outs can be suspended from the loop and the several comnecting wires or strong string can be suspended from the loop for hanging.

- Fun Boxes can be made for children to play in from large empty cardboard boxes. They can be decorated with paper or painted. You can seal a large box securely and then cut a large hole in one side for children to climb in and out of. There are a lot of possibilities - use your imagination and ask the children to help. 


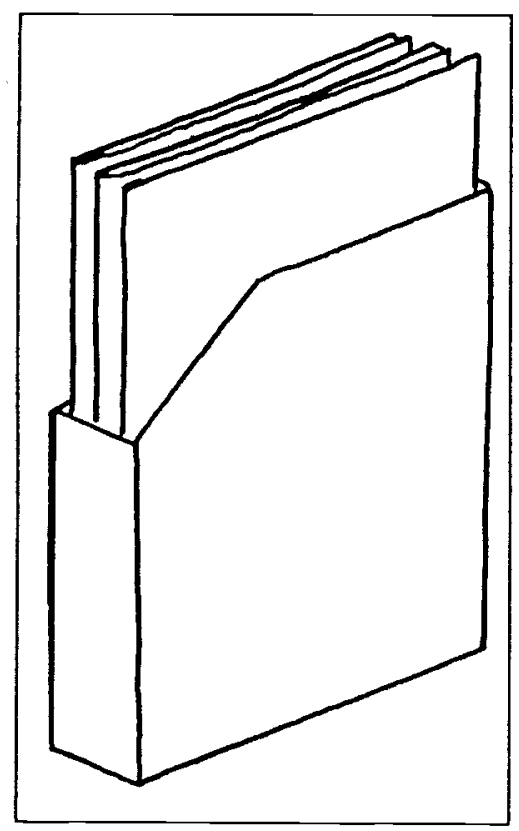

- Storing magazines and large books can be done by making storage containers from used cereal boxes. Cut a straight line across the top of the box about $5 \mathrm{~cm}$ down from the top. Cut a diagonal line at the front, about onethird of the way into the box. This makes it easier to see what is inside. The boxes can be covered with colored paper, gift-wrapping paper, or painted to make them more attractive.

- Shelves for the classroom can easily be made from wooden planks and bricks (or pieces of wood of comparable sizes). Lay down a wooden plank down and it can be covered with large sheets of colored paper. A large brick or piece of wood on either side gives the shelf its height. Lay the next wooden plank on top and cover it again. You want to keep the shelves low for both easy accessibility and safety. Make sure they are secure and do not risk falling. Check that the edges have been well sanded and are smooth. Bricks can be covered with cloth or other material to make them both more attractive and safer by covering any rough edges.

- Another idea for storage is to make baskets from old shoeboxes. Decorate the outside of the box with crayons, colored paper or paint. Remove the strip from around the lid. This will serve as a handle if it is place inside the center of the box and secure with staples. The corners can be strengthened with adhesive tape.
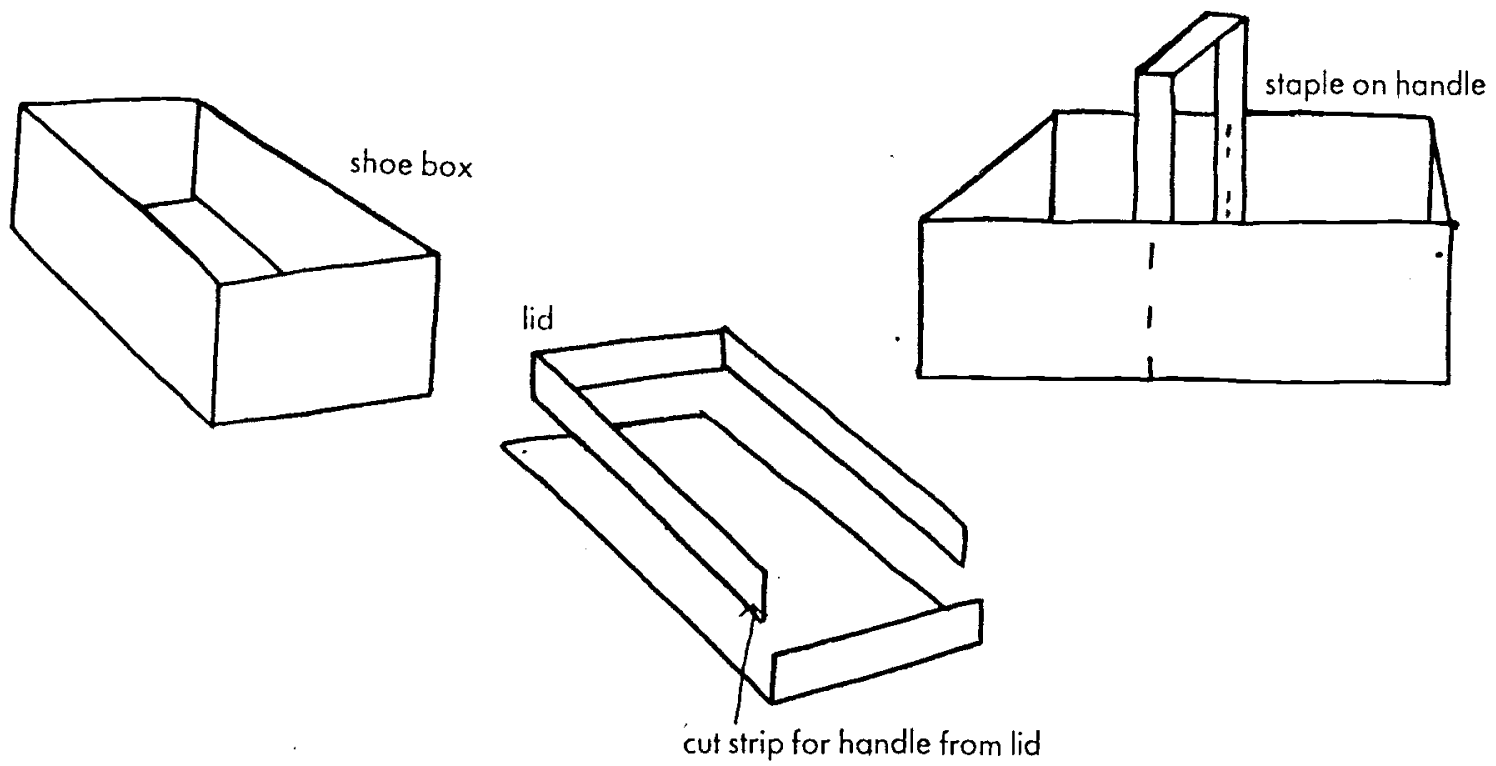

From Bright Ideas for Claswoom Manugement 
Activity: Language in Action

What You Need: Colored card and/or old free-standing picture frames (without glass), felttipped pens or markers

What to Do: Using simple pictures, symbols, signs, arrows, cartoons and captions taken from printed materials, make notices to help the children organize themselves. Ask the children for their ideas about signs needed on surfaces next to displays or for activity areas in the room etc. Hang them as is, or put them inside old photograph frames.

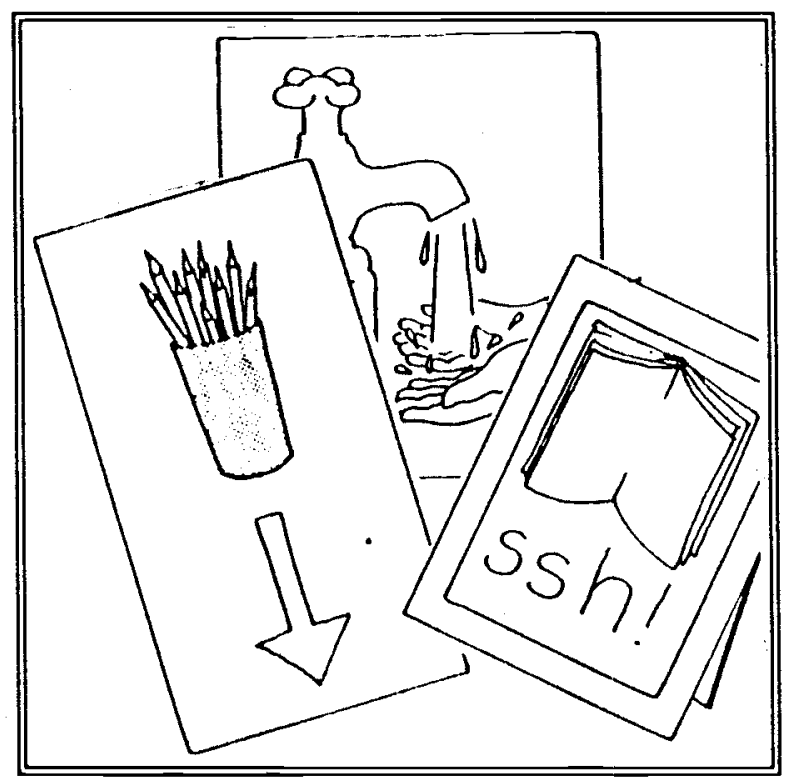

Activity: What's News Today

What You Need: A notice board, pins

What to Do: Use the notice board to pin up an interesting and/or amusing notice or letter, such as, announcing someone's birthday, or that someone is ill, things that are happening in the community, special days - first day of Ramazan, etc. You can also use it to pin up examples from the real world which you can discuss with children. For example, letters from parents, postcards, local newspaper cuttings etc. Encourage children to bring noticeboard items in from home too. Use it as a genuine reminder to the teacher, such as buying supplies for school, a shopping list for meals - let the children see you writing the message to yourself. For young children, more pictures and photographs, rather than many written notices can be used. The board can serve both as a learning tool, a source of information, and a way to keep the children's interest and curiosity alerted - as they note new additions to the board. 
Activity: The Surprise Box

What You Need: A large cardboard box, white paper, pictures of toys and familiar characters cut from magazines, transparent adhesive paper/plastic cover and ribbon.

What to Do: Make an attractive surprise box by covering a large box with white paper. Cut out pictures of toys, animals and familiar characters and stick them to the white paper. Cover with the plastic or adhesive paper for strength. Fix a colorful ribbon on the box, like a gift box, and a large bow on one of the flaps of the top of the box. The teacher can put special items in the box for children to explore,

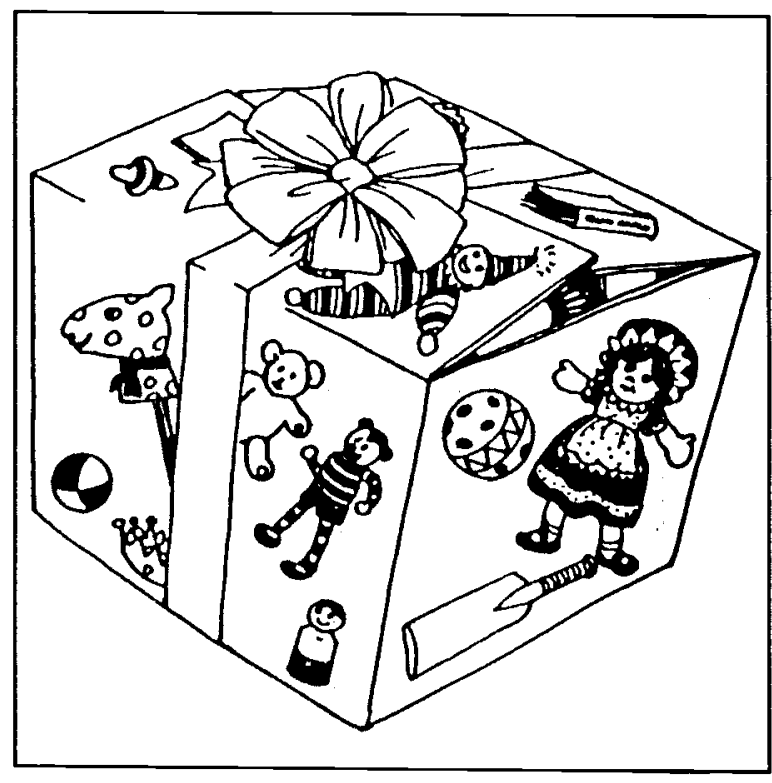
ask questions, or have a story told about it.

Activity: Wall Book Display Shelf

What You Need: Piece of card $37 \mathrm{~cm}$ x $16 \mathrm{~cm}$, white and colored paper, markers, children's drawings, paintings, writing, models and mobiles (The children's work can be connected to themes in books and stories told, that are in the kodakistan.)

What to Do: Make the book corner of the classroom as visually attractive as possible. Books can be displayed on the wall by the use of a card shelf. Fold the card to form a three-dimensional shelf to hold a book. Add displays of children's work on the wall or elsewhere around the shelf. Alternatively the shelf can simply be used for display in the classroom, not necessarily in the book corner.

Variation: Make a display table for books, soft toys and related children's work, by covering a table like surface in the kodakistan with an attractive piece of material or a tablecloth. Simple labels can be added to the display to introduce the concept of the written word to pre-readers and provide practice for those who can read.

$37 \mathrm{~cm} \times 16 \mathrm{~cm}$

\begin{tabular}{|l|l|l|l||}
\hline $9 \mathrm{~cm}$ & $8 \mathrm{~cm}$ & $13 \mathrm{~cm}$ & $7 \mathrm{~cm}$ \\
& & & \\
\hline
\end{tabular}

From Bright Ideas for Early Years

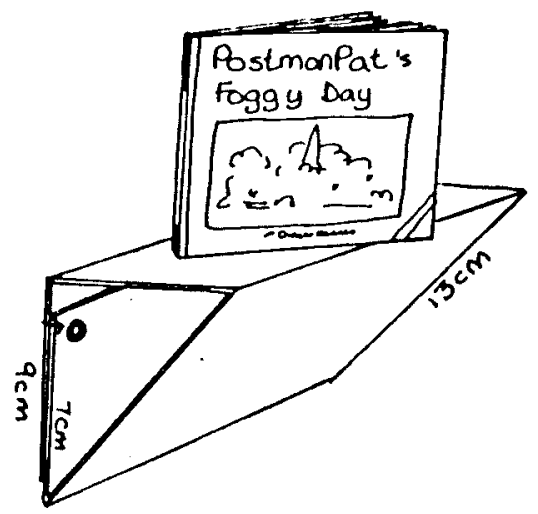




\section{Strategies for the Classroom}

- Greeting: Meet and greet all the children as they arrive in the morning. Make sure games and resources are available that they can get settled right away. Reserve some time at the end of the day to clean up and get children dressed and ready to go home. Say good-bye calmly and pleasantly. Try not to let them rush off in all directions, late or in a hurry.

- Lining Up: Encourage children to come into the classroom and leave it in an orderly and calm, quiet manner. If the class is boisterous and noisy, make them line up outside the class and walk in quietly and wait to be invited to sit down. This will allow some time for them to settle down. Dismiss them after they have cleaned up and sat down quietly.

- Dismissing: Try saying: "Watch me carefully and do what I do," or "Show me who s ready!" Follow this with praise and encouragement for those who are sitting straight and quiet and then let them get their things. Alternatively, ask everyone to sit with their eyes closed. A touch on the arm means that they go to get their belongings, coats, or are able to leave - those who peek lose their turn.

- Signing: Decide on a signal which means be quiet - the children can vote on what is preferred. For example, a raised hand, a finger on the lips or a raised traffic stop sign. This can also be used in a small group setting. When a child wants to speak for example, he uses the signal and other children respond by being quiet and using the signal as well until all are attentive.

- Attention grabbers: Experiment with useful phrases for gaining the children's attention. For example: "Show me your eyes - I want to see everyone's eyes looking at mine", or "All show me your hands - show me ten fingers, six etc." "All children with lace up shoes, or fair hair..." "Tiptoe quietly to your table." "Touch your elbow, touch your nose.." "Sit down and rest your heads." "Close your eyes."

- Troublesome arrivals: If a child arrives crying, or starts to cry when their mother leaves, quickly show them something bright and colorful, or noisy to distract them and draw their attention to the object. If you suspect a child will cry when the mother leaves, get him/her involved in an activity before the mother leaves. Some children will need a weaning period, to get accustomed to the kodakistan and being separated from their mother.

- Engaging brains: As soon as children are busy working, move around and try to make some positive statement about the work each child is doing. Try to make them understand why some aspect of what they are doing is good, or how it will be good or better than last time. Make positive statements to every child, but make them specific to their work. 
- Idle threats: Never make a threat that you cannot or would not carry out. Children soon test you out and find out your weaknesses. Very early in the relationship, give small but clear examples of your classroom rules and determination to uphold them calmly and fairly.

- Discipline through work: When you find the children noisy, check the following list:

1. Was the task too difficult for most? This will make them noisy and frustrated.

2. Was the task too easy for most? They will finish too quickly and have nothing to do.

3. Was there too much dead time for able and slow learners? The slow learners will not have time to do a thorough job. The able learners will complete it quickly. Move around the room to find out the children's needs and modify the task accordingly. Plan ahead, always try to think of extension work on principles and problems for the able, and smaller more structured steps for the slower ones. If the children are interested in what they are doing they will become involved in the task.

- Rules: Have as few rules as possible. Ensure that the rules you do have are those which encourage reasonable behavior and sociability. Always explain the reason for the rules to the children. Involve older children in the making of rules. Remind them of the rules if they break them and keep them yourself.

- Calming down: Move quietly to the child who is upset and put a calming hand on the arm, shoulder or head. Quietly ask them not to shout, make eye contact and try to sooth them. Keep an eye on them in case of further upset. Children shout because they are angry, upset, excited or if it is a typical mode of communication at home. When one child shouts, others imitate or shout louder to be heard. It is important that you do not get involved in this spiral, for the teacher provides a model which the children will imitate. Step in quickly and calm them down as indicated above. Do not do it harshly or negatively.

- Sending out/Time out: It is best not to send a child out of the room, but to send them to a quiet area or time out region of your own room. The time out chair or cushion should simply be a neutral zone for calming down and regaining composure and set for a very short duration. Encourage very young children who are upset or irritable to go and lie down on a special cushion for 30 seconds or a minute in order to calm down. Seriously upset or disturbed children can be left longer, perhaps even to sleep off their distress. Fluffy cushions should be provided for comfort and a soothing color for a calming effect.

- Progress encouragement: Only encourage the children to compete with themselves and to improve on their previous work. Failure engenders negative feelings and low self-esteem, especially in those who are always failing in comparison to their peers. Try to find something which each child is good at. 


\section{Display Can Promote Many Concepts...}

- Story Telling Story telling is often a daily event and can be followed by children painting scenes from the story. A display depicting the story's main event, or the story in sequence (collage or painted by children). Such pictures are an excellent way of encouraging children to talk, and can be used to help develop the children's skills.

- Sequencing and Prediction If the story is displayed in sequence, the children can be encouraged to note the progression from one situation to another. The teacher can emphasize the importance of sequence from a simple example: do you put your socks on first or your shoes? Small cards with the story illustrated in sequence can be made for the children to organize and retell the story using the visual aids. The teacher herself could tell the story leaving out the last card and ask the children to predict the ending.

- Questioning Questioning. skills can be developed by demonstrating the use of "question words" using the story picture cards as reminders to questions such as: Who? What? Where? When? How? Children can be encouraged to ask each other questions, and find out vast the amount of detail to be discovered by the use of a few short, simple words.

- Two Dimensional Shapes A display of 2-dimensional shapes showing examples from the classroom or home, or pictures of those shapes occurring in the environment, helps develop the concept of shape. The display can be coupled with a great deal of practical work to familiarize children with the various shapes. However, reinforcement in the form of a story display would fix the concept of shapes quite firmly. See "The Story of Sharifa Shape" in the Mathematics section of Part V. This story can be used as the basis of a display.

- Time Make a clock with moveable arms. Or make several clocks displaying things that happen at particular times of day: prayer, meals etc.

- Cardinal Number Displays Visual illustrations of nursery rhymes and songs is very effective for reinforcing numbers.

- Ordinal Number Displays These can be combined with the shape story described above. Instead of using days of the week use first day, second day and so on. Prayer times can be used for this purpose as well. Or, some standard sequence can be used like washing hands First we need water and soap, second we wet hands and make them soapy, third we rinse our hands, fourth we dry them. Use your imagination, as there are many possibilities and more than just the number concept can be taught. For rural areas - use the planting cycle for the common crop: wheat or rice, sowing seeds, irrigating, harvesting, threshing etc.

- Size A visual image of size differences and comparisons are useful. This can help develop size vocabulary: small/tiny/medium/middle-sized/big/large and huge. Or illustrate things like big, bigger, biggest - with simple shapes like colorful balloons or different kinds of animals - anything that is familiar to the children. 
Pictorial Representation: Simple Charts and Graphs Always an excellent way of reinforcing a lesson after a great deal of practical work. For example, if eye color was studied. First you can use a physical means, that is have the children form separate lines for each color: a line of brown eyed children, blue, green, hazel, grey elc. They could hold cubes or paper tags with the appropriate colors that can then be counted as a class to make a chart. Or everyone can clraw, color and cut out an eye that can be fixed on a grid of numbers on one side and names or swatches of color on the other. Then discuss by asking questions such as which is the most common color? How many have green eyes? etc.

\section{Some General Ideas for Display}

All levels of classroom can be used: wall space can be covered with both 2-dimensional and 3-dimensional displays. Boxes can be stapled or taped to the wall and work can be mounted on them for a 3-dimensional effect. Figures can be given a slightly 3-dimensional effect by padding them with newspapers or other scrap materials at the back.

Single pieces of paper (especially written work) can be folded down the center to form a triangular structure and mounted either along the fold or on one side so it opens out. The ceiling can be used with all kinds of mobiles. Floor space can be used for display tables, or constructions built up from the ground level (away from entrances or heavy traffic areas). String can be suspended from floor to ceiling and work can be mounted on the string. Washing lines are a popular means of suspending work or mobiles. Hanging screens can be used to fill in between space.

A drape or piece of cloth or colored paper can act as a backdrop to display. Displays should not be mounted the same way each time, because it will get boring for the children (and teacher). The point is to gain attention and have an impact - which requires change and variety. Any kind of material can be used, and various textures will in fact add to the display. A drape can be used as a backing to a display, as something to which work is pimned (wooden rod in the bottom to weigh it down) or to create a visual image such as a waterfall using silver paper.

Straining for quality: There is a definite need to use high standards in displays that the teacher uses to reinforce concepts and skills. Display is not "window dressing" or just for show, it is used to teach children to value and appreciate quality, their work, and as a learning aid. Just as children's work that is well done deserves recognition through a nice display, so should visual aids and other items made by the teacher be the best the teacher can produce and displayed accordingly. You do not need to be an artist, simply focus on neatness, creativity and inventiveness, have a sense of color and be aware of the total impact on the environment.

Do not forget to get the children's opinions about the displays. 
Part V: Suggested Games, Activities and Learning Materials

\section{Educational Games and Toys}


Educational Toys and Games

Activity Name: Threading Cards

Age Group: 3 to 6 years old

How Children Play: Children thread in and out of the holes of the card.

What Children Learn: Children practice their small muscle skills and develop their eyehand coordination.

What you Need: Stiff cardboard, pencil, scissors, colored markers, paper punch, yarn, adhesive tape, clear plastic adhesive, a box in which to store the cards

How to Make It: You can make your own simple animal patterns and shapes or trace simple pictures from a coloring book or storybook.

1. Copy the picture onto the cardboard and color with markers.

2. Cover the carclboard with the clear plastic adhesive, or use very wide adhesive tape, laying strips next to each other.

3. Cut the pictures out and punch holes in them.

4. Cul a piece of woolen yarn long enough to thread around the card.

5. Wrap a piece of tape around one end of the yarn string to make it pointy.

6. Tie the other end of the string onto the starting hole of the card.

7. Store all the cards in one box and paste a picture of threading cards onto the cover or side of the box, so children can easily see what is inside when the box is on the shelf.

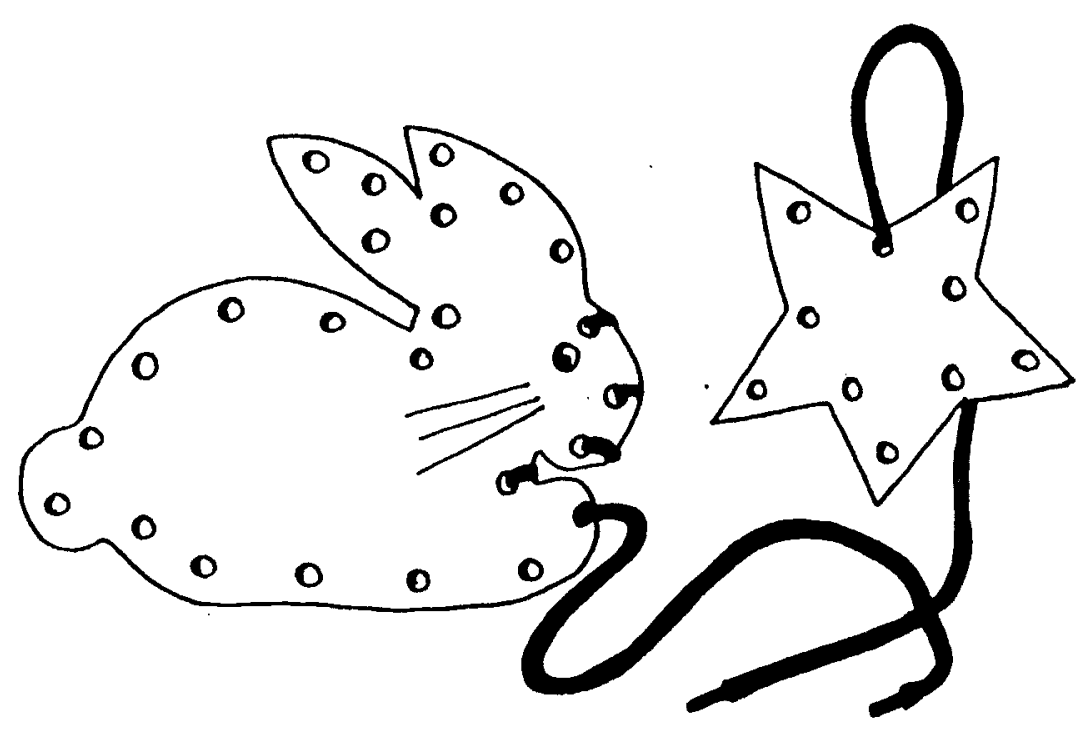


Educational Toys and Games

Activity Name: Shape Dominoes

Age Group: 5 to 6 years

How Children Play: Four children play at a time.

1. Each child receives seven cards.

2. The first child places a card in the center of the table.

3. The child to the left looks to see if he has a card with a shape that will match either half of the card on the table. He places the card so that the matching shapes are touching.

4. If a child does not have a card that matches, he misses a turn.

5. The game continues in this way until all the cards are used.

What Children Learn:

1. Children learn to recognize similarities and differences in colors, shapes and sizes.

2. Children develop their social skills by playing together.

3. Children learn to concentrate and follow rules.

How Teacher Can Help: When the game is introduced to the children, the teacher needs to sit with them and explain the rules and see that they are followed. Once they understand the game, they can continue on their own.

What you Need: Stiff cardboard, scissors, glue, markers, clear adhesive paper, storage box

\section{How to Make It:}

1. Make 'shape dominoes' as illustrated below onto cardboard. Only a few shapes are shown, but you can add your own.

2. Color the shapes with the markers.

3. Cut the cards and cover them with plastic adhesive or wide tape.

4. Trace some of the domino shapes onto a piece of paper and use that to label the storage box.
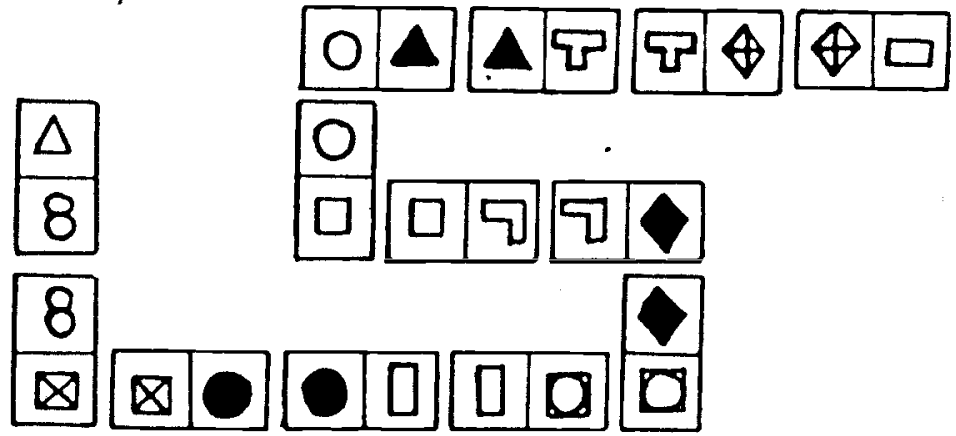


\section{Educational Toys and Games}

Activity Name: Feely Box

Age Group: 3 to 6 year old

\section{How Children Play:}

1. The child puts one hand inside the box and feels one of the cards. With the other hand she touches the card on top of the box which matches. She then pulls the texture card out of the box to see if she is right.

2. To make the game more challenging, the teacher can blindfold the child. The child then matches the card from the inside of the box to those on the lid. She puts one card on top of the other.

3. Once the child has matched all the cards, she can see if she is right. The next child can then have a turn.

\section{What Children Learn:}

1. Children develop their sense of touch by learning how things feel.

2. Children learn to compare by seeing how some things feel the same and others do not.

3. Children learn to match - putting two things that are the same together.

4. Children learn new words like bumpy and smooth.

How Teacher Can Help: The teacher can help by asking thinking questions, such as:

- Can you find a card inside the box that matches this one?

- Can you show me something smooth (bumpy etc.)?

- Can you put all the cards which feel rough together?

- How does this card feel? ... and so forth.

What you Need: A shoe box and lid, a stiff piece of cardboard, enamel paint and paint brush, a piece of material, scissors, strong glue and something to spread the glue with, a blindfold. For texture cards, include some of the following: scraps of material, sandpaper, cottonwool, crushed egg shells, sponge, plastic, corrugated paper, sawdust, elastic, etc.

\section{How to Make It:}

1. Paint the box and lid with enamel paint.

2. Cut a hole, big enough for a child's hand, in one side of the box.

3. Cut a piece of material $15 \mathrm{~cm} \times 12 \mathrm{~cm}$ as a flap over the hole. Glue it only on the top edge of the box so that it can be lifted.

4. Cut 12 squares of cardboard, each one measuring $5 \mathrm{~cm} \times 5 \mathrm{~cm}$.

5. Glue the texture onto the cut pieces of cardboard so that there are two of each.

6. Glue one of each of the pairs onto the lid, the other inside the box, and put the lid on.

Variations: Use a large piece of stiff cardboard instead of the shoebox. Glue one of each of the textures onto this cardboard. The advantage is that more than 6 textures can be used. 
Activity Name: Tins and Sticks

Age Group: 3 to 6 year old

How Children Play: Children should be allowed to play freely with the toy. They might do some of the following things:

1. Match the sticks to the tins.

2. Sort the sticks according to their lengths.

3. Using only one color stick, order the sticks from the shortest to the tallest, or the reverse.

What Children Learn: Children learn to classify - grouping all of those of the same color or size. They learn to make comparisons between the lengths of the sticks - long, longer, longest etc. They also learn to seriate (order) according to size. Children learn new words such as tallest, shortest, longer etc.

How Teacher Can Help: After the child has had time to play freely, the teacher can ask: Why have you placed all these sticks into this tin? Let us mix up all the sticks again so that you can sort them into different groups. Can you give me the shortest (or longest) stick? Which blue sticks are longer than this blue stick? Can you put the red sticks in a row from the shortest one to the longest one?

What you Need: 4 tins of the same size, 4 different colors of enamel paint and paint brushes, thin round wooden rods (or something similar that can be used for the sticks), a saw, pencil, ruler

\section{How to Make It:}

1. Using the pencil and ruler, mark off 4 of each of the following lengths on the sticks: $7 \mathrm{~cm}, 10 \mathrm{~cm}, 13 \mathrm{~cm}, 16 \mathrm{~cm}, 22 \mathrm{~cm}, 25 \mathrm{~cm}$.

2. Use the saw to cut the sticks where marked.

3. Put one $7 \mathrm{~cm}$ stick into each tin, then one $10 \mathrm{~cm}$ stick into each tin, and so on until there are seven sticks in each tin.

4. Paint the sticks in the first tin one color and paint the tin the same color. Paint the stick in the next tin a different color and the tin to match, and so on.

5. Once the paint has dried, the sticks are sorted and placed in their matching tins.

Variations: Pegs can be used instead of sticks. This will make it a much simpler toy, suitable for 3-4 year old children. 
Educational Toy's and Games

Activity Name: Seriating Cylinders

Age Group: 4 to 6 year old

How Children Play: Children should play freely with the cylinders. At first, the child should only be given 5 cylinders and gradually the number can be increased. Three year old chitdreen will not be able to seriate (order) as many cylinders at a time.

What Children Learn: Children learn to seriate (order) according to size (from the shortest cylinder to the tallest cylinder). Children learn new words like, taller, shorter, tallest etc.

How Teacher Can Help: After the child has had time to play freely, the teacher can point to the picture on the cylinder box and say, "Can you put the cylinders in a row to look like this picture?" Ask other thinking questions, like:

- How did you line the cylinders up?

- Which is the tallest cylinder?

- If I take this cylinder away, which is the tallest?

- Can you mix the cylinders up and start again with the tallest cylinder in front?

- Close your eyes. I am going to take one cylinder away. Open them - Can you guess which cylinder is missing?

What you Need: 7 paper towel rolls - $26 \mathrm{~cm}$ long, (If these are not available, you can use toilet paper rolls - this will make for a smaller and shorter set of cylinders. Or you can tape the toilet paper rolls together to make the full set. You will have to use sturdy tape to keep the cylinders strong.) A sharp cutting knife, pencil, ruler, enamel paint and paint brush, a box for storing the cylinders

\section{How to Make It:}

1. Measure and mark off the cylinders with pencil by taking off $2 \mathrm{~cm}$ from the first cylinder, $4 \mathrm{~cm}$ from the next, $6 \mathrm{~cm}, 8 \mathrm{~cm}, 10 \mathrm{~cm}$ and $12 \mathrm{~cm}$ from the last cylinder. Do not mark one of the cylinders.

2. Cut the cylinders where they have been marked. You will have 13 cylinders.

3. Paint all the cylinders the same color - they may need two coats of paint.

4. Make a picture of the cylinders to paste on to the box in which the cylinders will be stored.

Variations: The cylinders will encourage make-believe play as well when used with the building blocks.

This idea comles from Leaming with Scrap)

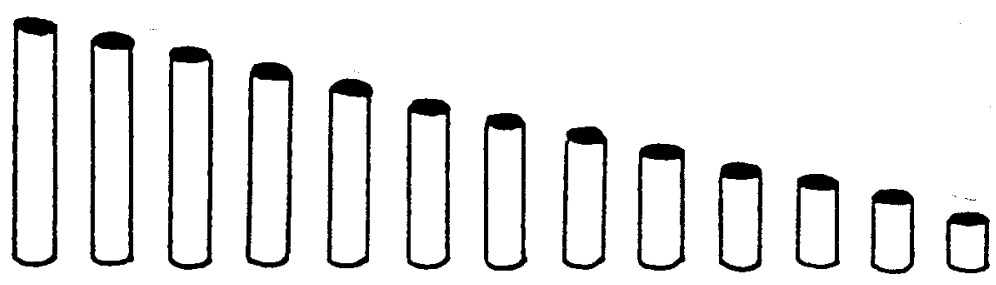


Activity Name: Bottles and Lids

Age Group: 2 to 4 year old

How Children Play: The bottles and lids are spread out in front of the child. She finds the lid that goes with each bottle and fits it on. The task is self-correcting because there are the same number of lids as bottles. If the child puts the wrong lid on one of the bottles, she has a lid left at the end which does not fit the remaining bottle.

\section{What Children Learn:}

1. Children learn to compare, for example, some things are the same size, others are not.

2. Children develop their small muscles and eye-hand coordination.

3. Children learn to make predictions by guessing which lid will fit each bottle.

4. Children learn new words, such as, too big, small, bigger, smallest and so on.

How Teacher Can Help: Ask questions that may help children to think, such as:

- Do you think this lid can fit on this bottle? Why or why not, try it and see.

- Do you think that this one is too small too?

- How about this one? Try it and see. Good!

- Can you show me the bottle with the biggest lid?

- Can you show me a lid you think will be much too small for this bottle?

- Can you show me one that you think will be too big?

- Can you now show me one you think will fit?

What you Need: 12 plastic bottles (that have lids) of different sizes, a box in which to store the bottles and lids

\section{How to Make It:}

1. Collect the plastic bottles and lids.

2. Make a picture of bottles and lids. Paste it on the box that will store the bottles so that children will know where to put this toy when they are finished playing (and where to find it when they want to play.) 
Educational Toys and Games

Activity Name: Button Sorting

Age Group: 3 to 6 year old

IIow Children Play: The child sorts the buttons into different groups.

What Children Learn: Children learn to classify (group) things that are alike in some way (color, size, shape etc.). Children learn about numbers. Children learn to seriate (order).

How Teacher Can Help: The teacher can ask thinking questions, such as:

- Can you tell me why you put these buttons in one group?

- Let's put all the buttons into one big pile. Can you put some of the buttons together in a different way?

- You've found a lot of buttons to put together. Why did you put them all together?

Or, if the child is having difficulty:

- Can you tell me about the button that you have in your hand?

- Yes, it is yellow. Can you find some more buttons that are like it?

- Can you put them all together in one group?

The child should be encouraged to sort in a variety of different ways.

What you Need: Several different sets of buttons, for example:

- One set may be of all different kinds that the child can sort in any way he chooses.

- Another could be of the same color but different sizes.

- Another might be similar in color, shape and size, but different in texture (wooden, plastic, leather etc.)

How to Make It: These buttons can be stored in different containers, clear jars or plastic containers with a picture of buttons on them.

Variations: Think of other things that can be collected and used for sorting, eg. shells, nuts and bolts, washers. 
Activity Name: The Outline Board

Age Group: 3 to 6 year old

Inow Children Play: The child places the objects on the outlines drawn on the board.

What Children Learn: Children learn to observe the shapes of objects. Children develop their matching skills. Children practice their small muscle skills and develop their hand-eye coordination.

Ilow Teacher Can Ilelp: She can ask:

- Can you find the shape of the pin on the board?

- Can you show me something which is round?

- Can you show me something which is made of rubber?

- Can you show me something that cuts?

What you Need: A piece of cardboard $40 \mathrm{~cm} \times 30 \mathrm{~cm}$, marker, clear adhesive paper, some of the following objects: block, key, shell, paper clip, ring, button, comb, clothespin, small flag, lids, rubber band, hair pin, scissors; a box in which to store the objects

\section{How to Make It:}

1. Draw around the objects onto the board with the marker.

2. Cover the board with the clear adhesive or wide tape.

3. Draw a picture of the outline board and paste onto the box that is used to store the objects.

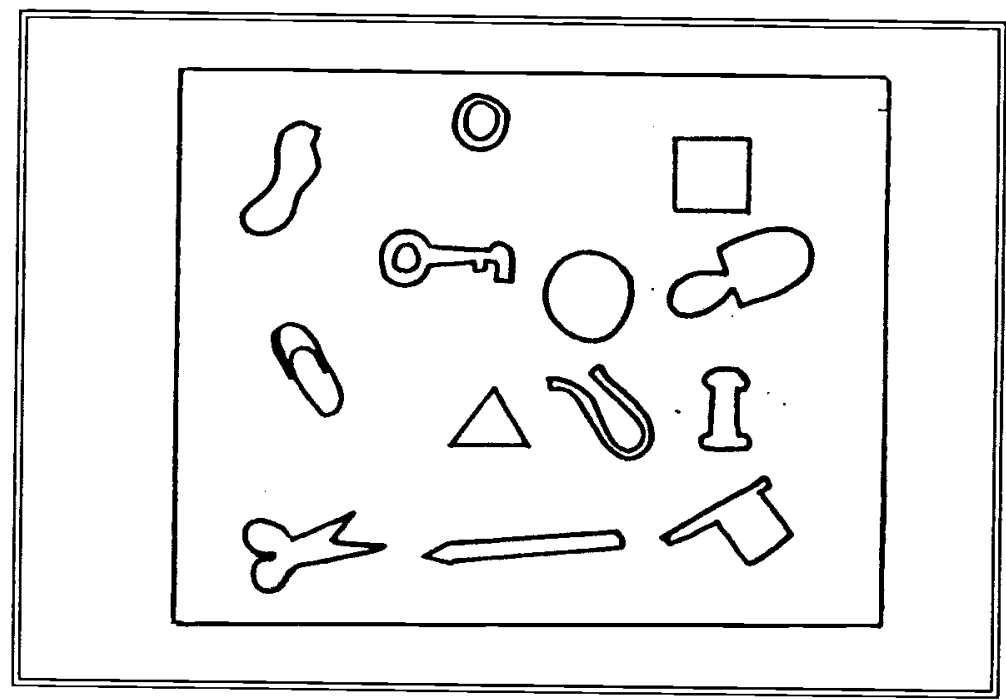

This iden comes fiom Lo'arning with Scrop) 


\section{Educational Toys and Games}

Activity Name: Finger Puppets

Age Group: 2 to 6 year old

How Children Play: The child places the puppets on his fingers and act out stories or makes up his own stories. He can play alone or with other children.

What Children Learn: Children practice their language skills. Children learn to express their feelings through the puppets. Children develop self-confidence. Children practice their small muscle skills.

What you Need: An old glove, needle and thread, scraps of material, wool, ribbon, etc., scissors, a box in which the puppets will be stored

\section{How to Make It:}

1. Cut the fingers off the glove.

2. Hem the bottom of each finger.

3. Cut and sew on faces with the material, wool and ribbon.

4. Store them in a box with a label picturing finger puppets.

Activity Name: Sock Puppet

Age Group: 2 to 6 year old

How Children Play: The child places his thumb into the heel of the sock and his fingers into the toe. He moves the mouth up and down so that the puppet "speaks".

What Children Learn: Children practice their language skills. Children learn to express their feelings through the puppets. Children develop self-confidence. Children practice their small muscle skills.

What you Need: A sock, cardboard, scraps of material, felt or wool to embroider the face, scissors, needle and thread

\section{How to Make It:}

1. Cut out pieces of cardboard to fit the toe and heel of the sock.

2. Staple the two pieces of cardboard together.

3. Fit the cardboard shapes into the toe and heel of the sock.

4. Make a face from the off-cuts of material, wool or felt. 
Educational Toys and Games

Activity Name: Picture Puzzle

Age Group: 3 to 6 year old

Ilow Children Play: The child fits the pieces of the puzzle together onto the base.

What Children Learn: Children develop their hand-eye coordination and practice their small muscle skills. Children learn how to solve problems. Children learn new words.

What you Need: 2 identical pictures from magazines (or other sources), but not smaller than $15 \mathrm{~cm} \times 20 \mathrm{~cm}, 2$ pieces of cardboard, the same size as the pictures, scissors, glue and a brush, clear plastic adhesive paper (or wide clear tape), a box for storing puzzles

\section{How to Make It:}

1. Cut out two identical pictures from a magazine. Glue each one onto a piece of cardboard.

2. Cover the pictures with the clear plastic adhesive or strips of clear wide tape.

3. Cut one of the pictures into 5 puzzle pieces (fewer if you want to make them simpler for younger children).

4. Store the puzzle in a suitable box.

Variations: Draw or trace pictures and color them in with markers. Cut smaller and more pieces for older children. 
Activity Name: Sound cans

Age Group: 2 to 4 year old

How Children Play: Children should be allowed to play freely with the toy. The child shakes a tin and then finds another tin that sounds the same.

What Children Learn: Children learn to recognize similarities and differences in sounds and in weights. Children learn to classify (group those with the same sounds). Children learn new words: soft, softer, loudest etc.

How Teacher Can Help: The children should be allowed to play freely. The teacher can ask questions like:

- Shake the tin. How does it does sound?

- Can you find another tin that sounds the same?

- Which has the loudest sound?

What you Need: Empty soft drink cans, small things to put inside: nails, small stones, buttons, sand; masking tape, colorful adhesive paper (or colored paper and wide adhesive tape if not available), scissors

\section{How to Make It:}

1. Put the same amount of the same material into the tins (so that two tins will be identical.)

2. Do the same with the rest of the tins, for example, 2 with nails, 2 with stones, etc.

3. Cover the holes in the cans with masking tape.

4. Cover the cans with the colorful adhesive paper; or cover with strips of colored paper and use the wide clear tape to hold the paper in place on the can.

This idea comes from Le'anning with Scrap) 
Activity Name: Posting Box

Age Group: 2 to 4 year old

How Children Play: The child experiments to discover which objects fit into which holes, then opens the top of the box and takes them out.

What Children Learn: Children practice their small muscle skills and develop their handeye coordination. Children become aware of shapes and sizes and how objects are alike or different. Children learn to make predictions by guessing which shape will fit into which hole.

How Teacher Can Help: The teacher asks questions to help children think:

- Do you think that the shape you are holding will fit through that hole?

- Why not? Try it and see.

- Which shape do you think will fit through the hole?

- Why did you choose that shape?"

What you Need: A sturdy cardboard box with lid, or a plastic ice cream container with a lid. Shapes (triangle, square, circle and rectangle) - these can be cut from wood; or objects such as plastic containers, matchboxes, blocks or balls could be used. You will also need scissors, masking tape, enamel paint and paintbrush.

\section{How to Make It:}

1. Reinforce containers/shapes with masking tape.

2. Paint the box and lid with enamel paint.

3. Trace the outlines of the objects on the box lid and cut them out.

4. Place the objects in the box and put the lid on the box.

This idea comes from Learning with Scrap

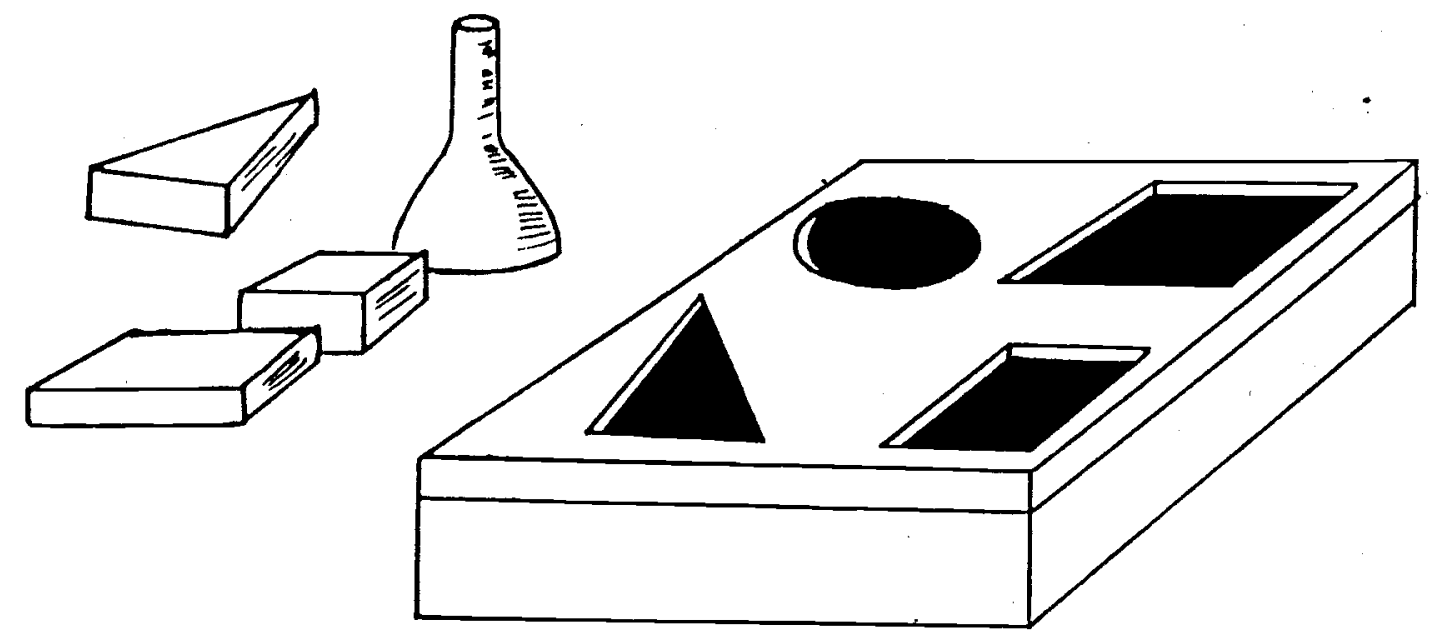




\section{Educational Toys and Games}

Activity Name: Blocks

Age Group: 2 to 6 year old

How Children Play: Allow children to select their own blocks and build in their own way.

What Children Learn: Children develop problem solving abilities. They learn about space, weight, balances, gravity, length, width, height and numbers. Children practice their social skills. They practice motor skills, develop eye-hand coordination and learn new words.

How Teacher Can Help: Provide low shelving so that children can choose their own blocks. Draw or paint shapes of the blocks on the shelves. Provide extra things that will help children to play creatively: toy cars, animal, sticks, pieces of cloth, spools and so on. Ask thinking questions, such as:

- Can you make a bridge for the big car to go over?

- Can you find a block that is the same size as this one to put on the other side?

How to Choose your Blocks: You need a selection of blocks of various shapes and sizes: There are special large building blocks that are made according to certain sizes - a basic unit block is of a certain length and other blocks are one-half or 2 times or 4 times the length.

When a child plays and builds with these blocks he begins to discover things like:

- he needs 4 unit blocks to make something as long as the longest block

- he needs 2 of the smallest blocks to make something as long as a unit block

Buying blocks can be expensive. You can use scraps of wood from a carpenter and saw into different shapes and sizes. Cardboard boxes and tins may also be used to make blocks.

What you Need: A selection of sturdy cardboard boxes of various shapes and sizes, such as, cigarette, cigar, match, cheese, cake, shoe boxes and pill containers. Tins with lids of various sizes: cold drink cans, thick wooden rods cut up (old broomstick handle), glue, masking tape, enamel paint and paintbrush,

\section{How to Make It:}

1. Select a variety of boxes of different shapes.

2. Several small boxes can be glued together to make larger boxes.

3. Strengthen the boxes with masking tape.

4. Paint the boxes with bright enamel paints.

5. Paint the tins and lids with bright enamel paints.

6. Store the blocks on low shelves so that children can choose their own blocks. 
PART V. SUGGESTED GAMES, ACTIVITIES AND LEARNING MATERIALS

Educational Toy's and Games

Making Blocks

Cylinders

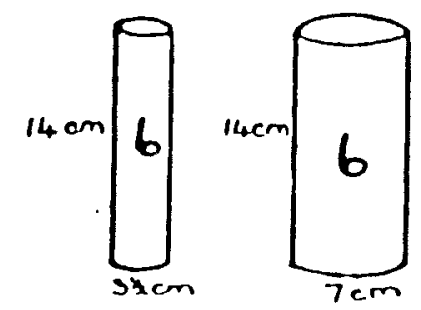

Pillars

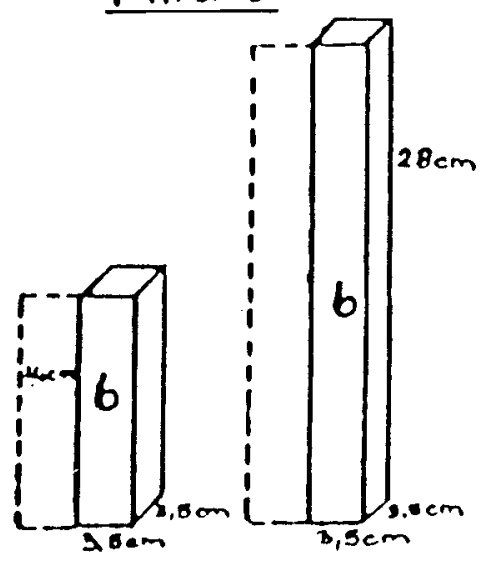

$\frac{\text { Curved Blocks }}{\text { (Cradles) }}$

These fit together to form circles.

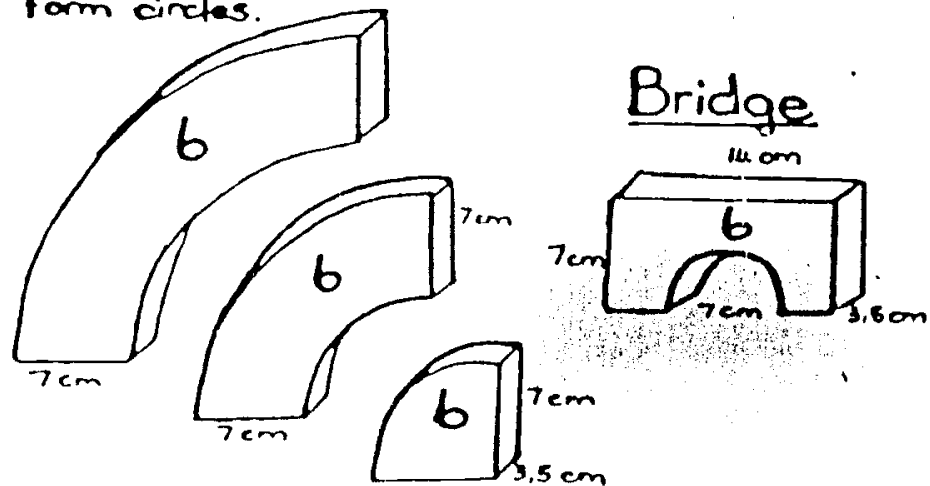

Basic Blocks Lengths).
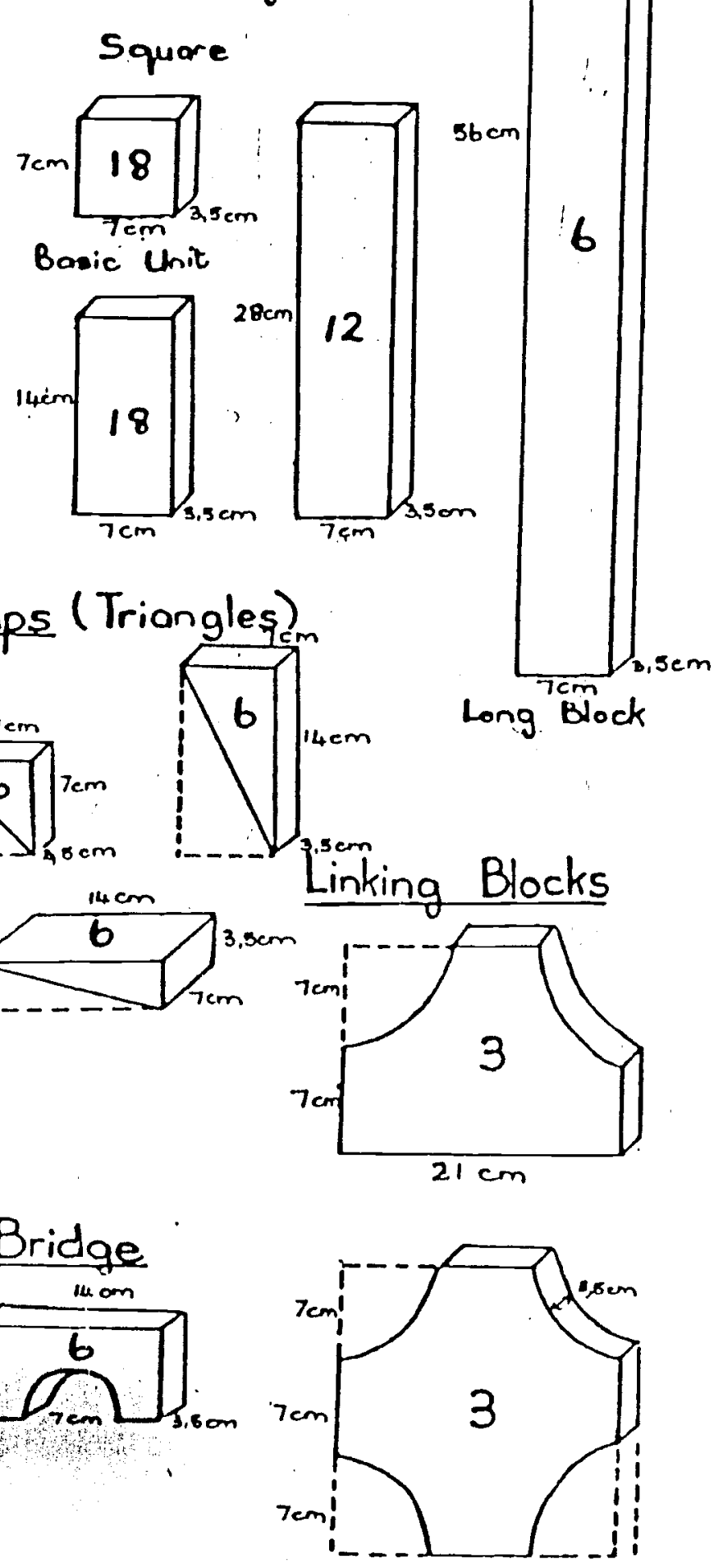

From Learning with Scrap

24 
Activity Name: Shape Patterns

IIow Children Play: In order of difficulty, the child can:

1. Open each strip. Try to make the pattern by choosing the correct individual shape cards and placing them on top of the corresponding shapes on the strip.

2. Open each strip and reproduce the pattern just below it, using the individual shape cards.

3. Open each strip. Look at the pattern on it carefully. Close the strip and reproduce the same pattern from memory.

What Children Learn: Perceiving and reproducing patterns of shape, color and position; recalling such patterns from memory.

What you Need: Cardboard, colored markers, scissors, container for shape-pattern strips, envelope for individual shape cards

How Teacher Can Ilelp: Ask some thinking questions such as: What is this shape? What do we call this shape? Taking 3 squares of three different colors ask, What is the same about all of these? (They are all squares.) How many circles are there in this pattern? Can you find all the red triangles? The yellow squares? Which do you think is the easiest pattern to remember? Why is it easy?

How to Make It: Make and cut out eight different shape-pattern strips. Do not cut along the dotted line. Fold each strip along the dotted line to form a flap which opens and closes. Make and cut out 56 individual shape cards - use different simple shapes.

From Helping Children Learn

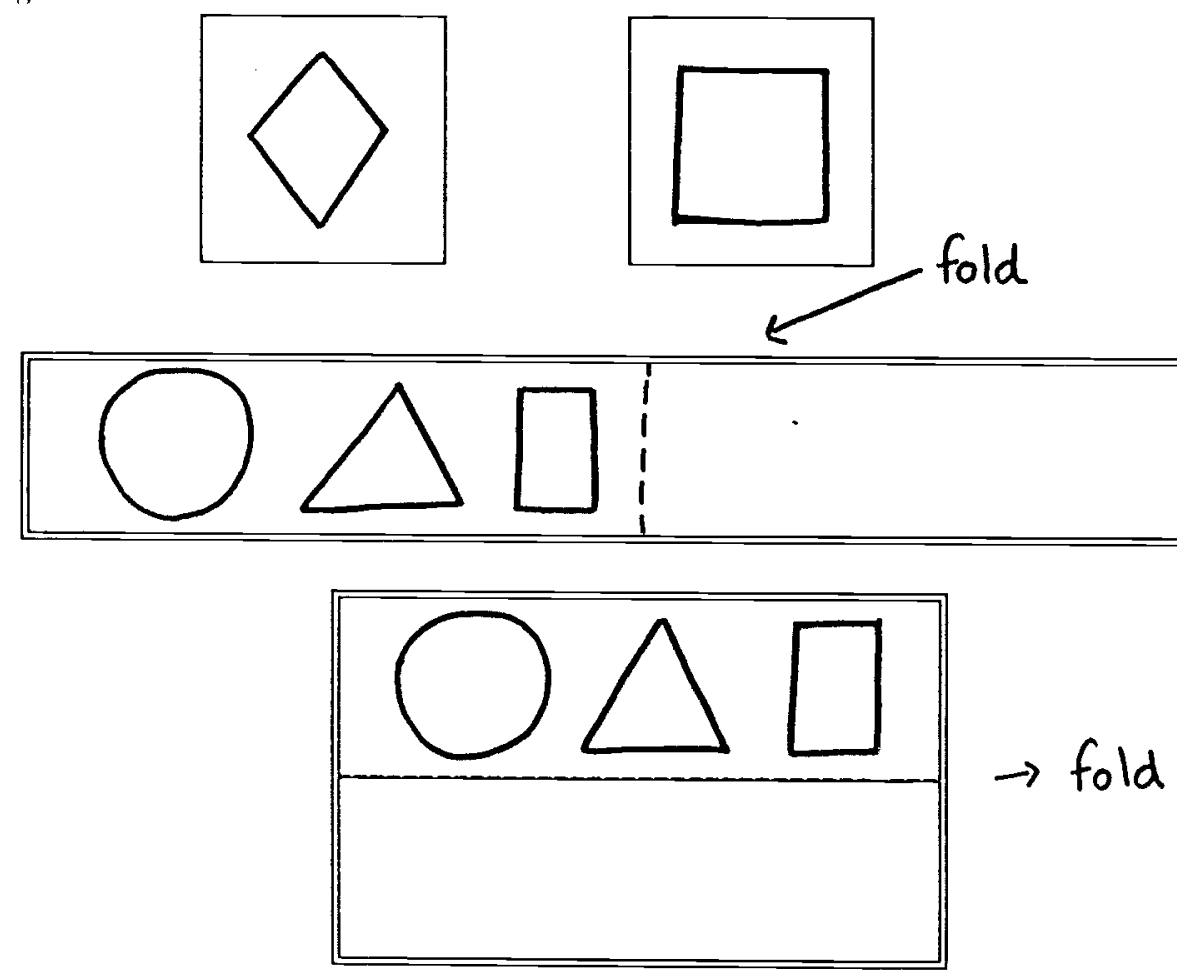


Activity Name: Pebble Patterns

How Children Play: In order of difficulty, the child can:

1. Try to make patterns by placing the black and white pebbles on top of the dots.

2. Lay out the cards and copy each pattern below the card, on the floor or table.

3. Look at each pattern carefully, turn the card over and reproduce the same pattern from memory using the pebbles.

What Children Learn: Reproducing patterns of color and position.

How Teacher Can Help: Ask some thinking questions, such as: Where did we find these pebbles? What are you doing with the pebbles? (Pointing to two cards.) Which of these two patterns has more pebbles? Which has less? How many black pebbles will you need for this one? How many pebbles are there altogether in this pattern? Children can create their own patterns on the floor using the black and white pebbles.

What you Need: Cardboard or heavy paper, markers, a collection of black and white pebbles, roughly the size of the dots on the pattern cards, a container for pebbles and cards.

How to Make It: Make 8 pattern cards. The cards should be viewed vertically.

From Holping Children Lecom
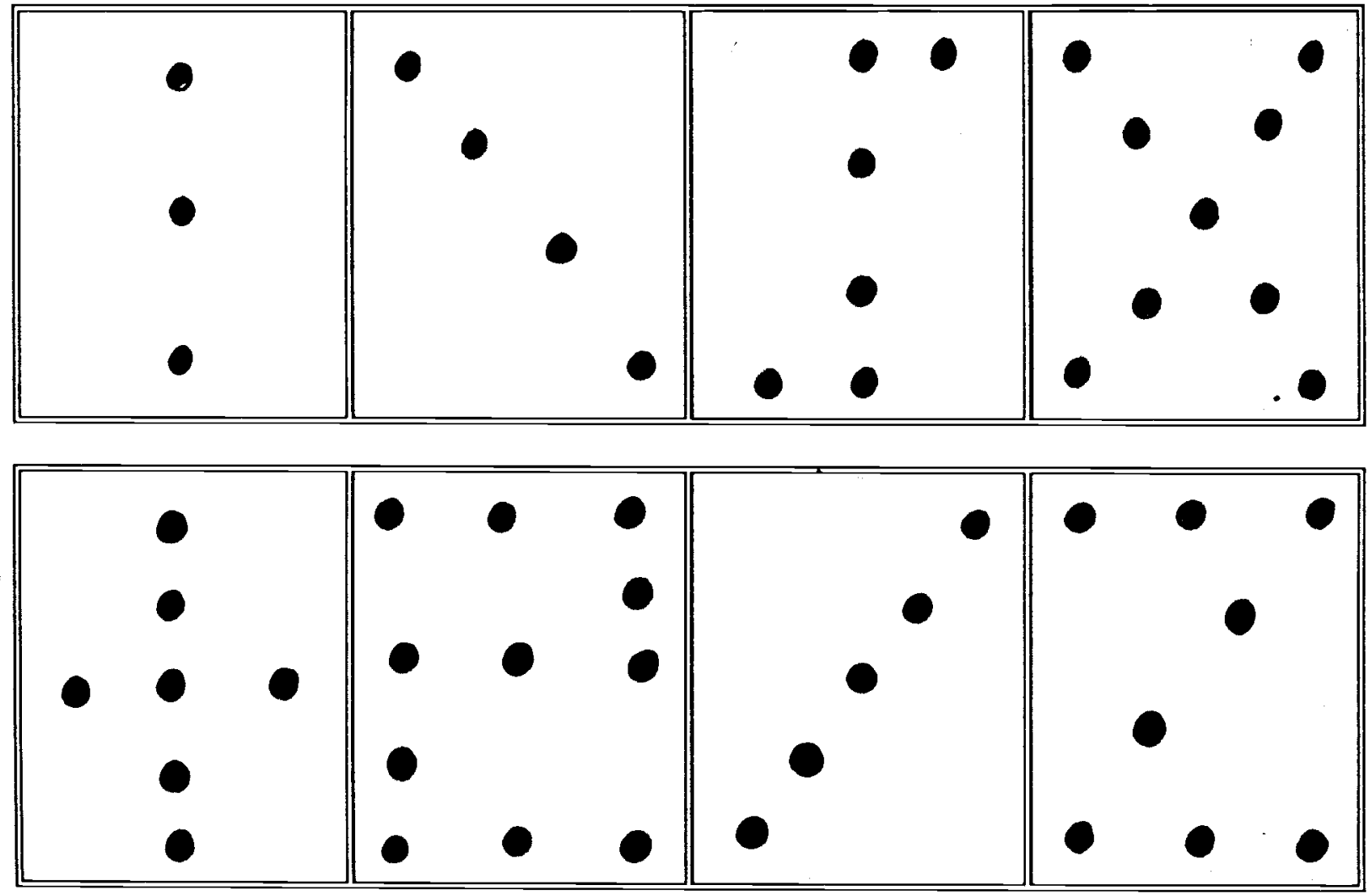
Part V: Suggested Games, Activities and Learning Materials

\section{Language Development}


- Bring some fruits and vegetables to school. The children can draw and color pictures of these and they can be cut out and made into a class book "Our Book of Fruit and Vegetables" with labels for each. Hang the book on the wall for children to refer to. Can be used with other themes as well.

- Make a color chart with the children, using paint, colored scrap material or paper. Label the colors clearly. The children can use it as a reference.

- Gather the children in a circle or comfortable sitting corner and perform action rhymes. If the class is too large, small groups can take turns, but try to involve all the children.

- Let the children mime (without words) everyday events either singly, in pairs or small groups. The rest of the class can guess what they are doing - for example, cooking food, riding a bike or brushing teeth.

- Kim's Game: Place several objects on a tray, remove one while the children close their eyes, and ask the class which object is missing. Have children take turns removing an object. Remove all the objects and ask the class to list what was on the tray.

- Make a telephone for children to talk to each other with. Use two tins and a piece of string. A small hole is made in the closed end of the tin and a the string is knotted and run through the hole in each tin. The other end of the tin remains open. One child talks into the tin, while the other holds the second tin against their ear. Instead of tins, you can use matchboxes and lids.

- I Spy: is a good game for work on initial sounds. One child chooses something in the room beginning with a certain sound. The rest of the class must guess what that child has chosen. The child starts the game with the words "I spy with my little eye, something beginning with...". The child who guesses correctly starts next game.

- On the first day of the week, you can set aside some time with the children for Home News Time. Sit with the children in a circle and let each one tell a short piece of news to the class about what happened cluring the weekend.

- Guess Who's Speaking: Children close their eyes. Ask 5 children to come to the front. One child goes to the back of the room while the children have their eyes closed and tells a short story or rlyyme. The rest of the class must listen and guess who is speaking.

- Broken Telephone Line: Tell a simple story or message to one child. That child then whispers the message to their neighbor who whispers it to the next child. This goes around the complete circle and the last child tells the class the message as he heard it. 
Activity: Tracing Letters

What You Need: Paper, markers, cardboard, - optional - photo album with plastic covered pages, a tray of salt or sand, water-soluble pens

What to Do: Make a book of letters of the alphabet, one letter per page very large. Indicate with arrows how to make the letter so children can follow with their fingers. You can put the letter pages in a photo album with plastic pages to protect them, or cover the pages with adhesive. Pens that wash away can be used to write on the pages and then be wiped away after the child is finished practicing. Alternatively, the children can follow the shapes of the letters in a tray of sand or salt, or do it outside on the ground.

The same can be done with the numbers 1 to 10 .

Activity: Alphabet pockets
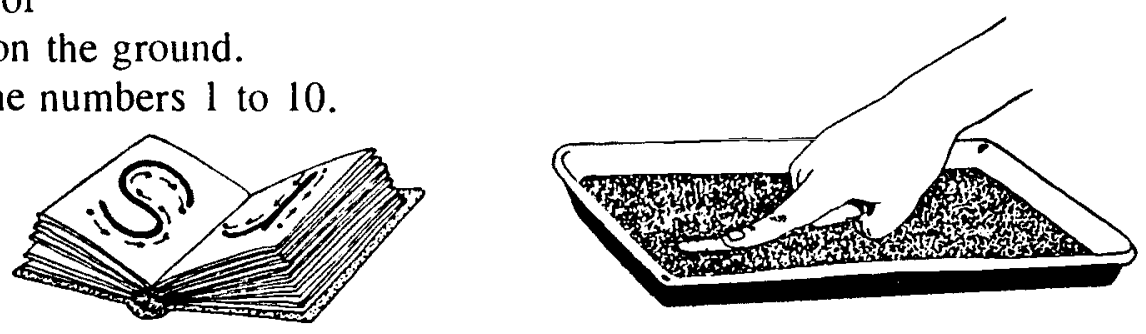

What You Need: Make hanging pockets - can be done in different ways: sew large open pockets in rows on to a single piece of cloth and hung at the children's height; make a row of pockets across one wall; make envelope pockets out of cardboard pieces stapled together on three sides, with the top open; make draw string bags that can be hung by the string; tape large envelopes on the wall in rows; or come up with your own idea based on the materials and space you have available.

Mark whatever kind of 'pockets' you choose to make with each letter of the alphabet and a picture of a word beginning with that letter. These can be sewn, drawn or glued on to the front. In each pocket you can have actual letter shapes, or flashcards with the particular letter on it. Distribute the cards or letters to a group of children and they have to place their letter into the correct pocket.

From Bright Ideas for Early Years 


\section{Activity Name: Story Sequence}

How Children Play: Choose a picture sequence, but do not show the cards to the child. First tell a simple story based on the pictures. Then mix up the four cards and see if your child can arrange them in correct sequential order according to the story. You might like to follow the above procedure for the rest of the stories, but depending on the child's abilities, try giving a mixed-up set of pictures and ask them to look through them carefully. See if the child can then make-up a story based on them and arrange the pictures in order.

What Children Learn: Interpreting pictures which depict actions and events; understanding relationships of sequence, cause and effect relationships; using vocabulary which expresses these relationships, for example, using the words 'after', 'then', 'first', 'next', etc.

How Teacher Can Help: Get the child to have a conversation with you that uses the words cited above under 'What Children Learn'. For example, ask questions similar to these:

"What did the children have to do before they could fly their kite?" "Did the kitten come in before or after she put the bowl down?"

What you Need: Heavy paper, magazines, or story books or drawing pens and paper

How to Make It: Prepare a series of four cards that tell a story in pictures. You can make up your own and draw illustrations. Or copy pictures from story books or cut them out from a magazine. The key is that they are simple and sequential.

Activity Name: Word Puzzles

How Children Play: Each 3 piece puzzle forms a word. The puzzles are self correcting since a complete picture is formed only if the word is spelled correctly.

What Children Learn: Learning to spell simple three letter words.

How Teacher Can Help: Help children hear the sound of each of the letters, especially the vowel sounds. Give them card, paper and crayons to make their own similar puzzles with other 3 letter (or short) words.

What you Need: Cardboard/heavy paper, glue, scissors, crayons, pens or magazine pictures

How to Make It: Make word puzzles. Use pictures from magazines or draw your own, of simple three letter words, such as nan. Paste the picture onto the cardboard square or draw it directly onto the cardboard. Write the word across the bottom in large, clear letters. Then cut the card into three strips so the children have to put the word together correctly. 
Activity Name: Language Card Games

How Children Play: Children can play several games with this set of cards:

Riddles: Put a few cards at a time in front of the child. Ask a riddle about one of the pictures. The child has to listen carefully and identify the card which has the answer. For example: It is cold and good to eat (ice-cream bar); It drives on the road and carries many people (bus). Encourage the child to make up their own riddles for you or his classmates to guess.

Spot the Words: Make up a simple sentence using two or three words depicted on the picture cards. The child has to listen to the sentence and pick out the two or three related pictures. For example: I had my medicine, ate some sweets and went out to swing (medicine, sweets, swing); In a small house lived a little girl and her brother (house, girl, boy); Make the game more challenging by increasing the sentences and using more words at one time.

Silly Sentence: Put the cards face down. The child must pick up three cards and use all three words in one sentence. For instance, for the cards showing a slide, a ball and a bus, the sentence could be: The girl went down the slide with her ball and ran for the bus. Sentences could be quite funny or silly depending on the pictures.

Say Something: Spread out all the cards face down. The child can pick up any card, look at the picture on it and say whatever they like about the picture. Children's responses will vary from: "It is a slide" to "I like to play on the slide." Encourage longer responses as the child becomes more familiar with the game.

What Children Learn: Developing listening skills; developing vocabulary and communication skills.

What you Need: Card or heavy paper, paper, scissors, glue and crayons or colored markers, a container for the cards

How to Make It: Make a set of picture cards. You can draw your own and color them to make them more attractive. Simple black and white line drawings are fine as well. Or, cut out pictures from magazines and other places and glue them onto the cards. Use pictures of things the children are familiar with and know something about - people, transport, toys, food and so on. 
Activity Name: Picture Talk

How Children Play: Use the pictures to encourage children to talk freely. Keep the atmosphere as informal and 'chatty' as possible. The picture cards allow for different uses of language as described below. But remember, questions should be open-ended. This means that there is no right answer or wrong answer. The idea is that children should feel free to express themselves. Here are some suggestions for activities.

Listen: Put four pictures face down on the table or floor. Ask children to listen carefully as you describe one of them. Turn the cards over and find the one that matches the description.

Show and Tell: Children can choose a picture and say whatever they like about it.

What are They Doing?: Distribute picture cards. Ask children to look at the people in each picture and answer the question: "What are they doing?" Their responses will involve the use of many action words (verbs).

What are They Feeling?: Children can try to answer the question: "What are they feeling?" Through understanding the context of each picture, they can use several adjectives for the basic emotions which all children experience, for example, happy, sad, afraid, proud etc.

What is Happening?: To answer this question, children have to go a step further They have to perceive each picture as a whole, integrate all the details in their minds and try to describe the action or event, the people, their feelings and so on.

Why?: Ask children why they think a particular action in a picture is taking place. For example, "Why might the boy be crying?" "Why is the girl holding up the picture?" "Why is the mother looking angry?"

What Children Learn: Developing listening skills; developing vocabulary and communication skills, that is, to describe people, events and action, to reason, to give explanations and make predictions, to express feelings and opinions and to imagine.

What you Need: A container for cards, markers, glue, scissors, heavy paper, magazines

How to Make It: Make picture cards - between 10 and 20. These can be drawn or copied from children's story books or cut out of a magazine. Paste the pictures onto cardboard squares of the same size. Include pictures of people doing many different activities, showing emotion, and aim to have the scene depicted be something the child can tell a story about. 


\section{Activity Name: $A B C$ Beginnings}

How Children Play: A good way to begin is by talking about the child's name and the sound it begins with. Or you can begin by taking any familiar word, for instance, ball. Have a ball for the children to see and handle. Pause for a moment on the first sound of the word - 'buh' - and ask children to say the sound after you. Ask, "Which sound do you make first when you say the word 'ball'? Help them to hear the sound 'b'. Show the letter card ' $B$ ' and say that the word ball begins with this letter which we call ' $B$ '.

Ask children to think of several other words they know which begin with ' $b$ '. Show them picture cards of other words that begin with ' $b$ '.

When you have introduced 2 or 3 letters in the same way, try using the folder you have made. Clip the three letter cards that have been introduced to the first three pockets. Take out all the picture cards for these letters. Mix the cards and see whether the children can sort them into the correct envelopes.

Gradually introduce new letters and give more pictures to sort. Make another folder when children are ready to sort more than 15 letters and sounds.

What Children Learn: Learning to recognize and name the letters of the alphabet; associating the letters with their sounds; listening to the sounds in words and classifying words according to their initial sounds.

How Teacher Can Help: Talk about the pictures as you introduce them.

What you Need: 15 small sturdy envelopes, a container for alphabet and picture cards, paper clips, a file folder, card or heavy paper, scissors and markers

How to Make It: Make a set of alphabet cards about the same size as the envelopes. Mark one letter of the alphabet on each card in neat, large and clear writing. Make a set of picture cards, about 3 pictures for each letter of the alphabet - that is three pictures of words that begin with ' $a$ ', three for ' $b$ ' and so on. Cut the flaps off the envelope and paste the envelopes on the inside of the file folder - 7 or 8 on each side - or as many as will fit. In this way you will have pockets in the file folder to which you can clip the alphabet card to the front of the envelope and children can put pictures that correspond to the letter inside the envelopes or pockets.

From Helping Children Le'urn 
Activity Name: $\mathrm{ABC}$ Collection

How Children Play: Use the folders from the activity $A B C$ Beginnings. Instead of pictures, let the children sort real objects in the same way.

What Children Learn: Learning to recognize and name the letters of the alphabet; associating the letters with their sounds; listening to the sounds in words and classifying words according to their initial sounds.

How Teacher Can Help: Talk about different objects - their color, uses, shape etc., but the main focus should be on the beginning sounds and the corresponding letters of the alphabet.

What you Need: A container for objects and a collection of small easily available objects for several letters of the alphabet, at least three objects for each letter that you select. For example: $\quad \mathrm{P}=$ paper, pencil, potato $\quad \mathrm{S}=$ stamp, soap, spoon

How to Make It: Let children help in collecting objects. To keep the objects safe and have it last longer, you can place each one in a small plastic bag and seal it with a staple or adhesive tape.

\section{Activity Name: No Peeping}

How Children Play: With eyes closed, the child has to put their hand into the bag (or use the 'Feely Box') and identify the object inside only be feeling it. Another time the child can identify the object, but instead of telling you, they have to describe it or talk about what it is used for so that you or other children can guess what it is.

What Children Learn: Developing vocabulary and communication skills; developing listening skills.

What you Need: A cloth bag that a child can put their hand into without seeing what is inside. The 'Feely Box' from the activity describe in Educational Toys and Games can be used for this purpose also. A collection of small familiar objects, for example, a spoon, chalk, matchsticks, keys, bangles and so on. 
Activity Name: Where Is Everybody?

How Children Play: Let the children talk about the picture freely. Ask them to you show you all the things that are happening in it and describe them. Children can hunt for different details as you ask questions such as: Where is the ...? Children must find the details and answer where a particular thing is in relationship to something else. The clothes are on the fence. The bird is in the tree. Ask as many questions as you can to get the children to use prepositions, such as, in, on, under, above, between and so on. Sometimes you may need to prompt them and ask them to use a particular word in the sentence, such as 'in between'.

What Children Learn: Understanding spacial relationships; using vocabulary and sentence structures which express relationships of position. For example, words such as, 'on', 'between', 'in', 'under' and so on.

What you Need: A container for pictures, pictures from magazines or story books

How to Make It: Collect or make large pictures that illustrate a lot of activity and are interesting to young children that will facilitate the use of prepositions. Paste them on heavy paper or cardboard.

\section{Activity Name: Written Down Talk}

How Children Play: The language experience approach to reading is essentially a method of teaching children to read through "written-down talk'. The metholl has four simple steps:

1. Encourage the child to talk about a personal experience, thought or feeling of immediate significance. They can draw a picture about it if they like.

2. Help the child to dictate one or two short sentences about the experience or picture. Write down the dictated sentences for them.

3. Help the child 'read' these sentences back to you. At first this might involve your reading words slowly and encouraging the child to repeat them.

4. Choose 2 or 3 key words from the sentences and write them on separate word cards. Help the child 'read' these word cards. You will find that the child soon begins to recognize these words because they have particular meaning for them. They are words the child has used and dictated themselves. Store the word cards in a small box or separate envelope for each child, to be used again and again. Examples of key words in the following sentences are in italics: I was scared of the lizard. My grandmother gave me sweets.

What Children Learn: I.carning to read through language experience.

What you Need: Paper, crayons, pens, a container for cards, slips of paper for word cards 


\section{Language Activities}

\section{AlPhabet GaMeS}

Here are some games for learning the alphabet and beginning phonics. You will need the letter and picture cards from $A B C B$ egimnings and the objects from $A B C$ Collection.

ABC Sequence The child can arrange the letter cards in alphabetical order. You can also play a game. Put a sequence of four letters on the floor, leaving one out, for example: $D, E$ -- G. The child has to find the missing letter.

Phonics Pairs Select pairs of picture cards for the letter sounds you want to stress. The game can be played with 2 to 4 players, or with a larger group depending upon the number of cards you select. Shuffle the cards and deal them. Each player places their cards in a pile in front of them, face down. The first player turns over the top card, names the picture and places it face up in the center. The next player turns over the top card from their own pile of cards. If the picture does not begin with the same sound as the one on the card placed by the first player, they have to turn it over again and put it at the bottom of their pile. If it does begin with the same sound, they name the picture and place it on top of the one in the center. They then turn over another card for the next player to match. The game proceeds until the first one to place all of their cards in the center wins.

Memory A game for 2 to 4 players. Select pairs of picture cards for the different sounds as above. Shuffle the cards and spread them on the floor or table, face down. Players take turns to turn a card over and name the picture on it. Then they must try to remember where another picture beginning with the same sound is, and turn it over. If the guess is right, the player keeps the pair and continues with more turns. When two cards that do not match are turned, they must be put face down again in exactly the same places. The player who has the most cards, when all the pictures have been paired, wins the game.

I've Got It A game for 2 to 4 players, or a larger group. Use the objects collection and the letter cards for this game. There should be 2 or 3 objects for each letter sound. Mix up the objects and distribute them amongst the players. A leader keeps the letter cards, and holds up one card at a time for all the players to see. All those who have an object whose name begins with that letter call out "I've Got It" and run up to the leader. The reverse is also fun. Select one object only for each letter and keep the collection with you (the leader). Deal the letter cards amongst the players. As you hold up each object, the player who has the corresponding letter card runs up with it.

Hide and Seek Pick out all the objects for 3 or 4 letters of the alphabet at a time and show them to the children. They put their heads down while you hide or place selected objects all around the room. Give the corresponding letter cards to 3 or 4 children who each have to find the objects for their particular letter. The first child to bring all 3 correct objects for a letter to you is the winner.

You can think of many more games using this basic card set and collection of objects. From Helping Children Learn 


\section{Activities to Promote Pre-reading Skills}

- Look for and say the names of objects found in and outside of the kodakistan.

- Play the game of identifying, matching, sorting concrete objects: grouping blocks according to shape, size, color or type - flowers, leaves etc.

- Play games using pictures of common objects.

- Play "Find the Hidden Object" - children look for objects hidden by the teacher based on stories told; children look for hidden objects in pictures.

\section{Activities to Promote Early Reading Skills}

- Play with alphabet cards and differentiate the shapes of letters:

find the shape which is different in a group of letters, such as $\mathrm{k} \mathrm{k} \mathrm{k} \mathrm{a,} \mathrm{and} \mathrm{which} \mathrm{are} \mathrm{the}$ same in a group of letters, such as $\mathrm{i} g \mathrm{~g} g$, matching letter shapes which are same.

- Play with the sounds of letters: play with the names of objects or pictures that have initial vowel sound, such as ' $a$ ' is for apple, say the name of objects or pictures where the initial syllable is made up of the letter $b$ and vowel $a$.

- Play with vowels and consonants:

blend vowels with consonants to form meaningful words, blend syllables with syllables to form meaningful words.

- Play with words: match pictures with words, blend syllables to form words, pronounce words shown, make simple sentences by arranging words on cards.

\section{Activities to Promote Pre-Writing and Early Writing Skills}

- Do hand and finger movements such as:

fingerpainting, clay, dough, plasticine, patterns in air using fingers, patterns in sand, clay or starch, feel shapes of letters cut out of sand paper, pretend to play piano or other musical instruments.

- Do exercises on eye movements such as:

arrange a series of pictures from right to left, left to right and top to bottom; make lines in the air right to left, left to right and top to bottom; make patterns in the air as above.

- Carry out exercises on eye-hand coordination:

tear paper freely, tear paper according to instructions, fold, cut and paste paper or other materials to form patterns, shapes or objects; thread beads, flowers, leaves, straw etc., copy patterns made by the teacher such as: a straight line, curved line, loops, points etc.

- Trace shapes of letters using fingers, crayons, pencils.

- Trace and copy shapes of letters in meaningful words.

- Recognize and copy and color shapes of letters in meaningful words. 


\section{LISTENING: SKILLS}

Mother Duck: A child is chosen to be Mother Duck. She leaves the room. The leader taps some children who are designated as ducklings. All children cover their mouths with their hands. Mother Duck comes in and says, "Quack, Quack." Only the ducklings reply, "Quack, Quack." Mother Duck listens and taps a child if she thinks he is a duckling. The procedure is repeated until she finds all her ducklings.

Who's There: A child is chosen to be the Magician and to stand in front of the room with his back to the class. The leader taps another child who goes up and knocks on the floor behind the magician, who in turn asks, "Who's there?" The visitor replies, "It's me; open up." The magician has to name the visitor. He can repeat the question 3 times. If he fails to guess, the visitor becomes the next magician.

Pack a Bag: The leader begins the game by saying, "I'm packing my bag and need your help, I'll put in a shirt. What will you put in?" The next child might say, "I'll put in a shirt and a book." Each child in turn must repeat the things already packed and add another. Continue till 5 or 6 children have had a turn, then start again. Another popular variation is, "I went to the market and bought..."

Simon Says: The leader gives directions which children have to follow, e.g. "Simon says, Hop on one foot," or "Simon says, Scratch your knee." When the words "Simon says" are omitted, children must continue to perform the previous action. Those who perform the new action, when "Simon Says" is omitted are out. Contimue until one child is the winner.

Treasure Hunt Game: The leader chooses a pair of children. One of them goes out of the room. The other decides with the rest of the children to hide an object somewhere in the room. She asks her partner to come in and tells her what the treasure is. She then tries to describe where the treasure is hidden, without pointing or looking in the direction of the hidden object. The partner has to find the treasure.

\section{From Helping Children Learn}

\section{To Acquire Language Experiences through Listening}

- Listen to sounds, guess what they are and imitate them - bird car, bell, piano, cat etc.

- Move various body parts to make sound - clapping hands, stomping feet, snapping fingers and other actions. These actions can be prompted by a story told by the teacher.

- Guess, say and imitate sounds made by the teacher.

- Listen to the teacher telling stories and respond by imitating sounds of animals mentioned in the stories.

- Listen to the teacher telling stories and respond with appropriate reactions - fright, sympathy, happiness etc. 


\section{Pre-Writing; AND THE IMPORTANCE of Words}

The Counters Game: Each child is given a sheet of paper complete with a numbered grid which has four spaces per line:

\begin{tabular}{||l|l|l|l|l||}
\hline 1 & & & & \\
\hline 2 & & & & \\
\hline 3 & & & & \\
\hline
\end{tabular}

The children need to place a counter (bean, button, pebble etc.) in the spaces each time the teacher says a word. Begin with children's names (not of those playing the game). The children repeat the names and place a counter on one space at a time. Once accomplished at this they could be encouraged to 'think' the words and place the counters.

After names, the teacher could use simple one or two syllable words, followed by actual sentences, and later more complicated multi-syllable words.

The Magician: As children progress, they need to understand why writing is necessary. They need to realize that it represents the words we speak and thus carries meaning - this is not obvious. Games can assist: An older student, or another adult who can read, leaves the room and the teacher hides an object chosen by the children. The teacher then writes on the board the object and where it is hidden. The magician returns and is asked what have we hidden and where have we hidden it? The magician reads the answer on the board and the exercise is repeated once or twice. Then the teacher asks the children - "Do you know how the magician knew? Do you know the magic secret? Do you think the magician was told?"

\section{More Ideas to Introduce the Concept of the Written Word}

An effective teacher needs to use every opportunity as it arises to illustrate uses of writing for example, a letter, writing a message to remind yourself, a shopping list warnings on medicines and poisons, how does the postman deliver letters? etc. Therefore we need writing, and some things to do to communicate this message:

1. Get children to differentiate between writing and pictures by coloring pictures and circling the writing.

2. Make a collection of things the children have gotten from home that include writing, for example, labels, newspapers etc.

3. Stage a name hunt by hiding cards with the children's name on them around the room and ask them to find the word which is their own name. 


\section{STIMULATING INTEREST IN READING;}

- Provide simple pictures with simple stories beneath.

- Labels on classroom walls and on children's own pictures.

- Make your own story and picture books.

- Look at books in reading corner, listen to stories from books.

- 'Read' on one's own - that is, look at pictures and talk about them as if reading.

- Read books aloud to children.

- Use and look after books properly to learn to value books.

\section{Reading Aloud:}

Being read to is a good way for pre-school children to make the connection between written and spoken words. Although they can not yet read or write themselves, they begin to realize that words can be written down and read back the same way over and over.

\section{How to Cultivate the Children's Interest in Books:}

Have a special corner for books and encourage the children to flip through the books anytime. Encourage the child to ask questions about what he sees in the books and answer him as best as you can. Tell the children stories from books.

\section{Provide the Following Kinds of Books:}

Books that have lots of pictures and drawings - colorful pictures which are clear. Books which have short sentences and attract the children's attention. Books that interest children are those that concern: people, animals, colors, shapes, nature, vehicles, anything that they are familiar with.

\section{Qualities to look for in selecting books to read aloud:}

- rhyming and repetition

- language well used: pleasant and exciting to read aloud, interesting and varied vocabulary, sentences flow

- consistent logic: characters act and solve problems within a given coherent framework

\section{Qualities to avoid}

- choppiness

- dull languige

- aimless plot, lack of resolution

From Malaysian Comese of Childhood Derelopment and Childeare, and

From Teaching lufants, and

Fron Young Children in Acrion 


\section{MAKING BOOKS}

Activity: My Story Book

What You Need: Thick card, adhesive tape, large sheets of paper, string, a long arm stapler, thick strips of cloth

What to Do: Fold several large sheets of paper in half and fix them at the folded edge with a long arm stapler. These will form the pages of the book. Cut card to make two covers, slightly larger than the pages of the book. Cut a further strip of card about $1.5 \mathrm{~cm}$ wide and as long as the two covers. Cut a strip of the cloth to stick to the card, and glue it completely around the card on both the outside and the inside. Use string to tie the writing pages into the book cover, and also to suspend the book for display. Bind the edges of the covers with adhesive tape (colored tape if available) in order to strengthen it. The cardboard might also be covered with strips of cloth. Label the cover and the inside can contain the children's own story - with words and illustrations, only pictures, or a collection of their art work can be pasted inside. It could also be a series of cut out pictures the child has selected to tell their story.

\section{From Bright leleas for Classroom Management}

\section{Checklist of questions to ask before making books:}

1. Who is the book for? Who is writing it and who will be reading it?

2. What is the purpose of the book? (How will it be used when it is finished?)

3. Which materials do we need?

4. What shape should it be?

5. How do we fasten the pages?

\section{Some points to consider when answering these questions:}

1. Here are some possibilities: - teacher writing for child

- child writing for parents/self/friend

- group writing for class, or the class writing for all

2. It is important to have the purpose clear in your mind. Perhaps you are trying to reinforce a teaching point by having the children prepare some work to put in a book. Or perhaps it is part of a classroom topic. When it has been finished it will need to be kept in the classroom within easy reach of the children so that they can refer to it.

3. Here are some suggestions: paper for the pages; card, cardboard, fabric for the cover; string, cotton, glue, adhesive tape for binding the book.

4. Varying the shape of books is one way of attracting and retaining the children's interest. The book might be the same shape as the subject matter, e.g. cats, triangles, flowers.

5. They might be sewn, tied, stuck or stapled or bound, depending on the materials available and the most suitable fastening for the design. 
Activity Name: Home-made Books

You can make different kinds of books for children:

- books about real things such as plants, people, transport (facts)

- books about make-believe things (stories)

What you Need: 10 pieces of thick cardboard $(25 \mathrm{~cm} \times 20 \mathrm{~cm})$, magazines, newspapers, old cards and postcards, paper punch, cord or string, clear plastic adlhesive, glue, markers, scissors

\section{How to Make It:}

1. Select a theme or story, for example, colors. Cut out suitable pictures from magazines or cards.

2. The cover of the book is made by pasting a suitable picture onto a piece of cardboard. Print the title with the marker.

3. Paste other pictures onto the remaining pieces of cardboard (words or sentences may be written.)

4. Cover with clear plastic adlhesive or wide clear tape.

5. Measure and punch holes through each page.

6. Thread the cord through the holes and fasten firmly.

This idea comes from Learning with Scrap

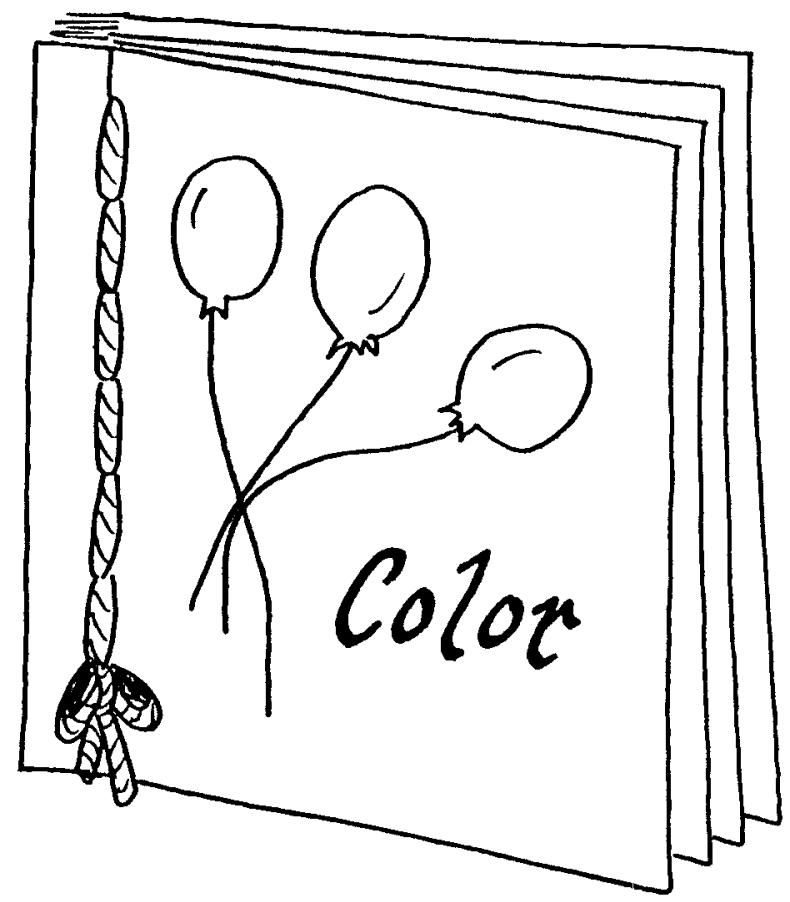




\section{Language Activities}

\section{StORY TElling}

What Happens Next?: Children use their imagination to predict what could happen after the action or event depicted in each picture, e.g. "They fight so much that one of them gets badly hurt," or, "Mother comes in, they stop fighting and start playing again;" for another picture "They catch a huge fish" etc. Remember there is no right answer, but several possibilities.

Make Up a Story: Each picture suggests a story. Children can choose a picture and make up a story about the people and the actions or events that it depicts.

\section{From Helping Children Learn}

Story Telling Time: One way to tell a story is to group the children so that all the children can see and hear. Use a book to tell a story and the tell the children the title and show them the pictures. Use pictures during story telling as much as possible. Use puppets during story telling or act out parts of the story in front of the children.

- During story telling use simple words and language, do not take too long to tell the story as the children may get bored. After story telling, encourage the children to ask questions and have a look at the story books. Have additional activities such as drawing or shaping something from the story told. Encourage the children to tell the story again and bring to their attention the moral of the story.

- Telling stories using sound effects is also very effective: animal sounds, trains, sirens, cars etc. Children can become involved in making the sounds or listen to the teacher. Rhyming poems are also a good alternative or addition to story time.

From Malaysian Course of Childhood Development and Childare

\section{Story Telling Ideas:}

- Start off a story and give the children turns continuing the story.

- Make up a story about animals the children are familiar with that walk to the big city and the adventures they have.

- Make up a story about a boy and girl who find a large sum of money and what they decide to do about the find. Use names of places the children know.

- Present a group of objects such as, a fruit, a matchbox and a hat, and make up a story in which all the items are included. The same activity can be done with just one item.

- Invent an imaginary animal and give it a special name and special features, for example, the ability to talk, to be invisible and so on. Tell a story about the animal's adventures.

- Factual events in history make good story material. History taught in this way is both enjoyable and memorable.

- Collect pictures of wild and domestic animals. Let children take turns making up and telling stories about them. This can be done with other themes instead of animals. 


\section{The Gingerbreadman}

An old man and an old woman lived in an old house in an old forest.

Every day the old man worked outside. He milked the cows, he brought the firewood, he looked after the plants.

Every day the old woman worked inside. She made the beds, she cleaned the house, she made the food.

One day she made a cake and made it in the shape of a man. She put it in the oven to bake, then she went back to work.

The dog walked past the window, sniffed and said, "Mmm, that smells nice."

The cat walked past the window, sniffed and said, "Mmm, that smells nice."

The mouse walked past the window, sniffed and said, "Mmm, that smells nice."

Two woodcutters walked past the window, sniffed and said, "Mmm, that smells nice."

The old man came in, tired from working and ready for his tea and cake. The old lady took the cake out of the oven.

Suddenly, the cake man jumped up and ran away! He ran out of the house and across the fields, singing, "Run, run! Quick, quick! You'll never catch me."

"Ah!" said the old man, and ran after the cake man.

"Ah!" shouted the old woman, and ran after the cake man.

The dog heard the noise, came to see what was happening and ran after the cake man.

The cat heard the noise, came to see what was happening and ran after the cake man.

The mouse heard the noise, came to see what was happening and ran after the cake man.

The two woodcutters heard the noise, came to see what was happening and ran after the cake man.

But the cake man ran too fast for all of them, and he ran away over the hill. They could still hear his voice singing, "Run, run! Quick, quick! You'll never catch me." 


\section{Oral and Verbal SKILlS}

\section{Encouraging Language through the Daily Routine}

- $\quad$ talking with others about personal experiences

- describing objects, events, and relations

- expressing feelings in words

- having spoken language written down and read back

- having fun with language, rhyming, making up, listening to stories, poems

- asking questions that help children learn

- encouraging interaction and cooperation

- referring one child's questions to another

- interpreting and delivering messages

- stimulating conversations

- encouraging active listening

- acknowledging children's choices and decisions

- taking dictation

From Young Children in Action 
Part V: Suggested Games, Activities and Learning Materials

Mathematics 


\section{Mathematics Activities}

\section{Counting Up to Ten}

- Collect mother tongue counting rhymes for and from the children involving counting from 1 to 10 and from 10 to 1 for oral practice in class.

- Count aloud, as a class and individually, objects in the classroom, for example: chairs, pencils, or better still the children themselves.

- Have between five and ten children form a group in front of the class and ask individual children to come and count them.

\section{The Concept of Size}

- Show the class objects of different sizes; compare children of different heights; choose objects of different lengths. Ask which is larger or smaller, taller or shorter, longer or shorter.

- Next give the class some practical experience. Put the objects on the floor and sort them into groups according to their various properties: for example, size, length, height. Draw rings on the floor (or do the activity outside and use chalk) and label each ring clearly so that the children can sort accordingly, for example: large objects, small objects etc.

- Draw some objects on the blackboard and ask children to color in or put a ring around:

- the larger/smaller object

- the taller/shorter object

- the longer/shorter object

\section{One-to-one Correspondence}

- To teach one-to-one correspondence, make equal collections of naturally pairing objects, for example, match the children's feet with their shoes by taking off the shoes of three or four children and letting another child draw chalk lines from shoes to feet.

\section{'More than' and 'Less than'}

- When the children are familiar with equivalent sets, make one set which has more members than the other, introducing the terms 'more than' and 'less than'.

- Put several objects on the tables in the classroom. The children can work in groups sorting them into equal sets. Start with sets of 2 and 5. Let them have number cards and place the correct card on the corresponding set.

\section{Writing the Numbers 1 to 10}

- When teaching the writing of numbers one to ten: ask the children to draw the shape of the number in the air; let them trace the number in the sand; cut several of each number from sand paper, and the children can trace over the numeral with their fingers; make a series of tracing cards for number practice - the class can trace over the numbers on thin (tracing) paper. 


\section{Mathematics Activities}

\section{Ordering Numbers 1 to 10}

- Draw five rings on the blackboard. Number them clearly 1 to 5 underneath. Pick individual children to come out and draw the correct number of objects in each ring.

- Now draw five rings on the blackboard containing 1,2,3,4 and 5 objects. This time the children can count and write the correct number under each ring.

- Draw pattern sequences on the blackboard for the children to continue:

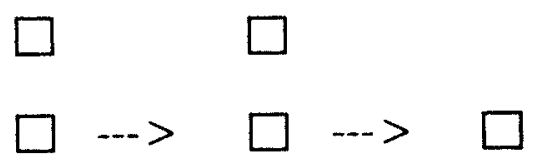

\section{Simple Addition up to Ten}

- Give oral practice in adding up to ten using classroom situations. For example, "Fahima has two oranges and Tahir has one. How many oranges have they all together?"

- Show the partitioning of sets using objects, such as pebbles, chalks, pencils and beads. Put them into a set and show the children how to partition the set in different ways, using a stick as a marker.

\section{Recognizing Left and Right}

- Let the children arrange their shoes in a line on the floor, one shoe pointing to the left, one to the right.

- Each child can draw round both hands, color them in and cut them out. The children can then arrange the hands in left and right patterns on a strip of paper to display on the classroom wall.

\section{Shapes}

- The children can explore the shapes in their environment, looking around the classroom and outside the building for squares, triangles, rectangles and circles.

Some Questions to Ask

- What shape is the blackboard, the clock, the table top?

\section{Knowledge of Currency}

- Discuss the value of coins and notes in current use. The children can then make their own coins by laying tracing paper over real coins and rubbing them with a pencil. Then they can cut out the rubbing. These paper coins can be used for making charts to show all the possible ways of making up different sums of money. 


\section{Measuring Length, Height, Weight and Capacity}

See Science Activities for more ideas on measuring

- Choose a group of children of differing heights and ask other children in the class to put them in order from the tallest to the shortest. Do the same with long objects, for example: rope, pencils, sticks and matchsticks.

- Working in pairs, the children can measure each other against the wall. This will establish who is taller or shorter. They can use long strips of paper first, and then move on to using a measuring ruler.

- Collect a selection of different containers, for example, bottles, pitchers, tins, jugs and buckets for the children to fill. Let the children experiment. First, let them fill the containers with sand or water and guess which containers hold more. Then take one small container and ask children to count how many times they use the small container to fill each of the large ones.

- First compare objects with which the children are familiar. Let them hold a small book and a large one. Ask them which is heavier. Then ask them to estimate which might be heavier - a dog or a cow, etc.

\section{Telling the Time}

- Make a demonstration clock face with movable hands out of cardboard or thin wood and a pin or paper clip. Draw the children's attention to the length of the hands, the longer hand showing minutes, the shorter hand showing hands. Pass the clock round the class for the children to position the hands correctly. Always keep the longer hand on the 12 . Then move on to half past the hour, then quarter past and quarter to.

Some Questions to Ask

- Which hand is longer?

- Which hand is shorter?

- Which way does each hand move?

- How many numbers are there on the clock face?

- Which hand moves faster than the other?

- Using the clock face, discuss with the class the fixed times in their day. Individual children can move the hands on the clock to show:
- getting up time
- school time
- time to go home
- play time
- meal times
- bed time 


\section{Mathematics Activities}

Activity Name: Toothpick Counters

What you Need: Cardboard squares numbered as illustrated below and toothpicks.

How to Play and Make It: Help the child make two peg-boards for counting. Use cardboard and round toothpicks. Number one pegboard from one to nine from the upper right to lower right. Number the other pegboard from one to nine from lower right corner to upper right corner. With a sharp instrument, punch holes corresponding to the number in each pegboard.

What Children Learn: Number names and one-to-one correspondence

How Teacher Can Help: The teacher should talk about number names and counting.

.From One, Two, Buckle My Shoe: Math Activities for Young Children
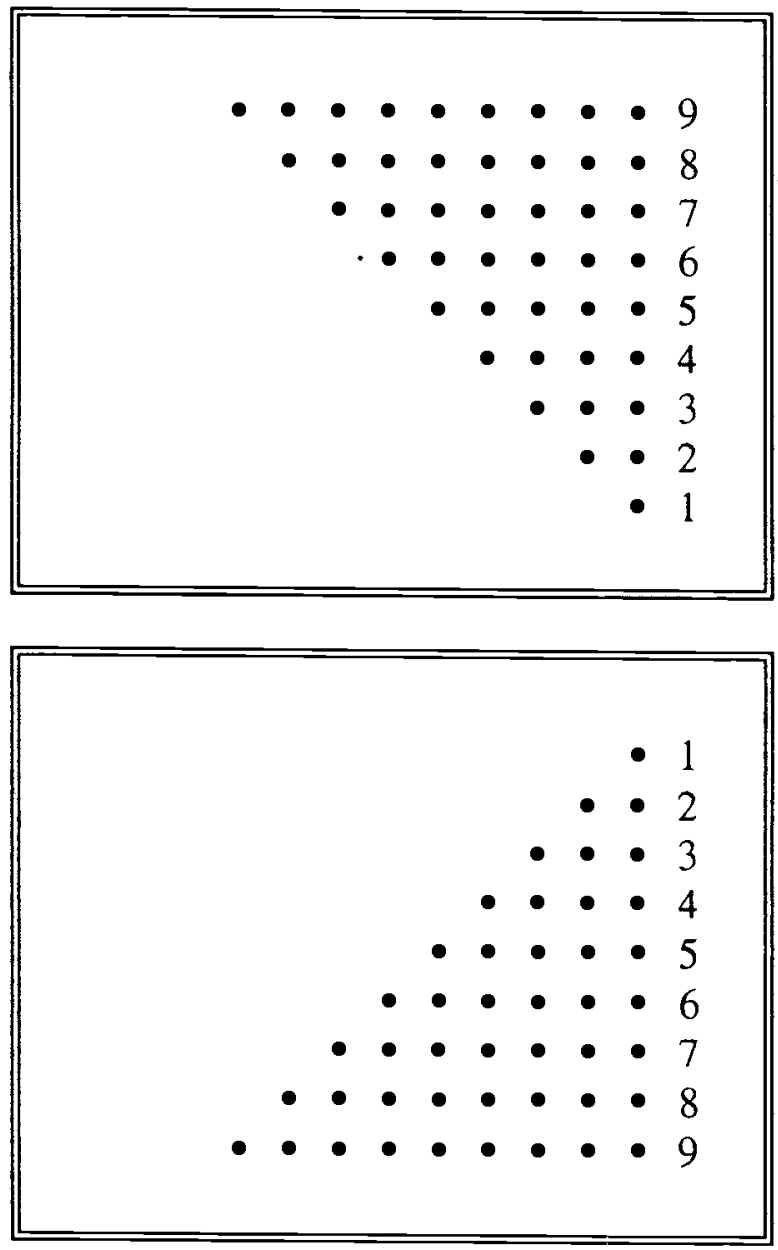
Activity Name: Building Shapes

What you Need: Thin sticks, toothpicks or ice cream sticks

How to Play and Make It: Use different numbers of sticks to form geometric shapes. Example: three sticks for a triangle, four for a square, six for a rectangle. Encourage the child to match the shapes you form. Glue the shape onto paper to take home or display.

What Children Learn: Recognition of geometric shapes

How Teacher Can Help: The teacher should talk about different simple shapes.

\section{Activity Name: Making Shapes}

What you Need: A lorry should be constructed in advance for each shape. The lorry shape should be glued to a piece of poster board. Do not glue the top strip of the lorry bed and this leaves a pocket to receive shapes.

How to Play and Make It: Glue a different shape to the bed of each lorry. Help the children trace or draw and color different shapes (triangle, circle, rectangle, square). Encourage the children to match their shapes to the correct shape on a lorry and put their shape into the correct lorry.

What Children Learn: Recognition of similarities and differences between basic shapes.

How Teacher Can Help: The teacher should talk about likenesses, differences and shapes.

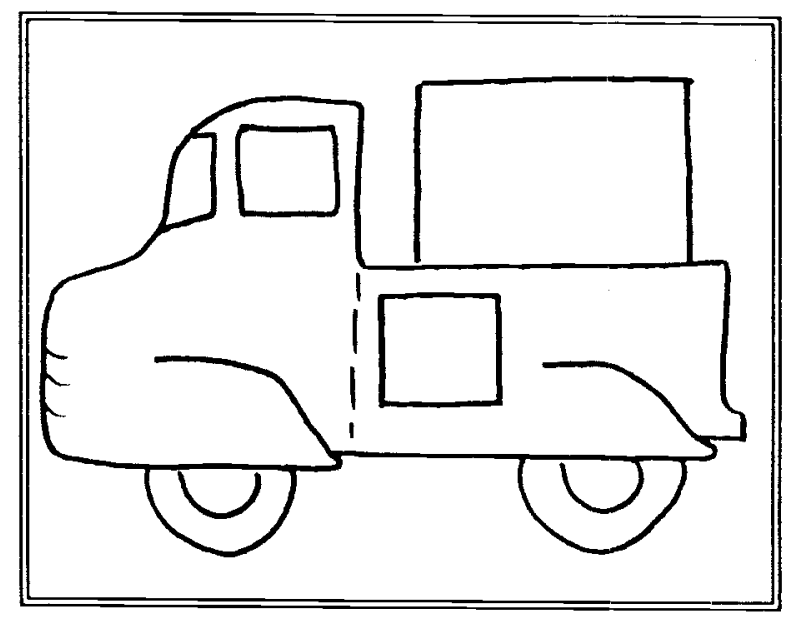

From One, Two, Buckle My Shoe: Math Activities for Young Children 
Mathematics Activities

Activity Name: Step and Count

What you Need: Pieces of newspaper, markers

How to Play and Make It: Cut pieces of newspaper into large circles, squares, triangles and rectangles. Number the shapes with magic markers from one to nine. The children should step on the shapes in order naming the numeral and the shape. It may be necessary to begin with shapes only adding numerals later.

What Children Learu: Shapes, numerals, counting, becoming familiar with number sequence

How Teacher Can Help: The teacher should talk about counting, identifying numbers and shapes.

Activity Name: Beanbags Galore

What you Need: Scrap cloth, dried beans or corn, cardboard and board markers

How to Play and Make It: Make three or four beanbags by sewing scrap materials together and filling with beans, corn or sand. Cut from cardboard ten shapes (triangles, circles, squares, rectangles) and color the shapes different colors with markers and number them 1 to 10. The object of this game is to have the child try to toss a beanbag and make it land on a cardboard shape. In the beginning, the child should be asked to name only the color. Later on, after the child is comfortable with the colors, shapes and then number names may be added.

What Children Learn: Shapes, numbers, names and colors

How Teacher Can Help: The teacher should talk about shapes, colors and number names.

From One, Two, Buckle My Shoe: Math Activities for Young Children 
Activity Name: Measuring with Foot Lengths

What you Need: Tracing paper or newspaper, pencils or crayons, scissors, pencil, chalk

How to Play and Make It: Help the children trace the outline of one of their feet on paper (newspaper will do) and cut it out. Help the children measure things like the length of the room, the desk or a bookcase using their "feet". Help the children record their measurements in foot-lengths. ("The desk is eight of Marzia's feet long.") Allow some children to measure the same objects using a piece of chalk and record their measurements in chalk lengths. Repeat using pencil lengths for example.

What Children Learn: Developing the idea of accurate measurement and the necessity of uniform measurement.

How Teacher Can Help: The teacher should ask: Do all of the children get the same measurements? If not, why not? Talk about using uniform instruments for measure.

Activity Name: Which is Taller?

What you Need: Groups of three items of yarious sizes (blocks, pencils, sticks, pieces of string)

How to Play and Make It: Ask three children to stand before the others holding one item from a particular set. Encourage the rest of the children to order the three from the tallest to the shortest (always from the right to left). Display other groups of items and allow the children to order these items.

What Children Learn: Size, sequence, linear measure, ordering according to size

How Teacher Can Help: The teacher should talk about ordering, tallest, taller, shortest, shorter.

From One, Two, Buckle My Shoe: Math Activities for Young Children 
Mathematics Activities

Activity Name: Counting and Matching

What you Need: Posterboard or heavy paper, board marker, an assortment of small items such as paper clips, keys, stamps, stick, peas, etc. and glue

How to Play and Make It: Prepare a duplicate set of cards (1 to 10) using a number of objects with a corresponding number of dots. With a group of twenty children or fewer, randomly pass out the cards so each child has one. All the children may stand in a circle. One child is called upon to name an object and the number of objects. The child then walks around the inside of the circle until the matching card is found. After everyone has a turn, cards may then be taken up and redistributed. The game may be played again.

What Children Learn: Counting, matching like groups

- How Teacher Can Help: The teacher should talk about counting, the same as matching.
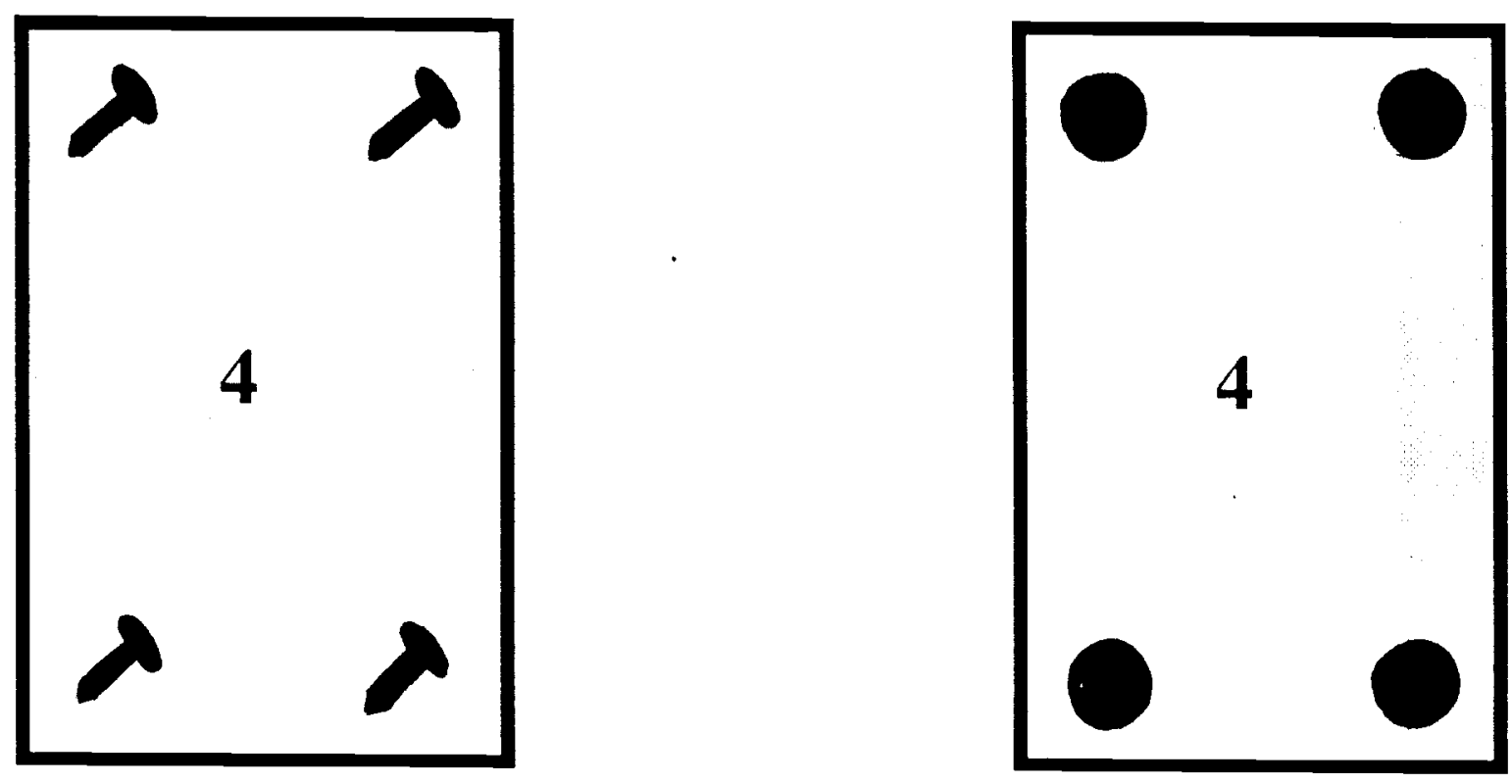

From One, Two, Buckle My Shoe: Math Activities for Young Children 


\section{Mathematics Activities}

\section{Activity Name: Ring Drop}

What you Need: Ten wire hoops, a $15 \mathrm{~cm}$ wooden rod (broom handle), nailed to a $10 \mathrm{~cm}$ wooden square

How to Play and Make It: Prepare hoops in advance by painting them different colors. Children will be encouraged to drop the hoops over the handle one at a time. Each time the child "rings" the handle the child should name the color and count the number of hoops which have been successfully "ringed."

What Children Learn: Counting, color, eye-hand coordination

How Teacher Can Help: The teacher should talk about colors, counting circles, paying games and hoops.

Activity Name: Bouncing and Counting

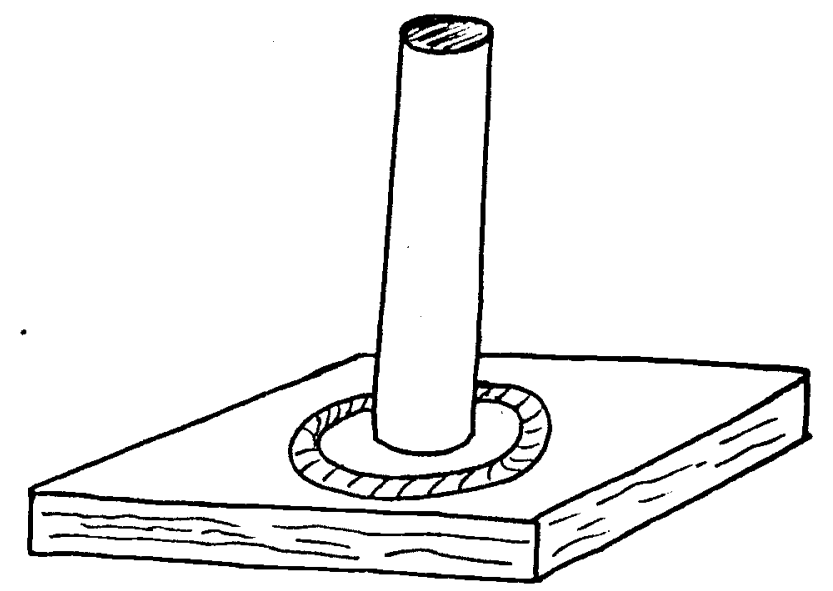

What you Need: A large rubber ball

How to Play and Make It: One child bounces a ball while another child (or group of children) with thier back(s) turned listens. The child that is listening must be able to tell the bouncer how many times, from one to ten, the ball was bounced.

What Children Learn: Number recognition, counting

How Teacher Can Help: The teacher should talk about counting.

From One, Two, Buckle My Shoe: Math Activities for Young Children 
Activity Name: Beans and Numbers

What you Need: Heavy paper or posterboard, board markers, beans

How to Play and Make It: Use almost any kind of paper in order to draw ten blocks. Begin with one colored dot in the first block, then two colored dots in the second block, then three colored dots in the third and so on, until the tenth block has ten dots on it. Supply the child with beans or any other small objects and allow him to put the same number of beans in the block as dots. It may be necessary to show the child, depending on age. As the child continues to play this game at other times, numbers should be used to refer to the blocks. For example say to the child: "Did you cover all four of the dots with beans? "Can you cover the five dots with beans?"

What Children Learn: One-to-one correspondence, matching, learning number names

How Teacher Can Help: The teacher should talk about numbers and matching.
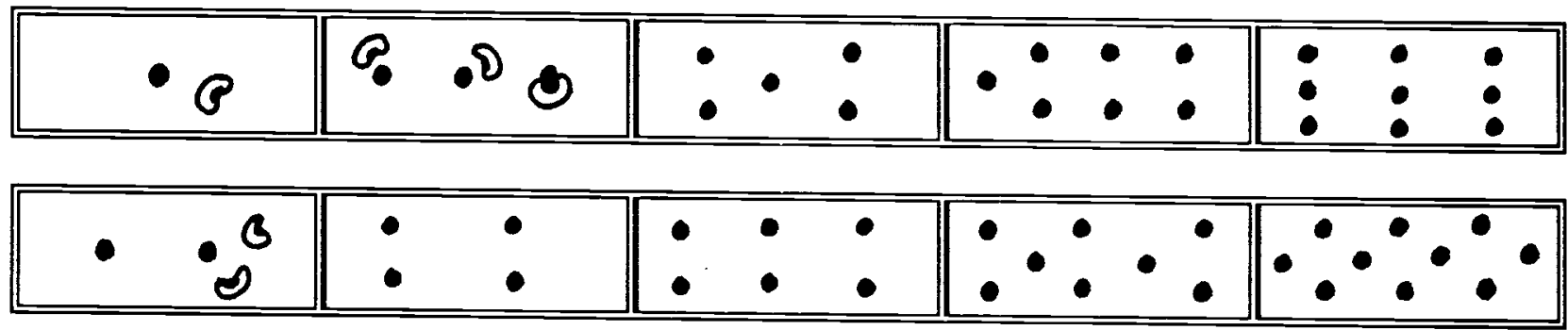

Activity Name: Puzzle Numbers

What you Need: Cardboard squares, markers, scissors or knife

How to Play and Make It: Number nine cardboard squares one through nine. Cut each board into four pieces to form a puzzle. Cover the pieces with plastic and mark the back of each piece to identify which puzzle that piece belongs to.

What Children Learn: Number names, number identification, fitting shapes together

How Teacher Can Help: The teacher should talk about number names.

From One, Two, Buckle My Shoe: Math Activities for Young Children 


\section{Mathematics Activities}

\section{Activity Name: Touch Cards}

What you Need: Nine sheets of sandpaper, 54 buttons, package of pipe cleaners or woolen yarn, glue, scissors, nine $20 \mathrm{~cm}$ by $25 \mathrm{~cm}$ pieces of cardboard

How to Play and Make It: Number nine sheets of sandpaper one through nine. Cut the numbers and glue one to the top half of each piece of posterboard. Below each numeral write the number name. Cut out pieces of pipe cleaner or woolen yarn and glue onto the number names. Below the number

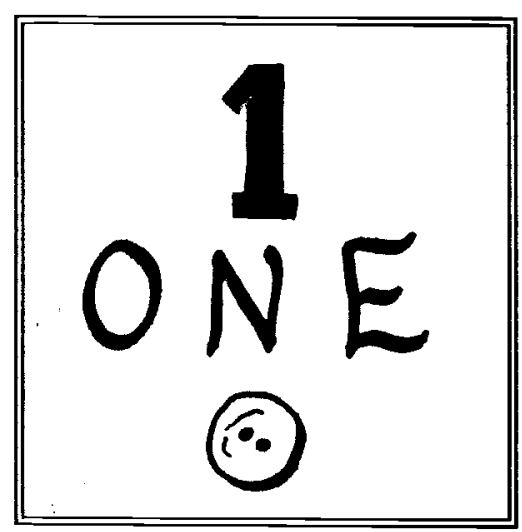
name glue on a corresponding number of buttons. The child can feel the numeral, the number name and the corresponding objects.

What Children Learn: One-to-one correspondence, number names

How Teacher Can Help: The teacher should talk about number names and one-to-one correspondence.

\section{Activity Name: Number Worm}

What you Need: Heavy cardboard, markers, scissors

How to Play and Make It: Make a "number worm". Cut each section (1-10) so that the numbers will only fit when arranged in consecutive order. That is, the two (2) will only fit to the one (1), like puzzle pieces. Children will discover sequence of numbers as they fit together to make the "number worm".

What Children Learn: Number names, counting in sequence

How Teacher Can Help: The teacher should talk about number names and sequence.

From One, Two, Buckle My Shoe: Math Activities for Young Children

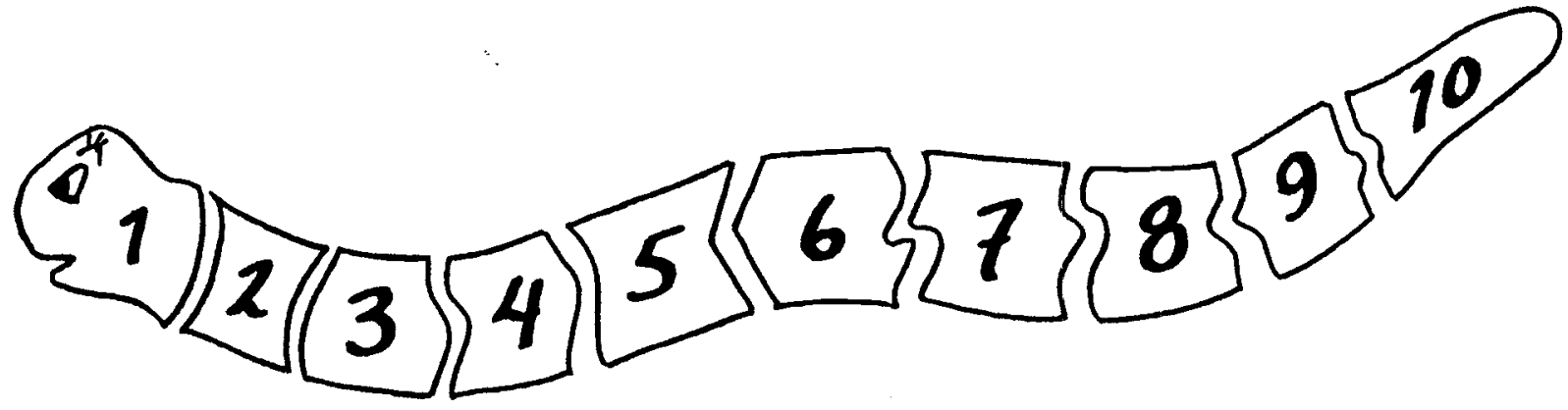




\section{Mathematics Activities}

\section{Activity Name: Clothes Pin Counting}

What you Need: Heavy paper, posterboard, markers, clothespins

How to Play and Make It: Any kind of heavy paper may be used to construct a board. Divide the paper into five sections. Put one colored dot in the first section, two in the second and so on until the last section has five dots. Color in one dot on the first clothespin, two dots on the second and so on. The child, after he is shown how, will enjoy pinning the clothes pins to the blocks with corresponding dots. In time, the child will associate the number name with the number of dots.

What Children Learn: Counting, number names, one-to-one correspondence

How Teacher Can Help: The teacher should talk about number names and matching.

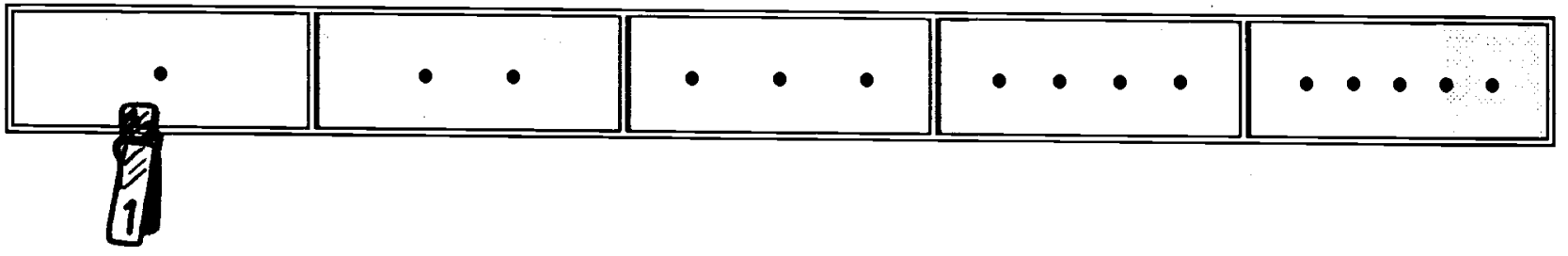

Activity Name: Counting and Eating Peanuis

\section{What you Need: Peanuts}

How to Play and Make It: One sure way of introducing learning is to pair learning with a pleasurable activity. Not too many things are more pleasurable to young children than eating peanuts (or a comparable healthy snack, like raisins).

Make five piles of peanuts. The first pile should be a single peanut, the second, two, the third, three, the fourth, four and the fifth, five. Count the number of peanuts in each pile. The child will most likely always get the first pile correct but will have more problems as the pile gets larger. If the child can correctly count the peanuts, allow the child to eat them.

What Children Learn: Counting, one-to-one correspondence

How Teacher Can Help: The teacher should talk about counting, naming numbers and oneto-one correspondence. 


\section{Mathematics Activities}

Activity Name: Counting with Cards

What you Need: The cards numbered one to nine from a deck of playing cards. An assortment of like objects, that match the numbers on the cards such as one key, two sticks, three buttons and so on.

How to Play and Make It: Lay out the objects that have been sorted, and the cards. Encourage the child to match the groups of items with the numbers on the cards. As the child progresses, all of the objects may be put in one pile so that it will be necessary for the child to sort the items before matching.

What Children Learn: Grouping, classification, one-to-one correspondence

How Teacher Can Help: The teacher should talk about the numbers on the cards and count the spots on the cards (spades, clubs, hearts and diamonds). Talk about each assortment of objects and matching the number of items to the number on the card.

\section{Activity Name: Obstacle Course}

What you Need: Normal classroom furniture

How to Play and Make It: Set up an obstacle course using tables, chairs, blocks, ropes, tires, stools, boxes and other furniture. Number the obstacles one through nine (or however many obstacles you choose to have). Write the numeral and attach the numeral to the obstacle. Lead the children through the course describing each one, for example: "I am crawling through the box, it is obstacle one. I am sitting on the chair, it is obstacle two. I am jumping over the stick, it is obstacle three." Encourage the children to verbalize a description as they go through each obstacle. The obstacles can be very simple, because remember it is very important to assure safety for the children.

What Children Learn: Number sequence, verbal number association

How Teacher Can Help: The teacher should talk about use of many spatial relation words such as under, over, around, through, beside, behind, on top of. Ordinal positions such as first, second, etc. may be brought into the conversation.

From One, Two, Buckle My Shoe: Math Activinies for Young Children 
Activity Name: Sequencing Numbers

What you Need: Coat hangers, five pieces of heavy cardboard numbered from one to five, a small green circle cut from heavy paper and clothespins

How to Play and Make It: Hang the coat hanger on a door knob. Glue the green dot on the right side of the coat hanger. Glue the numbers on the heavy cardboard squares in sequence from one to five beginning to the left of the green dot. Encourage the child to pin the correct numbered clothespin to the correct numeral card.

What Children Learn: Sequencing numbers, right to left progression

How Teacher Can Help: The teacher should talk about left to right progression, sequencing numerals.

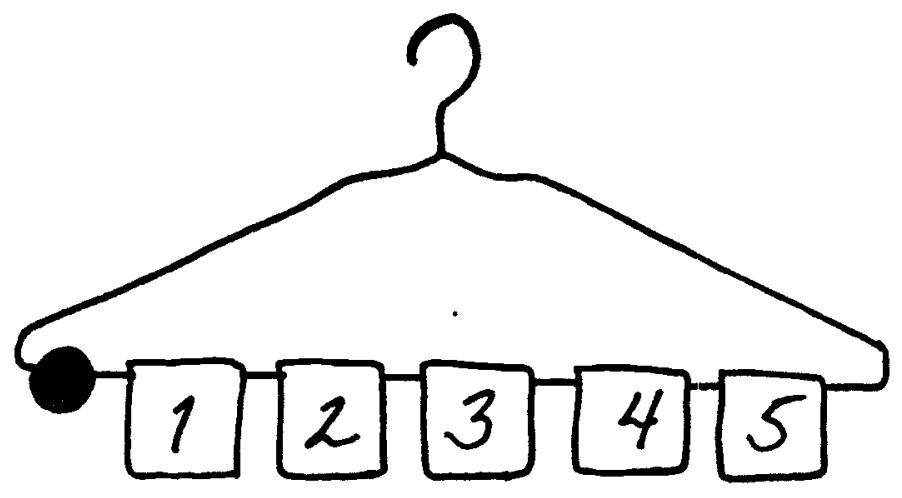

Activity Name: Full and Empty

What you Need: Several different size containers, some almost empty, some almost full, some half full, and some quarter full of rice or beans etc.

How to Play and Make It: Help the children to arrange the containers from the least amount to the most. After arranging the containers pour all the contents (rice, beans or sand etc.) into one container and have the children refill the containers from the smallest amount to the greatest amount. Identify "half-full" and "quarter-full."

What Children Learn: Objects may be ordered and arranged according to amounts of solids or liquids they contain.

How Teacher Can Help: The teacher should talk about amount, greatest, least, smallest, halves, quarters, more, less etc. 


\section{Mathematics Activities}

Activity Name: Tossing the Bean Bag

What you Need: An old sheet or piece of cloth, different colored markers, bean bags or other objects for tossing

How to Play and Make It: With different colored markers draw and color squares, circles, triangles and rectangles on the old sheet. Children may toss a bean bag and have it land on a shape. The children should be encouraged to name the shape, color and number.

What Children Learn: Shapes, numerals, colors

How Teacher Can Help: The teacher should talk about shapes, colors, numerals, tossing

Activity Name: Simple Subtraction and Addition

What you Need: Foam rubber $5 \mathrm{~cm}$ thick, markers and beans

How to Play and Make It: Cut an approximately $5 \mathrm{~cm}$ square from the foam rubber. Using the marker, number the sides with dots to make a die (one to six). Put ten to twenty beans (or buttons etc.) in the middle of a circle of children. Children will take turns rolling the die and removing the number of beans and counting the number left (simple subtraction). Another version: give each child ten beans and put five beans in the middle. $A$ child rolls the die and add the number shown on the die (simple addition) and count the results.

What Children Learn: Simple addition and subtraction, one-to-one correspondence

How Teacher Can Help: - The teacher should talk about simple subtraction and addition.

Activity Name: Simple Additions

What you Need: Make several sets of numbers from one to ten 0 12 $\mathrm{cm}$ by $20 \mathrm{~cm}$ cards, safety pins or adhesive tape

How to Play and Make It: Pin or tape a numeral on the back of each child. One child is "it." Different children take turns giving combinations which make the numeral on the child's back. When "it" guesses the numeral pinned on the back, the child that gave "it" the correct combination becomes "it."

What Children Learn: Simple number usage, simple addition

How Teacher Can Help: Talk about numeral combinations and simple addition.

From One, Two, Buckle My Shoe: Math Activities for Young Children 


\section{Mathematics Activities}

Activity Name: Matching Worms and Birds

What you Need: Nine birds should be cut from heavy paper. Tape a paper clip to the beak of each bird and put a number on each bird (1-9). Cut out nine worms. Put dots on each worm (1-9).

How to Play and Make It: Encourage the children to find the worm with the correct number of dots to match each bird. Children will put the correct worm in the paper clip.

What Children Learn: Matching groups of objects to the correct numeral

How Teacher Can Help: The teacher should talk about how the bird is very hungry and looking for a worm.

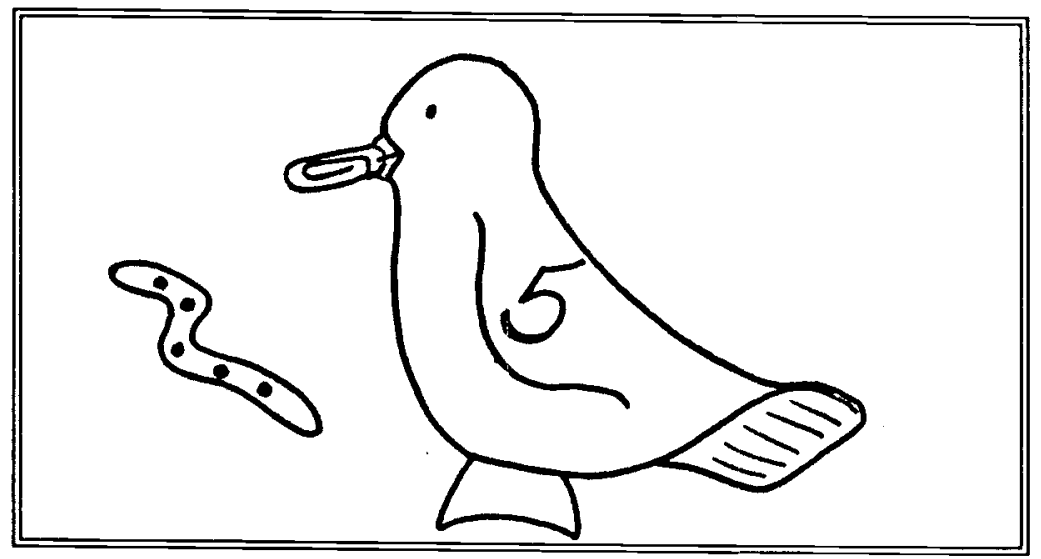

Activity Name: Matching with Cards

What you Need: Deck of playing cards with face cards removed

How to Play and Make It: Lay out playing cards one through ten. Place the rest of the deck of cards next to the ones spread out. One or more children taking turns will try to match the top card from the deck with one of the displayed cards. The child matching should be encouraged to count the spots on the cards and read the numerals if they are able.

What Children Learn: Matching sets, one-to-one correspondence, counting, numeral recognition

How Teacher Can Help: The teacher should talk about matching, recognizing numerals and taking turns. 
Activity Name: Apples in a Tree

What you Need: Green, red and brown colored paper, markers, glue

How to Play and Make It: Cut nine "tree tops" from green paper, nine "tree trunks" from brown paper and 45 small size "apples" from red paper. (Or color white paper, if you don't have colored paper.) Arrange and glue to the "tree tops" from one to nine apples. Number the "tree trunks" with a marker from one to nine with a corresponding number of dots.

Children should be allowed to match tree trunk with corresponding tree top.

What Children Learn: Numeral recognition, one-to-one correspondence

How Teacher Can Help: The teacher should talk about numerals and numbers.

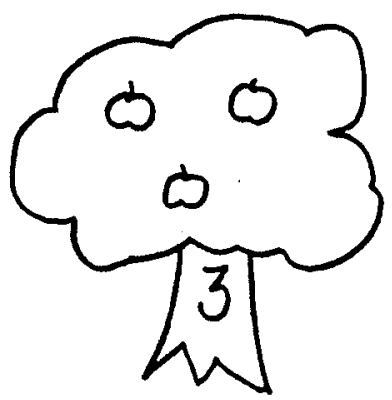

Activity Name: Button Box
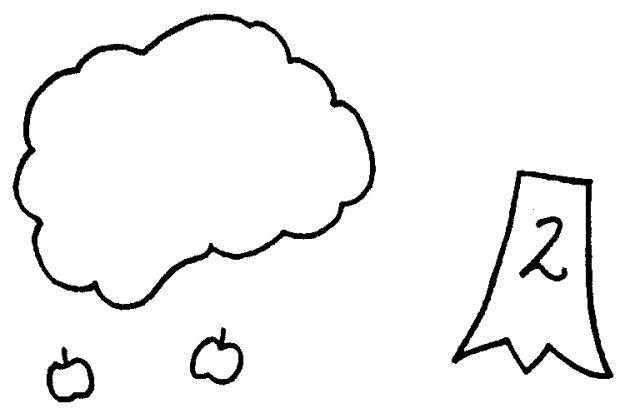

What you Need: An assortment of many sizes, shapes and colored buttons are needed. A box or container to store them in.

How to Play and Make It: Supply the child with a box of assorted buttons. Help the child to notice the differences between sizes, colors, textures and number of holes. Allow the child to play and experiment as she pleases.

What Children Learn: Counting, classification, sorting

How Teacher Can Help: The teacher should talk about sizes, shapes, colors, textures, number of holes in the buttons, sorting and classifying.

From One, Two, Buckle My Shoe: Math Activities for Young Children 


\section{Mathematics Activities}

Activity Name: Beans in a Jar

What you Need: Empty clear glass jar, beans

How to Play and Make It: This is a fine teaching game especially when coupled with a reward. Use an empty jar, almost any size or shape, which has clear glass. Put a random number of beans, between one and ten, in the jar. Ask the child to look at the beans and guess how many are in the jar. After the child guesses, empty out the beans and help the child count the beans. If the guess is correct the child gets a small tangible reward. Surprising how fast the guesses get to be correct. The number of beans can be increased slowly.

What Children Learn: Estimation, guessing

How Teacher Can Help: The teacher should talk about number estimation.

Activity Name: Teaching Ordinal Numbers

What you Need: Paper cups, shelled peanuts

How to Play and Make It: Place four cups, numbered 1, 2, 3 and 4 on a table. Have a child cover her eyes while a peanut is hidden under one of the cups. Have the child open her eyes and guess which cup the peanut is under. The child must say "the peanut is under the (first, second, third...) cup," and not simply point or say, "That one." If the child is correct she eats the peanut. Label and add more cups as the child learns more ordinal numbers.

What Children Learn: Ordinal numbers

How Teacher Can Help: The teacher should talk about ordinal numbers.

From One, Two, Buckle My Shoe: Math Activities for Young Children 


\section{Mathematics Activities}

Activity Name: How Many Dots?

How Children Play: Place the numeral 1 card in front of the child and tell her that this shows ' 1 '. Ask her to point to the dot on it and say 'one'. Then she can put one pebble on the card. Continue in this way up to card 5 . When the child can recognize the numerals 1-5 and count the corresponding dots and pebbles accurately, move on to cards 6-12.

What Children Learn: Recognizing numerals 1 to 12 and matching number to numeral.

How Teacher Can Help: The dots serve as a guide. Help the child to learn how to carefully place one pebble for each dot. In this way, if there are 6 dots on a card, she is bound to place 6 pebbles correctly and gradually learn what 6 means. You can then cover up the dots and see whether she can put the right number of pebbles on the card just by reading the numeral on it.

What you Need: Pebbles or beans, containers for pebbles and for cards, cardboard or heavy paper, markers

How to Make It: Make 12 separate cards for the numbers 1 to 12 . Each card should have an equivalent number of dots to correspond to the number, as illustrated.

From Helping Children Learn
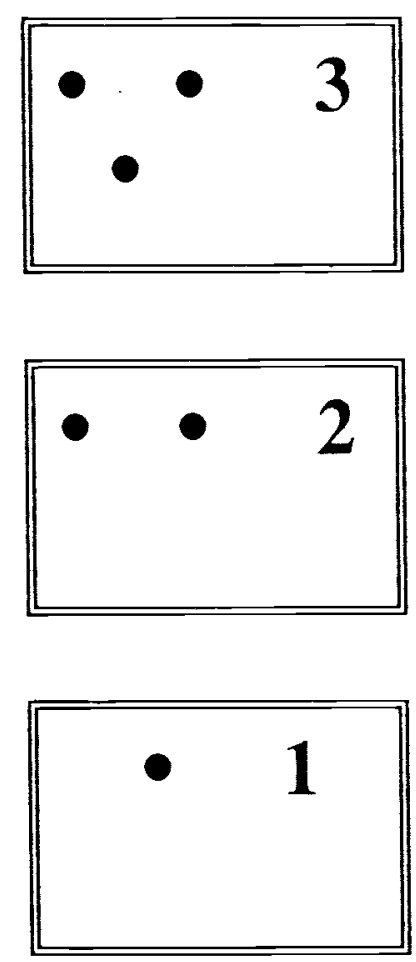


\section{Activity Name: Count and Sort}

How Children Play: Shuffle the cards, the child can count the objects on each card and put it in the correct envelope on the file. All cards can be sorted this way.

Prop up the folder and play a game in the classroom. Divide the cards into 3 sets, each set containing 10 cards for the numbers 1 to 10 . Divide the children into 3 teams. A set of 1 to 10 is given to each team. As you call out a number such as 7, the person in each team who has the card for 7 must run up and put it in the correct envelope in the folder in front of the classroom. The first to do this scores a point for their team. The team with the highest score at the end of the 10 rounds wins.

Make 2 sets of cards, each set containing 10 cards for the numbers 1 to 10 . Give one set to the child. Show any card and ask them to find a card from the set that has the same number of objects as the card you show him. Since no two cards for the same number have the same objects in the same arrangements, this activity helps to strengthen the important concept that number is a property of a set of objects: 7 is 7 regardless of the kind of objects or how they are placed.

What Children Learn: Recognizing numerals 1 to 10 ; counting; matching number to numeral.

What you Need: A file or cardboard folder, $25 \mathrm{~cm} \times 30 \mathrm{~cm}, 10$ small sturdy envelopes, markers, cardboard or heavy paper and a container for the cards

How to Make It: Cut the flaps off the envelopes. Paste the envelopes on the inside of the file or folder, 5 on each side. Write a numeral on each envelope in order from 1 to 10 . Make 30 picture cards for the numbers 1 to 10,3 cards for each number (e.g. 4 boats, 4 trees, 4 bows etc.), and place them in different positions. 
Activity Name: Pinwheels

How Children Play: Children can count the pinwheels on each card and put the corresponding numeral 'tin' in the place provided for it on the card.

Put away the tins and use only the pinwheel cards. Mix them up and spread them out on the floor or table. Children turn around while you take away a card. They can then look at the cards and figure out which number you have removed.

Use pebbles or beans to match one-to-one a pebble for a pinwheel, or count out the number of pebbles marked on the numeral tins.

What Children Learn: Recognizing numerals 1 to 10 ; counting; matching number to numeral.

What you Need: Pebbles or beans, containers for pebbles and one for cards, cardboard or heavy paper, markers

How to Make It: Make a set of cards with pictures of pinwheels on them. Pictures of flowers would work well also. Make a set of ten cards: one card with one pinwheel, one with two, one with three pinwheels and so on. Make pictures of tins or flower pots and cut out. Make ten of these as well. Each should be numbered with the numerals 1 through ten. In this way children can put the pinwheels in the cardboard "tins", or flowers in the flower pots. The pinwheel cards can be used separately as described above. The tins or flower pots can be flashcards for practicing recognizing number symbols. Keep these materials in a storage container with separate envelopes for tins and pinwheel cards. Children can play with the game on their own as well. 
Activity Name: The Marble Collection

How Children Play: This is similar to the activity "How Many Dots?" except that there are no dots to show the meaning of each number. You can start with jars 1 to 5 and see if the child can count out the correct number of marbles and put them in the jars. Then move on to jars 6 to 10 .

What Children Learn: Recognizing numerals 1 to 10 and matching number to numeral.

What you Need: Cardboard from a box, paper and colored markers, scissors, container for cards and envelope for cut out 'marbles'

How to Make It: Cut out the pictures of jars to make 10 separate numeral jars and mark each jar with numbers 1 through 10 . Cut out small square cards $(2 \mathrm{~cm} \times 2 \mathrm{~cm})$ with a marble drawn on it for a total of 63 marble cards.

\section{Activity Name: Bangles}

How Children Play: Children will enjoy adorning themselves with these bangles. The task is to put them on in order from 1 to 10 . You can make several sets for the classroom. Children can work in pairs. One child can put the set on, leaving out a number. Her partner has to determine which number is missing. Children can also learn how to put on the series backwards from 10 to 1 .

What Children Learn: Recognizing numerals; learning number sequence from 1-10.

What you Need: 10 plastic bangles, children's size, adhesive first aid tape (width $2 \mathrm{~cm}$ ), black marker

How to Make It: Cut 10 pieces of the adhesive tape, about $3 \mathrm{~cm}$ long. Attach a piece to each bangle by folding it over to form a tag. With the marker, write a numeral on each tag that can be clearly read. 
Activity Name: Counting Coat Hangers

Age Group: 3 to 6 year old

How Children Play: The child playing with this counting game should recognize the numbers 1 to 5 . The child can count the number of items on the coat hanger that correspond to the number marked on the hanger. This reinforces the concept of how much each number symbol represents. The children should be involved in selecting or making picture of clothes, cutting and attaching them to the hanger.

What Children Learn: To encourage the child to match the name of the number to an amount when counting. Always ask him to touch each article as he counts the number aloud.

What you Need: 5 coat hangers, paper, pen, magazines, crayons or colored pencils and alternatively handkerchiefs or pieces of cloth

How to Make It: Write the numbers 1 to 5 on separate pieces of paper and attach each one to a coat-hanger. Make your numbers large and clear. Cut out pictures of articles of clothing from a magazine, or draw picture of clothing. Stick an equal number of articles of clothing to the number on each of the hangers. For example, the hanger with the number 3 on its tag could have one pair of pants, one sock and one shirt. Alternatively, you could tie handkerchiefs or scraps of cloth that are approximately the same size to the hanger.

Activity Name: Stepping Stones

Age Group: 3 to 6 year old

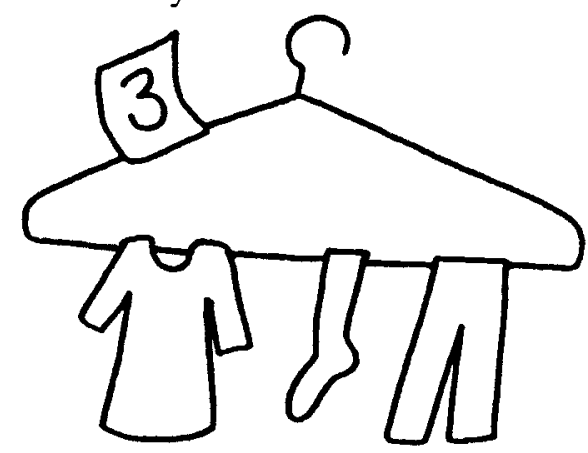

IIow Children Play: Scatter the pieces of paper around the room and tape them to the floor. Explain to the children that you are going to play some music or sing a song. When the music stops you will call out a number. The child then has to find the correct number and sit or stand on it. Have several sets of numbers in different areas for children to do it simultaneously, or have children take turns for safety sake. You can introduce a reward for finding the correct number if you like - like a raisin or almond. Or you can give each child a reward so as not discourage a good effort.

What Children Learn: To help children recognize number symbols.

What you Need: 5 pieces of paper, markers, adhesive tape, music or a song, raisins or nuts

IIow to Make It: Draw large numbers - 1 to 5 - one on each sheet of paper. 
Activity Name: Count the Caterpillar

Age Group: 3 to 6 year old

How Children Play: The child constructs a caterpillar by using one of the faces and the circles with the number symbols. The object is for the child to put them in the correct sequence. Underneath this number caterpillar, the child makes a second caterpillar from the circles with the matching dots, 1 to 5, to correspond to the number symbols. Children can take part in making their own caterpillar faces. Young children, or those just learning the game may need your assistance to help get the sequence right. A child can play this alone, with a partner, or it can be done in a small group, each child taking a turn adding a piece to the caterpillar.

What Children Learn: To show the correct sequence of numbers from 1 to 5 , encouraging the child to put them in order from right to left, in the way they are written in a book.

What you Need: Twelve paper plates, or paper circles and markers

IIow to Make It: Draw a caterpillar's head on two of the paper circles - simple smiling face with antennae. Write the numbers 1 to 5 on five of the other circles. Draw the numbers largely and clearly. Then draw dots on the remaining five plates to correspond with the number symbols.

From Realy for Maths

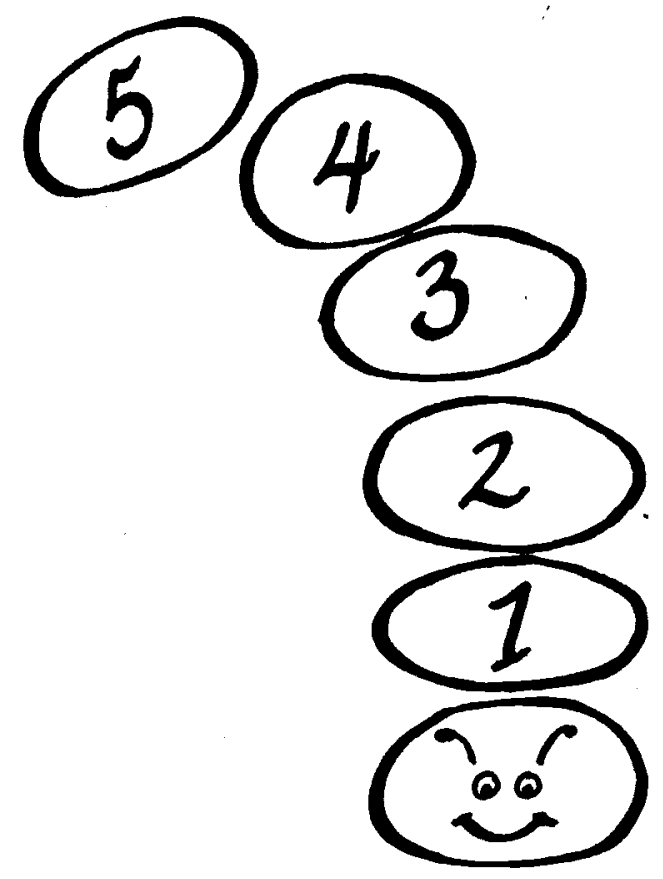


Activity Name: One Potato

Age Group: 3 to 6 year old

How Children Play: Ask the children if they can guess which of the fruits or vegetables will be the heaviest. Once a guess has been made, give the child two of the foods and ask them to compare which is heavier (that is, which pushes their hand down the most). Work with a small group of children and let everyone have a chance to try. Repeat this until all the foods have been weighed against each other. Which is heaviest? Which is lightest? This activity can be done with other kinds of items as well. It will be interesting to include items that are large and light, compared to some which are small and heavy - such as a large sponge and a small heavy stone.

What Children Learn: To encourage children to use their hands to feel the weight of various foods, deciding which is heavier and which is lighter.

What you Need: Three vegetables or fruits to begin with, and later you can add more. Make sure the weights are obviously different.

Activity Name: Water Levels

Age Group: 3 to 6 year old

How Children Play: This activity is best with a very small group of children, so everyone can get involved as much as possible. Fill the sink or plastic tub with water. Add food coloring to make the activity more exciting if you like. Ask the children to choose two containers and guess which one would hold more water. Help fill the containers if they can not do it alone and explain that you are going to use the plastic bottle to measure them. Using a funnel, pour the water from the first container into the bottle. Put a rubberband around the bottle where the water reaches. Empty the water and repeat the activity with the second container. However, make sure the rubberband stays in place. You can use adhesive tape or mark the bottle with a boardmarker if you do not have a rubberband. The rubberband or any other marking you choose to use, will show if the second bottle held more or less than the first, since the water level will be above or below the mark. The children can see if their guess was correct. Lots of practice and free play is needed at these early stages, but once children have grasped the idea of comparing two containers with ease, you can move on to three.

What Children Learn: To introduce the idea of measuring capacity by making a mark on the side of the container to show the level of the water. This is an introduction to using standard measures.

What you Need: An assortment of plastic containers, a plastic wash tub or sink, food coloring (optional), a large plastic bottle, rubberbands, preferably colored, a funnel 
Mathematics Activities

Activity Name: How Many Raisins in a Moment?

Age Group: 3 to 6 year old

How Children Play: Explain to a sinall group of children that you will put raisins (or nuts) one by one into one bowl while a child walks, then skips and then runs across the room. You can also do this outside and mark off a start and finish point. Use a separate bowl for each movement so that the children can compare how many raisins it took to do each one. If you keep a steady rhythm (about one raisin per second), the children will clearly see that it took more raisins to walk than to run. You can add more movements if you are doing it outside, such as hopping, jumping, crawling and rolling. The children do not need to know numbers for this activity, as a comparison of more or less raisins in each of the bowls will determine which movement took a longer time. Older children can count the raisins aloud and put the information on a chart - to compare actual numbers as well as simply looking at the quantities.

What Children Learn: To provide the experience of measuring lengths of time without having to count or tell time. By seeing 'a lot' the child will know that it has taken a long time, whereas 'a few' will mean a short time.

What you Need: A large bowl of raisins (or similar healthy snack, like nuts) and several small bowls

Aclivity Name: Hands and Feet

Age Group: 2 to 6 year old

How Children Play: Help children draw around their hands and feet, and also those of a doll or small cuddly toy - like a teddy bear. The children should cut them out or the teacher can if the task is too difficult for them. Then ask the children to look at them closely and decide whose belong to who. It can be easily checked by placing the cut out hands or feet against their own. Older children can measure objects using their feet and hands. They will discover they need more of the doll's prints than of their own.

What Children Learn: To understand the idea of 'big' and 'little'. This activity will help children recognize size, and enable them to decide which objects are big and small in relation to themselves.

What you Need: Paper, scissors, crayons, dolls or one or more soft toys 
Activity Name: Splashing Time

Age Group: 3 to 5 year old

How Children Play: This is best to do with a small group of children in order to involve as many children as possible. Ask the children to choose two containers and guess which one holds more. Once they have made the choice, ask if anyone has an idea of how to check to see if their guess is correct. A common response at this stage, is for children to say, "Fill them up with water." Show them that if you fill one with water and then pour that into the other container, you can see which holds more: does it spill over? or, is there room left in the bottle? This work will need careful explanation and will probably be best to transfer from a large to small container first, as the overflow of water is easier for the children to identify. Allow for plenty of time for free play and experimentation, as these are complex concepts for young children. Older children can put containers into order from 'holds the most' to 'holds the least', or the reverse.

What Children Learn: To give children the experience in estimating and measuring capacity by the direct comparison of containers to find which holds more or less.

What you Need: Assorted plastic containers of different sizes, with wide necks; a sink or tub of water and waterproof aprons

Activity Name: Heavier and Lighter

Age Group: 4 to 6 year old

How Children Play: A child can place one object in one pot of the balance, for example the book. Then ask the child to put another object in the other pot. Ask her which is the heavier item? If the children can not answer, explain that the heavier objects go down on the scale, while lighter objects are pushed up by the heavy ones. When the child can do this easily, ask her to fill one of the pots with one type of weighing material, like buttons. Then ask her to fill the other pot to the same level with another item like marbles. Again, ask the question, which is lighter, which is heavier? Repeat this activity with all the available materials and involve all the children.

What Children Learn: To help children realize that some objects are heavier, or lighter, than others, and that some things can be large but not heavy (sponge or cork), while others can be small but very heavy (marbles).

What you Need: A balance as the one described in "Make a Balance". Assorted objects of different weights, for example, a book, a cup, a slipper, a small soft toy, a metal car, a ball. Separate trays/tubs of different weighing materials: buttons, marbles, corks, pebbles. 
Activity Name: Make a Balance

Age Group: 2 to 5 year old

How Children Play: To use the balance, wedge the knitting needle into a keyhole or drawer. Young children will be excited by simply watching the scale move up and down. Each side of the balance can be filled with various items to see which is heavier and lighter or the same. Allow for a lot of free play with the balance.

What Children Learn: To show how scales work by demonstrating the fact that it is the weight pushing down on one side that makes the other side go up.

What you Need: A stick, or a round, narrow piece of wood, approximately $45 \mathrm{~cm}$ long, string, two identical plastic tubs, a metal knitting needle (or something comparable), two small balls of clay or plasticine. Objects to weigh, such as, shoes, bricks, small doll, car, book, ball, beads, buttons, corks, keys.

How to Make It: Make a simple balance as illustrated. The knitting needle can be heated and used to poke holes in the plastic containers to pull the string through. Alternatively, tie string around the tubs and attach the four suspension pieces to it. The clay at the ends of the stick or wooden rod will stop the tubs from falling off.

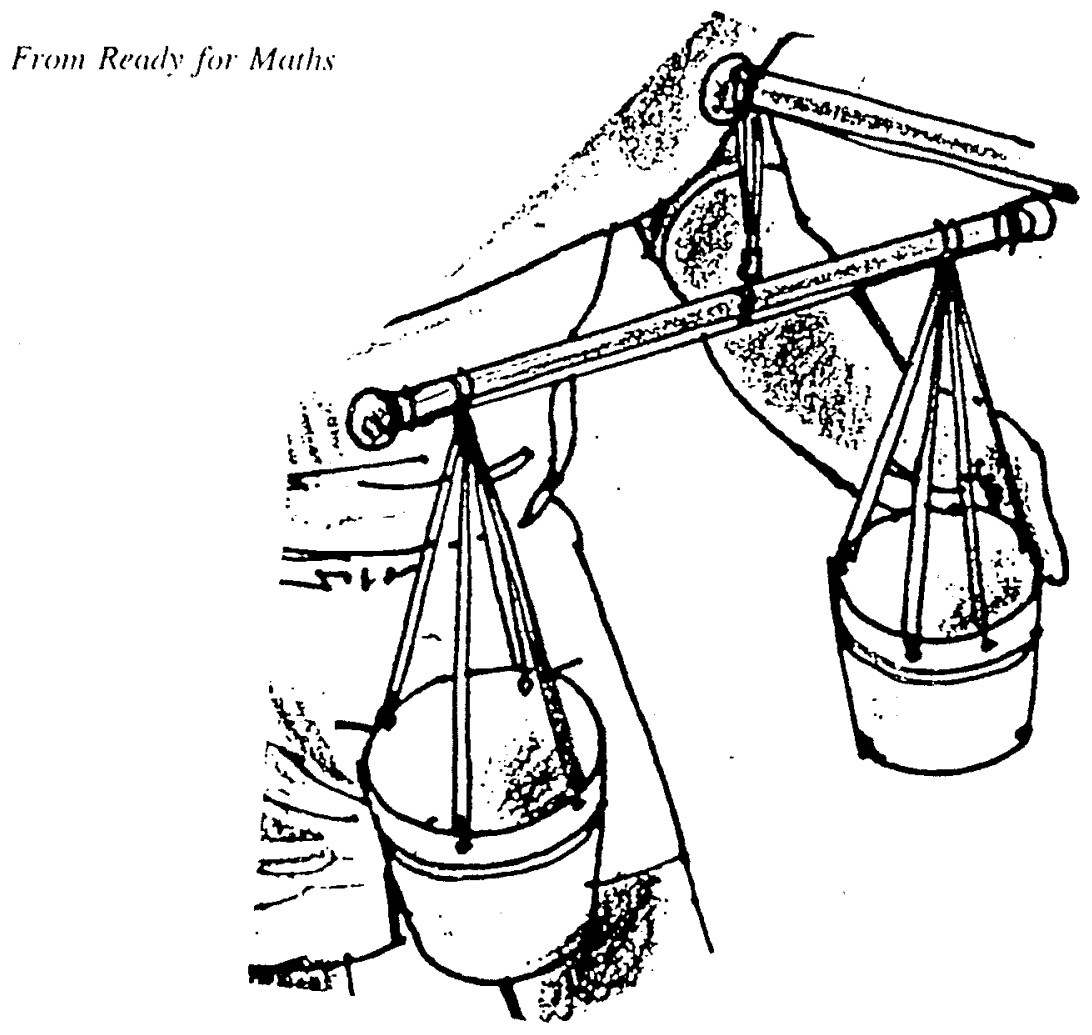


Activity Name: A Pair of Scales

Age Group: 5 to 11 year old

What you Need: Shoe box, scissors, knitting needle (or something comparable), tin lids or round box lids, coins

How to Make It: To make a pair of scales, find the halfway point and cut the base of the shoebox.

1. Punch holes in the side supports and corresponding holes in the sides of the upturned lid.

2. Suspend the lid between the supports by passing a knitting needle through the punched holes.

3. Tin lids, or the two halves of a cheese box can then be glued on to the lid.

4. Coins can be used as weights.
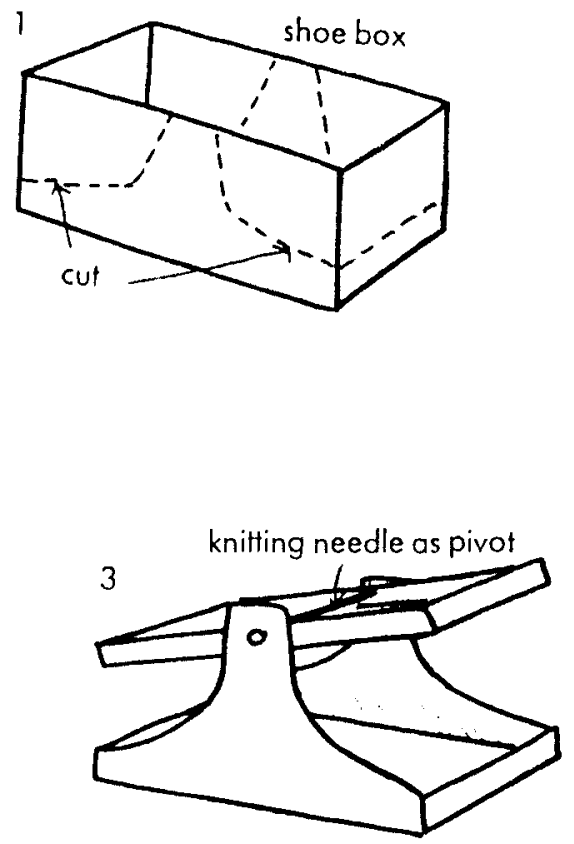
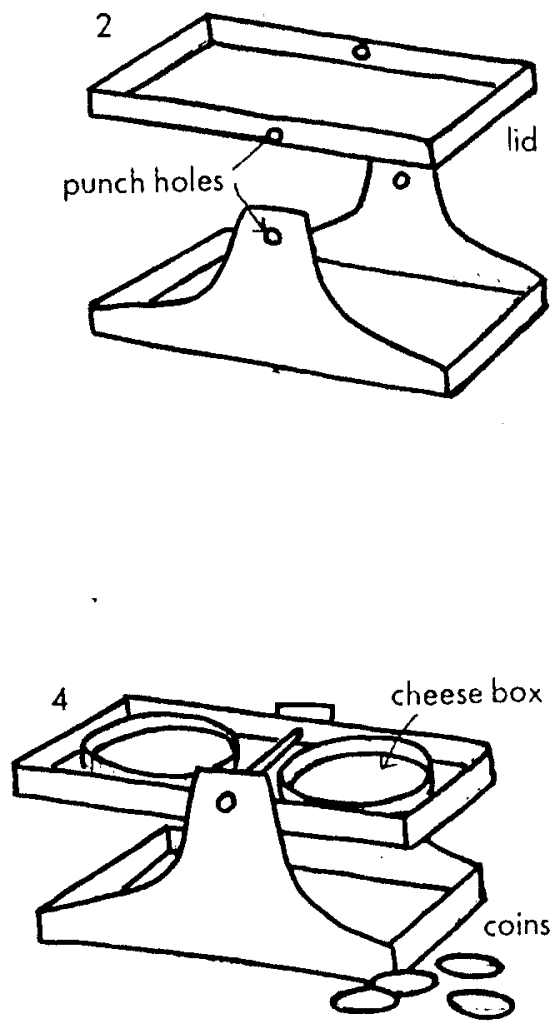
Activity Name: Clap your Name

How Children Play: Each child says his or her first name, and the class then claps the number of syllables: two for Almed, three for Sohaila, etc. The information can be displayed on a chart - make sets for one clap, two claps etc. with the children's names in the correct set. Discussion can follow along these lines: How many children are there with two claps? How many claps all together?

What Children Learn: Counting and comparisons

What you Need: Large sheet of paper and pens

\section{Activity Name: Picture Shapes}

How Children Play: Children work in pairs and take turns throwing the die or choosing cards. They choose the shape corresponding to their throw. After eight throws each team has eight shapes with which to make a picture with their shapes - they can make a face, or a house, a flower or just a design. Let them use their imagination and encourage their efforts.

What Children Learn: Matching shapes and making patterns

What you Need: Colored paper, a die or cardboard and glue

How to Make It: Cut out shapes from colored paper and glue them to the faces of a die. Alternatively, you can make six cardboard squares of the same size and glue the shapes on there. Then the children can take turns by rolling the die or choosing one of the cardboard squares which are lying face down. Shapes can include, a small square, a big circle, a small circle, a triangle, rectangle and so on. 
Activity Name: Find the Number

How Children Play: Working in pairs, the children choose a number label and thread that number of beads on to a bent pipe cleaner or a shoelace. They then atlach the correct number label. It is better on the pipe cleaners as they are fairly rigid and makes it easier for the children to compare the strings of beads. Has this one more beads or less than the other. However, shoelaces or heavy string can work also if pipe cleaners are not available.

What Children Learn: Matching numbers with symbols, making comparisons

What you Need: Pipe-cleaners or shoelaces, large threading beads, heavy paper and markers

How to Make It: Cut out nine card labels. Write large bold numbers 1 to 9 on one side of each of the cards, and mark the appropriate number of dots boldly on the other side. Make a hole in each card at the top

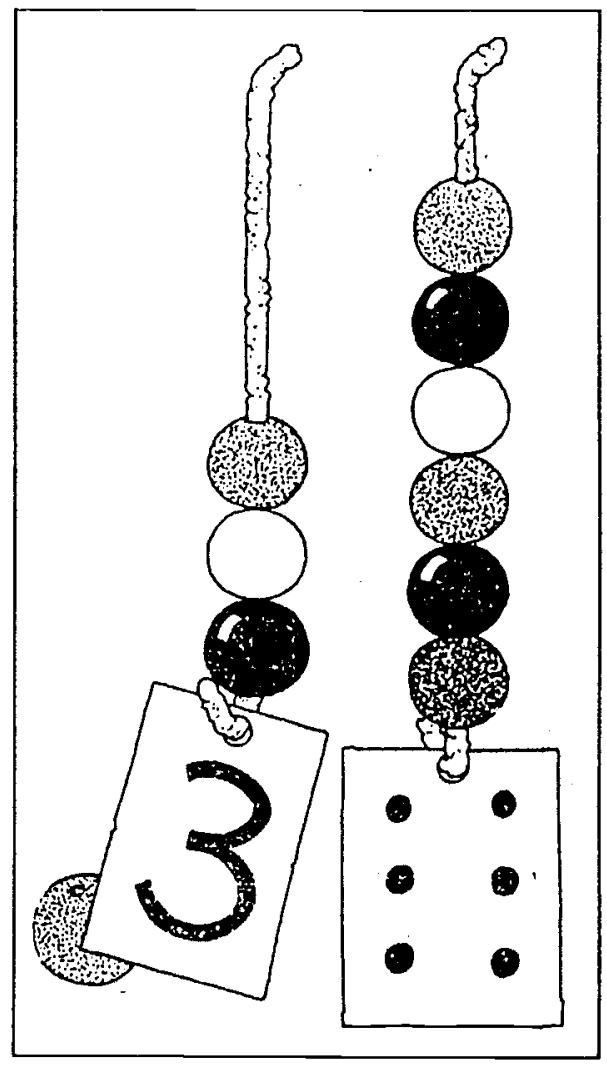
center.

\section{Activity Name: How Tall Are We?}

Ilow Children Play: Working in pairs at the beginning and at the end of the term, the children measure each other's height to the nearest centimeter. After discussion about who is tallest, shortest or about the same height, the children can record the results on a chart. At the end of term the children compare the measurements. Who was tallest at the beginning of the term? Who is the tallest now? How many children were about the same height as each other at the beginning of term? How many at the end?

If the children are too young to record their own heights, the teacher can do it for the class. Instead of using centimeters, you can use a more simple measure, like a mark on the wall with children's names that can be easily compared against each other at the end of the term.

What Children Learn: Measuring and comparison. The teacher should stress the approximare nature of measure.

What you Need: Large sheets of paper and measuring equipment 
Activity Name: Hoopla!

How Children Play: The children take turns throwing the rings and scoring. They can score one point for each time they ring it. To make it more challenging they can try to ring the tubes in sequence, one through six. The children can just have fun trying to ring the tubes without taking score to begin with.

What Children Learn: Developing motor skills, counting and simple adding through score-keeping, reinforcing the sequence of numbers.

What you Need: 6 cardboard cylinders, thin card or heavy paper, scissors, adhesive tape and paints

IIow to Make It: Collect 6 cardboard cylinders or make cylinders from thin card. Paint each one a different color and stick them in a shallow box lid with a number next to each tube, 1 to 6 . Each player needs at least three rings to play with. These can be made by sticking together two cardboard circles whose centers have been removed. Or cut a thin plastic bottle into rings. In either case, make sure that the rings fit over the tubes. You can color or paint the rings the same as the tubes.

\section{Activity Name: Number People}

How Children Play: This game involves the whole class. Divide the children into equal teams, with no more than ten in each. A caller and each team hold an identical set of cards, each one $10 \mathrm{~cm} \times 15 \mathrm{~cm}$, and numbered 0 to 9 for a team of ten, 0 to 5 for a team of six, and so on. Within a team, each child holds a different number card.

The caller shouts out any two numbers, provided each digit is different, for example 9 and 4 , but not 8 and 8 for a team of ten; 4 and 3 but not 4 and 4 for a team of five. It must of course be possible to make the number called from the cards issued. As soon as the number is called the first team to send out 'number people' to the face the class with the numbers in the correct order scores a point. The game is repeated, and the score recorded. The teacher can decicle what score the game will be finished at. The team with highest score is the winner. Many variations of this game are possible. Simple addition sums might be called, with the 'number people' coming out to form the answer with their cards.

What Children Learn: Recognizing numbers, sequence and simple addition

What you Need: Markers or pens, and sheets of paper, preferably heavy 
Activity Name: Button Charts

How Children Play: Diagrams can be made showing some simple, child-centered information. Buttons, pebbles or beans can be used as markers to record information, one marker for each child in the class. Use various kinds of charts to find out: Who has older brothers?, Who has younger sisters? Who likes mangos? Who likes pilau better? The charts offer a chance to make numerical comparisons.

What Children Learn: Comparison of numbers

What you Need: A set of buttons of about the same size or beans, pebbles etc., paper, markers or pens
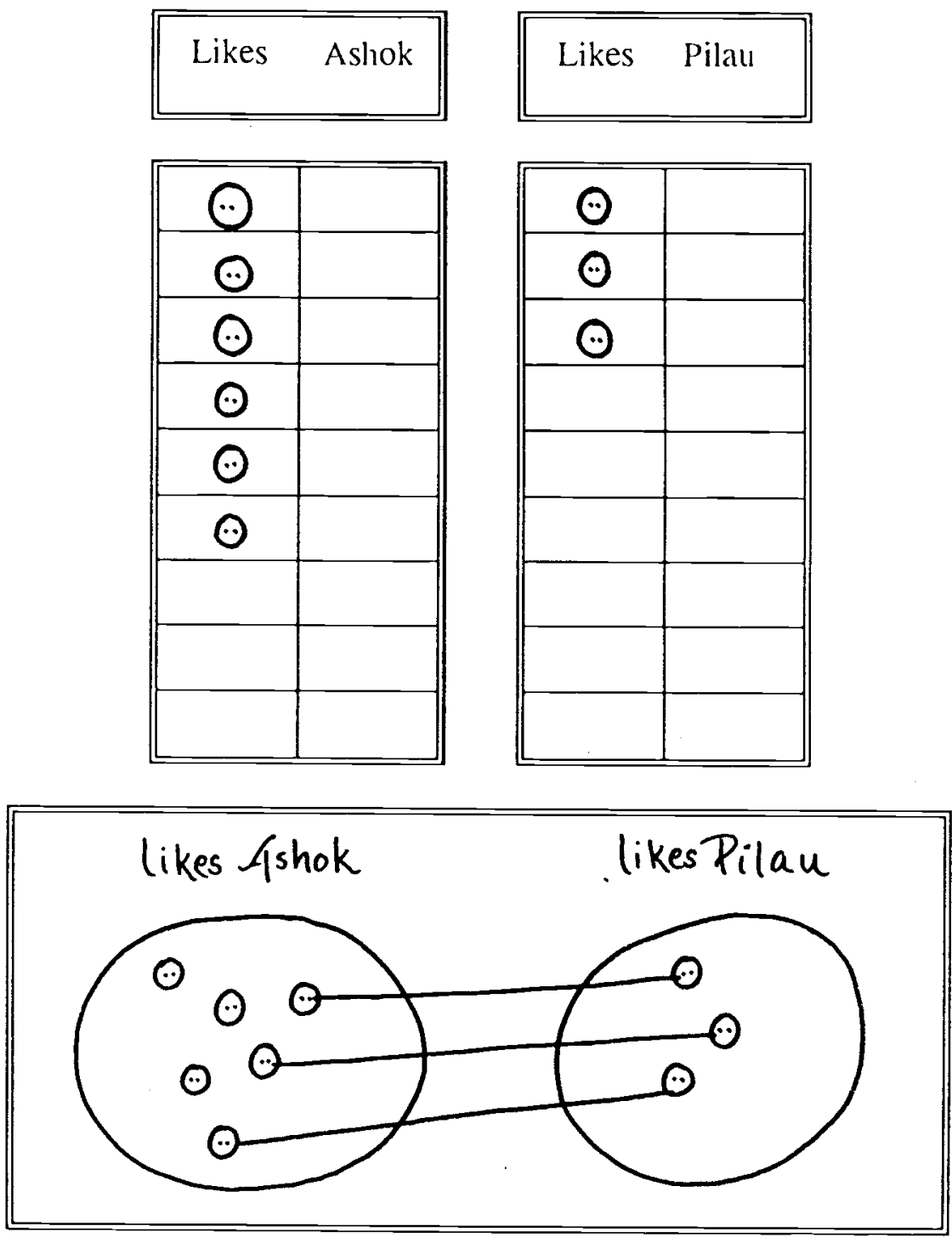

From Brighth ldeas for Maths 
Activity Name: Playing with Shapes

How Children Play: This is a game played with a board. A single player can test their own skills, but it is more fun for several children to play and take turns. Children take turns rolling the die. If a circle is on the die, for example, the child has to select a circle from the shapes and cover the circle on the playing board. The game is complete when all the shapes are covered. A variation of this game is preparing playing boards for four players. Then when the die is rolled all four children cover the corresponding shape on their own board. The first one to cover all the shapes on their playing board is the winner.

What Children Learn: Matching shapes

What you Need: Heavy paper or thin card, scissors, a die or cardboard and glue

How to Make It: Prepare a playing board on heavy cardboard with a square, a circle, a diamond, a semi-circle, a triangle and a rectangle shape drawn on it. Make the board and shapes large enough to make it easy for young children to handle the shapes and place them on top of the playing board. You can color the playing board with markers or cover with paper to make it altractive for the children. Cut out matching shapes from the thin card or heavy paper that are the same size as those on the playing board. Then paste the same sequence of shapes onto a die. Instead of a die, you can paste smaller matching shapes on individual cardboard squares of equal size. These can be laid face down and children can choose a card, therefore serving the same purpose of choosing a shape at random by rolling a playing die with shapes pasted on the faces.

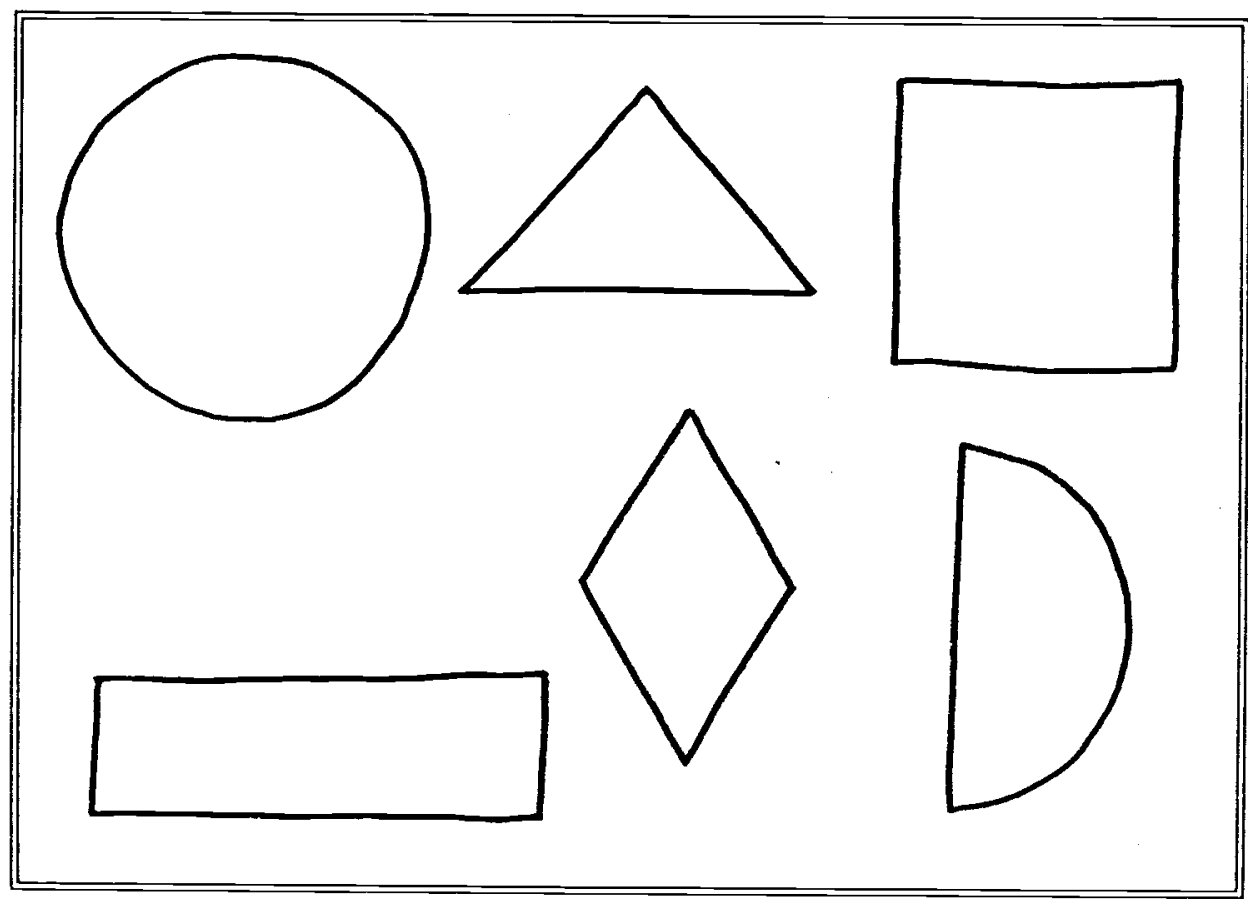

From Bright leets for Maths 
Activity Name: Checking Pairs

How Children Play: Lay out a row of 4 or 5 cards, a double row if the children's abilities are more advanced. Make sure that there is a matching card for each of the cards laid out on the playing space. The children imitate the existing pattern by laying down matching cards to imitate the pattern already there. You and the children can make up many different games and activities with this set of matching cards.

What Children Learn: Following patterns

What you Need: Card or heavy paper and crayons or colored markers/pencils

How to Make It: Prepare cards, all the same size - about $5 \mathrm{~cm}$ by $5 \mathrm{~cm}$ - that can serve as matching pairs. They can be either plain colored squares or simple patterns (stripes, diagonal lines, etc.). This depends on the age group and how difficult the game should be.

From Bright Iolas for Maths

Lay down a row of the matching cards, the child should lay down a matching card below the existing row:
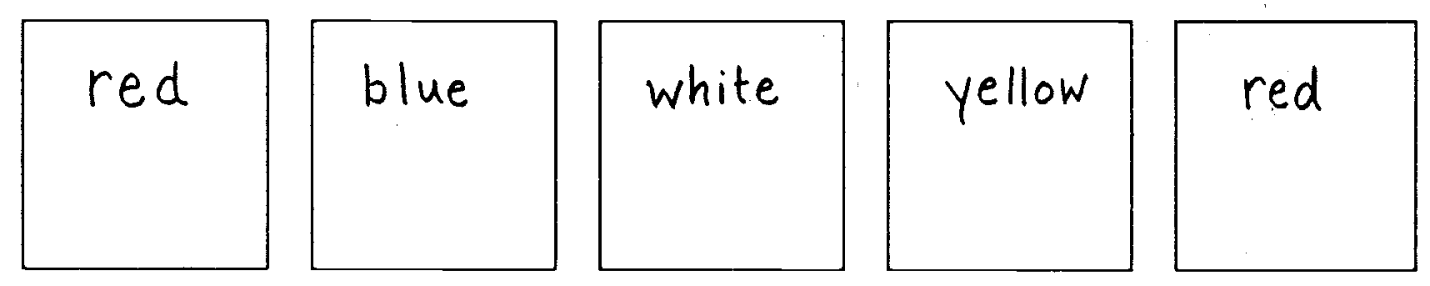


\section{The Story of Sharifa Shape}

This story can be used to learn shapes, and can also help with learning the days of the week and/or ordinal numbers - first, second, etc. The story should be accompanied by pictures of Sharifa on each day - or be part of a classroom display.

On Friday (1st day), Sharifa Shape woke up as a triangle, feeling very hungry. All day long, she did not stop eating. And she went to bed feeling very full indeed.

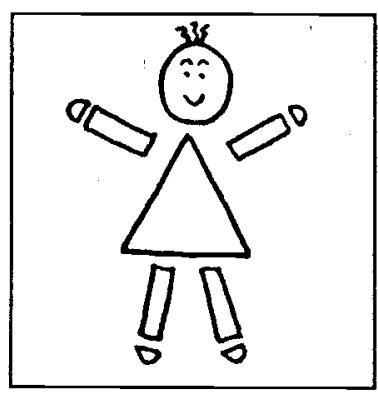

On Saturday (2nd day), when she woke up, she had grown another side and had become a square. All sides were equal in length. But she still felt hungry and ate just as much as she had on Monday.

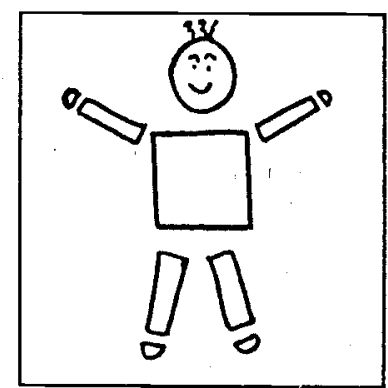

On Sunday ( $3 r d$ day), she awoke to find that two of her sides had grown longer than the other two. Her body looked very long as a rectangle. But still she carried on eating, and this time she ate even more than before.

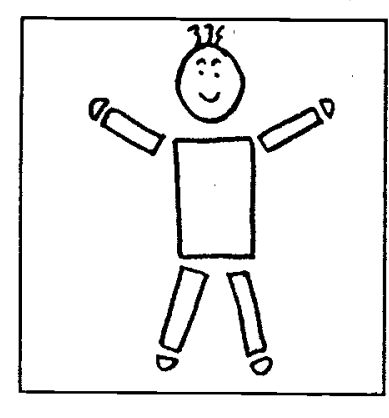

On Monday (4th (lay) she discovered that she had grown yet another side. Now she had five sides and was a pentagon! But greedy Sharifa carried on eating and eating!

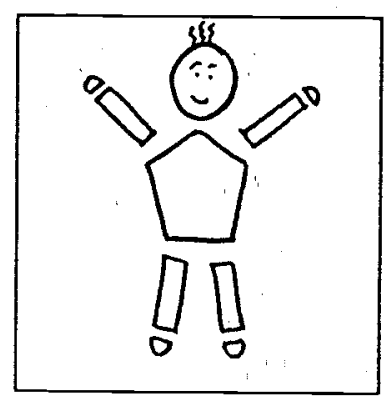




\section{Mathematics Activities}

\section{The Story of Sharifa Shape continued}

On Tuesday (5th day) she had grown another side. As a hexagon, she had six sides now. But still she continued to eat more and more.

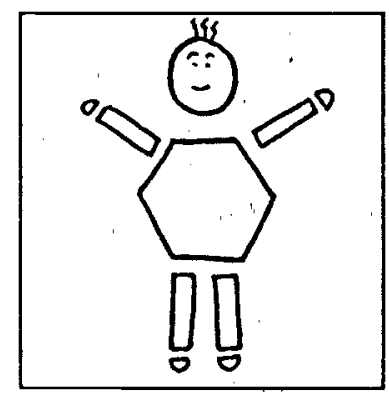

So that by the time Wednesday (6th day) morning came, she had grown not one more side, but two, and was now an octagon with eight sides! Her eating continued until by Saturday night she felt so ill she had to send for Doctor Shape, who put her on a very strict diet.

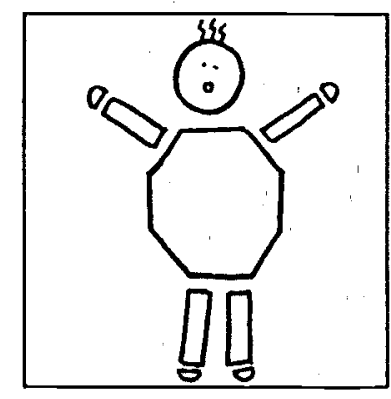

The diet was so strict (Sharifa wasn't allowed any food at all, and could drink only water.) that by Sunday night (7th) Sharifa was back to three sicles again - a triangle! She felt much better and promised the doctor that she would never be so greedy again!

\section{From Teaching Infants}

Incorporate the concept of shape and color into everyday activities:

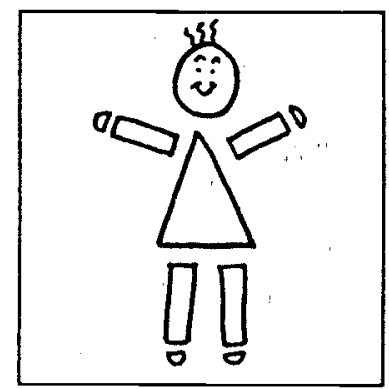

- Try to use the names of colors whenever a child has a choice to make, for example, Do you want the red lollipop? Later on, the importance of colors coming in different shades

- Match and sort objects into different sets of colors.

- Everything in the world has its own shape and its the shape that a child identifies when she names an object. Encourage the child to touch and handle all sorts of things which have their own individual shapes, as this us how young children learn best.

- Use words like rough, smooth, pointed, curved, straight and so on to reinforce the concept that all things have a shape.

- Introduce 3-dimensional objects - cubes, cylinders, spheres, cuboid - the ends of such 3dimensional objects are called 'faces'. If you draw a real face on the end of cylinder, this will help the children learn. 
Play games involving matching the number of objects with the corresponding numeral:

- Teacher arranges a set of objects, children imitate and name the corresponding number.

- Children arrange a set of objects to match a picture showing the same number of objects.

- Children match groups of objects with their corresponding numerals.

- Teacher shows a numeral and the children pick up a group of objects corresponding to the number and say each of the numbers.

- The teacher shouts out a number, and children have to form a group of that number.

Play games on numbering according to order and position/seriation:

- Number children arranged in a certain order.

- Number objects according to their position.

- Play games that emphasize making comparisons.

- Arrange several things in order and describe their relations.

\section{Play games to introduce addition and subtraction:}

- Playing store during imaginative play: buying and selling things in a pretend shop.

- Share things such as biscuits, treats and other things to understand the concept of equal, more and less.

Play games involving the concept of space:

- Find hidden objects by following oral instructions using descriptive words like: inside, outside, above, below, under, in front of, behind, beside, front and back, in between and through, narrow and wide, high and low, far and near, and so on.

- Cut out different shapes and piece them together again to form a pattern.

Play games involving the concept of time:

- Talk about what happens daily according to a time sequence: waking up, praying, dressing, eating and so on.

- Arrange pictures according to a time sequence, or repeat the events of a story in order.

- Play games using the clock; sing songs about time.

- Act out situations as depicted in pictures illustrating morning, night-time and so on.

From Malaysian Course of Childhood Development and Childare

Facilitate the development of classification skills:

- Provide interesting materials to encourage children to talk about attributes, similarities and differences.

- Engage in activities in which children can observe and describe how things are the same and how they are different. Sorting and matching is one effective way to do this.

- Use and describe objects in different ways.

- Talk about the characteristics that something does not possess (this rock is not soft); or the group it does not belong to (this carrot is not a fruit).

- Help children distinguish between some and all. 


\section{Play games with matching pictures:}

- Make your own pack of matching cards. Look through old magazines and catalogs and cut out pictures of boots, shoes, slippers, gloves, earrings, eyes and other pairs. Glue one of each pair onto a card. Shuffle the cards and children can play matching games with the cards. You can also draw and color your own pictures.

\section{Ladybird Learning at Home Series}

\section{Engage in activities that teach the concept of money:}

- Practical experiences can help reinforce the concept of money such as a shop in the classroom where students can buy things. The type of store - vegetable, stationary, clothing - can change from time to time.

- Also games with money can help, such as "The Bus Conductor Game":

This is only appropriate if there are buses in your community. You wam to use things which are familiar to the children. If there are no busses, replace it with something else the children know.

A display is first made by the children, of a bus and a bus route. The route can be simple, for example, from the Bus station to the - vegetable vendor - mosque - school baker and the park. Each stop is 2 Afghanis.

Children set up chairs like a bus, one child is conductor with a bag to collect the money. Anything can be used to represent coins or paper notes, or they can be made during an art activity.

Children get on and off the bus, pay 2 Afghanis for the number of stops they want to travel - this will involve counting - the number of stops, counting money; use of ordinal numbers - I want to get off at the second stop; simple addition/multiplication - I have to pay 2 Afghanis for each stop and want to travel for $3: 2+2+2$ or $2 \times 3$.

This idea can be adapted and changed to fit the abilities of the children.

From Teaching Infants

Involve the children in practical measuring activities:

- Length: Measure tables or the length of the garden using three different ways, for example, using a string, a measuring stick and hand lengths.

- Volume: Use different sized containers to measure water. Ask the children questions.

- Weight: Weigh themselves, weigh things in their hands and on a homemade scale. Children experience weight in their everyday play, for example, when they fill a bucket with sand it becomes heavy when before it was light; when they play on a see-saw; when a balloon flies away; - children won't understand these concepts without explanation.

- Height: Measure the children's height against a wall. Discuss tallest, smallest and so on.

- Temperature: Compare things that are warm and cold - ice, cold water, warm water. Discuss the dangers of extreme temperatures - boiling water, getting dressed appropriately for snow. The children can feel their own temperature; then run and feel their own temperature again. 
Play games that teach the concept of grouping and sets:

- Give a list of characteristics and children have to join the right group. For example: "The children with white shoes stand over here. The children with black shoes stand over there." Then make it more complicated - introduce sets: "The children with black hair stand here. The children with green eyes stand there. Clildren with black hair AND green eyes stand in the middle. You can use rope to make circles for groups to stand inside of. The circles can overlap for children with both characteristics to stand in.

Play games that teach the children the concept of sorting:

- Things to sort: Many different materials can be used for this purpose: pine cones, nuts, leaves, stones, shells, peas, beans, seeds, dal, bottle tops, marbles, plastic toys, beads, rods, ribbons, wool, strings, pictures, buttons. Allow for a lot of free play.

- Storage: These materials can be stored in transparent plastic storage jars or containers which are clearly labeled.

- Materials to facilitate sorting: Use ice cube trays for sorting and set making with small objects. Or you can place several small bowls on a tray. Another idea is to use hoops (rings) - place rings made of string or rope on baking trays for this purpose.

Involve the children in gathering objects for activities:

- To make collections of things related to a specific topic being discussed in the kodakistan, children can be encouraged to bring items from home.

- Children can be directed to make collections inside and outside the classroom, for example: "Go and collect some leaves".

- These collections can be the starting point for matching, pairing, sorting, set making, seriation and number games and activities.

\section{From the KEP Training Curriculum}

Play games to learn and review counting:

- Collect counting rhymes and songs related to counting to teach the children.

- Arrange two sets of objects in 1-to-1 correspondence.

- Provide a large supply of different countable objects and incorporate counting into other activities, for example, counting movements in PE lessons or drum beats in Music.

- Numbers can be related to Islamic thouglit:

$\begin{array}{lll}\text { When teaching } & \text { one } & \text { Allah is One } \\ \text { When teaching } & \text { two } & \text { Two rakaats in Fajr prayer } \\ \text { When teaching } & \text { three } & \text { Three rakaats in Maghrib prayer } \\ \text { When teaching } & \text { four } & \text { Four Holy Books and four rakaats in Dhulhur } \\ \text { When teaching } & \text { five } & \text { Five daily prayers/Five pillars of Islam } \\ \text { When teaching } & \text { six } & \text { Six pillars of Imam } \\ \text { When teaching seven } & \text { Seven children of the Prophet } \\ \text { When teaching eight } & \text { Eight types of people to be given Zakaat } \\ \text { When teaching nine } & \text { Nine wives of the Prophet } \\ \text { When teaching ten } & \text { Ten Angels working for Allah }\end{array}$


Mathematics Activities

\section{Activity Name: I Win Game}

How Children Play: Each player has a game card and about 20 beans. Place the addition flashcards face down and you are ready to begin. Turn up one flashcard at a time and show it to the players. If they have the answer on their game card, they must cover up that numeral on their card with a bean, for example, if $2+1$ is shown, all those who have the number 3 on their game card must cover it. Continue flashing the cards. The first child to have a vertical, horizontal or diagonal row of numbers covered on his card is the winner and calls out "I Win!" Uncover the winning row and check whether the addition facts for the winning numbers were flashed.

What Children Learu: Adding numbers up to 10; developing speed in mental number work.

-What you Need: 20 beans or pebbles for each player, container for game cards and a container for pebbles, envelope for flashcards, heavy paper or thin card, markers, scissors to make flashcards and game cards

How to Make It: You will need to make flashcards for addition sums up to ten, for example, $5+3,7+1,2+2$ and so on for all possible combinations that do not exceed the sum of 10 . Then prepare four game cards, consisting of 4 horizontal and vertical rows. Each square will have a numeral between 1 and 10 placed at random.

From Helping Children Lea'n

\section{Sample Game Card:}

\begin{tabular}{||c|c|c|c|}
\hline \hline I & W & \multicolumn{1}{c|}{ I } & N \\
\hline \hline 3 & 8 & 6 & 2 \\
\hline 9 & 6 & 5 & 10 \\
\hline 5 & 3 & 4 & 7 \\
\hline 7 & 4 & 10 & 9 \\
\hline
\end{tabular}

Sample Flash Cards:
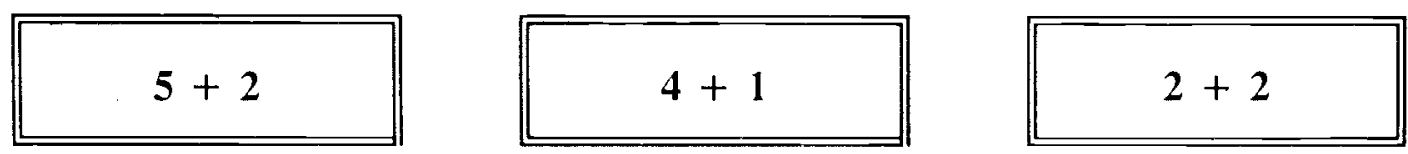
Activity Name: Odd Man Out

IIow Children Play: Explain to the children that on each card there is one set which does not match the numeral on the card. Help them to count each set and identify the 'odd man out' on each one of the cards by putting a pebble on it. For example, if on the numeral card thrce, there are three sets: one set of three apples, one set of three stars and one set of two butterflies. The set of butterflies is the 'odd man out' because there are only two in that set. The child would mark the butterflies with a pebble or a bean.

What Children Learn: Counting and comparing

How Teacher Can Help: After working with the child on the first (or more cards if necessary) until they understand, the child can work independently or with a partner.

What you Need: Pebbles or beans, cardboard or heavy paper, container for cards and for pebbles, markers and paper

How to Make It: Make cards for each of the numbers you wish to teach the children: 1 to 5 or 1 to 10 , etc. Mark each card with a number, 1, 2, 3 and so through to what ever number you are teaching. On each card draw three sets of simple objects which correspond to the number on the card and are easy for the children to count, (shapes, fruits and simple line drawings). One set of objects should always have an incorrect number of objects so that the children can identify the 'odd man out'.

From Helping Children Leimn

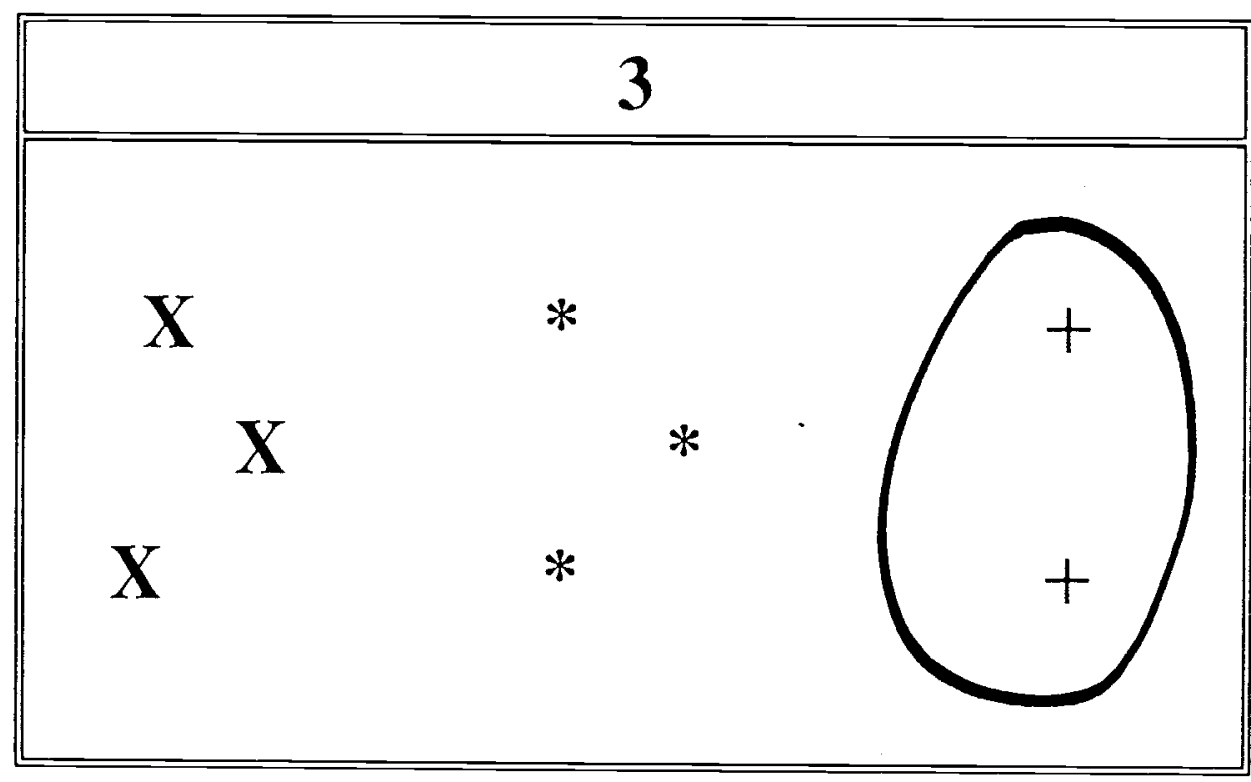

The child place a pebble on the set which does not equal three. 
Activity Name: Weight Match

How Children Play: The child can try to:

1. Find the two tins which weigh the same and make 4 pairs.

2. Take one tin from each pair, mix them up and then put them in order from the heaviest to the lightest and vice-versa.

Ask thinking questions which lead the child to make responses such as:

"This tin is heavier than this one."

"This is the heaviest."

"This is lighter than both of these." etc.

What Children Learn: Comparing weights, using mathematical vocabulary like, heavier than, lighter than, heaviest and so on. Learning seriation (putting things in order) by weight.

What you Need: 8 small tins of equal size covered with the same colored paper. Sand, adhesive tape and a carton to store tins.

How to Make It: Make 4 pairs of tins, fill the same amount of sand in each pair, as follows: Pair 1 = Empty

Pair $2=1 / 2$ cup each

Pair $3=11 / 2$ cup each

Pair $4=3$ cups each

Seal the lids firmly with adhesive tape.

Activity Name: Yesterday, Today, Tomorrow

How Children Play: The teacher helps the children to read the day and date every day. Cross out the previous day as you go along. Circle any special days during the month and write in why they are special.

What Children Learn: Understanding concepts of time; recognizing and using numbers to read a calendar; learning the ordinal numbers - first, second, third etc.

How Teacher Can Help: Ask, "What was the date yesterday?" "What date will it be tomorrow?" "What is one more than 15; one less than 15?" Let children count to special days, to answer questions like, "How many more days to Eid?"

What you Need: A calendar hung at children's eye level, with large easy to read numbers and shows one month per page. 


\section{Activity Name: Hungry Hens}

How Children Play: Let children talk about hens, what they eat and tell them that they are going to feed some hens of their own now. Put 3 hen cards on the floor or table with a numeral card 3 on each hen card. Say, "Each pair of hens here eat 3 grains between them. In how many different ways can we give them 3 grains?" Children must show a different combination for the number 3 on each card by sharing 3 beans in different ways between each pair of hens, for example:
Card 1
Card 2
Card 3
Card 4
$2+1$
$1+2$
$0+3$
$3+0$

Repeat the activity with other numbers up to 10 . Remember, each time put the same numeral card on all the hen cards. Help children to understand that the same number is made up in many different ways. The number 6 , for instance, could be made up of $5+1$, $2+4,1+5,3+3$ and so on. Each pair of hens can show a different combination for the number 6 . After doing this activity informally several times, children can try to record these combinations on paper or by using the small numeral cards and use symbol cards for ' + ' and ' $=$ '. For example, they can record $2+4=6,3+3=6$, and so on. Do not forget the concept of 0 in number combinations, for example, $0+6=6$.

You can help children to begin understanding subtraction informally by using the hen cards. If a card has the combination $4+3=7$, you can take the 3 beans away and let the child observe that when you take way 3 from

7 , it leaves 4.

What Children Learn: Strengthening number concepts; getting ready to add and subtract.

What you Need: Small cardboard squares or heavy paper for numeral cards, at least 6 'hen cards' as illustrated, container for 'hell cards', container for beans or pebbles

How to Make It: Make small cards with a numeral written on each -5 or 6 cards for each numeral 3 to 10. Make at least 6 'hen cards' as illustrated. These can be drawn on paper and then glued to heavy paper or cardboard.

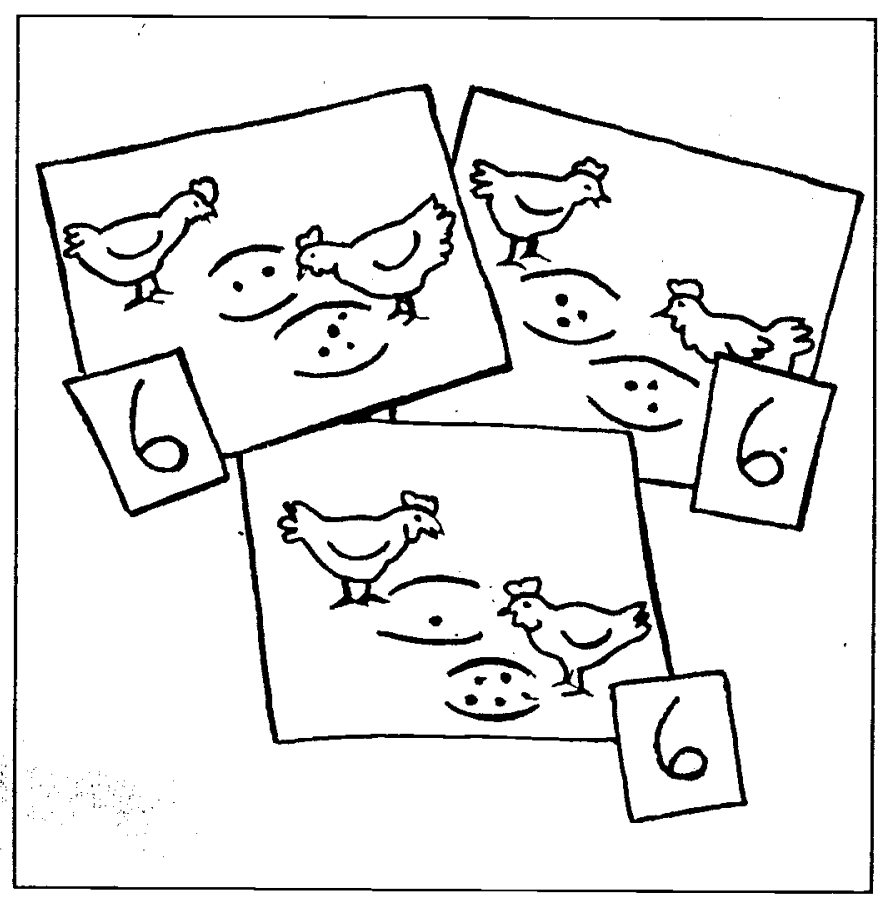


Activity Name: Animal Race

How Children Play: This is a simple board game for 2 to 4 players. Each player takes an animal counter and puts it on 'Start'. Before the racing begins, the players roll the dice in turn. The child with the highest score starts. Players must roll the dice in turn and move their counters the same number of spaces along the race-track as the number they rolled on the dice. The first player to reach the 'Finish' wins. For children who like a longer game, races of two laps around the course can be run.

What Children Learn: Recognizing numerals, counting, and getting ready to add numbers.

What you Need: Container for board game, counters and dice, a pair of dice, cardboard, heavy paper, markers, glue scissors, colored pencils/markers etc for making the board and counters more attractive is optional.

Ilow to Make It: Make a board game on sturdy cardboard. You can draw it on paper and paste it on the cardboard, or draw it directly onto the cardboard. The game board is simply a clouble circle or oval shape to resemble a track. Make the track 3 to $5 \mathrm{~cm}$ wide - to match the size of the animal counters you will make. Divide the oval or circular 'race track' into boxes by drawing simple lines. Mark one box 'Start' and next to it mark the box 'Finish'. Make four squares out of cardboard or heavy paper to match the size of the boxes on the race track. Draw or glue on pictures of four different animals - preferably animals which run fast, like a rabbit.

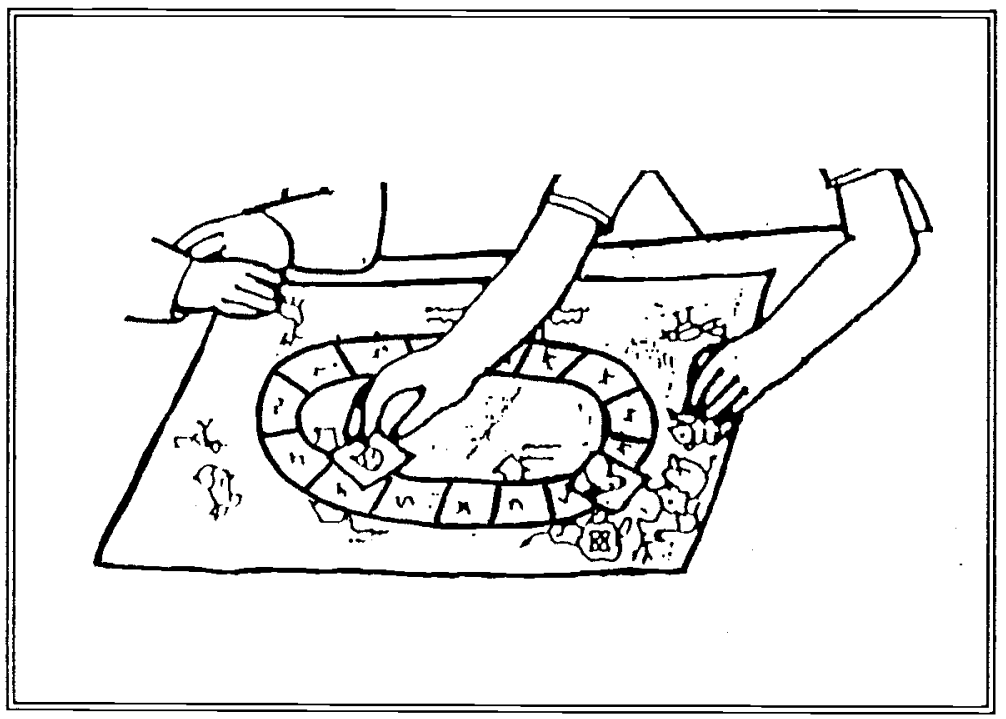




\section{Mathematics Activities}

\section{Activity Name: Caterpillar Caper}

How Children Play: Talk about the number of days until a special event, like a holiday or birthclay. Children can count and make sure that there is a section on the caterpillar's body for each of these days. Everyday they can tear off a section of the caterpillar's body, beginning with the tail. Children have fun seeing the caterpillar shrinking and reciting, "One days less, 7 days left", "One day less, 6 days left", and so on. Excitement reaches its peak when they reach the caterpillar's head and the day has arrived!

What Children Learn: Understanding number sequence; understanding 'one more' than and 'one less' than; learning that the months usually have 30 or 31 days.

What you Need: A large sheet of blank paper, crayons or markers and scissors

How to Make It: When there are 15 or 20 days left for a very special event, make a caterpillar as follows: Draw the outline of the caterpillar on paper by using a bottle cap about $5 \mathrm{~cm}$ in diameter to trace the sections of the body. Make a section for each day that is left up to the event. The head of the caterpillar has the event written on it, the tail has the number of the amount of days left for the event. The sections in between have the remaining numbers, starting from number 1 on the section next to the head. Children can color the caterpillar brightly and cut it out.

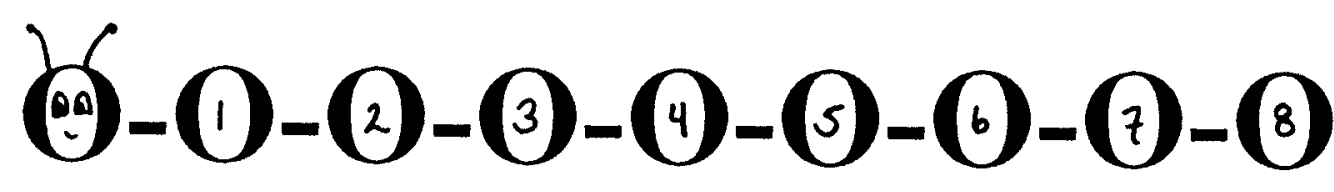


Mathematics Activities

Activity Name: Find My Partner

How Children Play: Shuffle the cards. The child looks at each picture card in turn and tries to find an object which goes with it, for example, hair goes with comb. The card and the object are matched.

What Children Learn: Associating objects which belong together, understanding relationships.

How Teacher Can Help: Discuss the following with the child: Why did you put this picture with the orange seeds? In what way do these two belong together? Point to other pairs and ask the same kind of questions. Pick out four things which are used at home and name them. Tell me how each one is used. Pick out two things you could play with. What is this made of? What color is it?, and so forth.

What you Need: Clear plastic bags - one for each item, stapler or adhesive tape, paper, heavy paper or cardboard, scissors, glue, magazine pictures, pens and coloring pens (optional), container for cards

How to Make It: Collect about 15 different small objects and draw or cut out pictures of 'partner' objects. The following is a recommended list, you can add your own ideas:

$\begin{array}{ll}\text { Objects } & \text { Pictures } \\ \text { orange seeds } & \text { orange } \\ \text { matchbox (empty) } & \text { matclistick/fire } \\ \text { eraser } & \text { pencil } \\ \text { leaf } & \text { tree } \\ \text { plastic beads } & \text { necklace } \\ \text { shirt buttons } & \text { shirt } \\ \text { small baby's rattle } & \text { baby } \\ \text { ring } & \text { hand/finger } \\ \text { shoelaces } & \text { shoes } \\ \text { stapler } & \text { staples } \\ \text { kite string (small bundle) } & \text { kite } \\ \text { postage stamp } & \text { letter } \\ \text { key } & \text { lock } \\ \text { watermelon seeds } & \text { watermelon } \\ \text { chalk } & \text { chalkboard }\end{array}$

From Helping Children Learn 


\section{Mathematics Activities}

Activity Name: Group Them

How Children Play: Shuffle the cards. Ask the child to spread out the cards and decide which ones might belong together because they are alike in some way. Give your child time to think it out. Ultimately she will group the pictures according to the three categories: Food, Clothing and Shelter. Help her along only if you need to do so.

What Children Learn: Understanding the term 'grouping'; classifying into three categories.

How Teacher Can Help: Discuss the following with the child: Why have you put these pictures in one group? What are all the things in this group? (Food, Clothes or Things to Wear, Houses). Pick out pictures of things you like to eat. What are they? Can you make smaller groups from the clothing pictures by thinking of ways in which some of the clothes are the same? Tell me about your groups (for example, children's clothes, men's clothes etc.) Try grouping pictures of food in the same way.

What you Need: Paper, pens, crayons, glue, scissors, heavy paper or card, magazine pictures and container for cards

How to Make It: Make 24 cards, large enough for small hands to handle easily and see the pictures clearly. You can either draw the pictures or cut them out of magazines and glue them onto the cards. Choose three distinct categories, such as Food Items, Things to Wear/Clothing and Shelter/Houses. Draw or cut out 8 pictures for each category. You can choose other categories or make additional sets of cards if you like.

From Helping Children Learn 
Part V: Suggested Games, Activities and Learning Materials

\author{
Art and Craft \\ Materials for Art/Craft
}




\section{Art and Craft Activities}

\section{Printing with Cardboard Blocks}

Materials: cardboard, scissors, glue and string

- First cut a piece of cardboard to act as a backing for the block. Then cut a simple shape out of the cardboard and mount it on to the backing using glue. This forms the basic block. If you can find any textured paper which has a raised pattern, this will produce even more attractive results.

- The children then put paint on to the raised surface and press it carefully to the paper to produce a repeat pattern. A string block can be made in the same way, using string to make the raised surface.

- With young children you may need to make the blocks for them. Older children can make their own blocks or at least create their own shape or design for the pattern.

\section{Folding Patterns and String Pulls}

- Materials: paper, brushes, paint and string

- First the children fold their paper in half and open it out again. On one half of the paper they can blob, splatter or brush paint on using different colors. Then the paper is folded over carefully and smoothed with hands. When they open it out again, there will be a symmetrical pattern.

- A similar effect can be achieved by dipping string in paint and laying it on half the paper. The paper is then folded over leaving one end of the string showing. When this end is pulled, it leaves a symmetrical pattern.

\section{Taking a Line for Walk - Doodling}

Materials: paper, pencils, crayons or paint

- Ask the children to draw a continuous line (without lifting the pencil off the paper) as if they were taking it for a walk across the paper. Encourage them to be free as they draw. You can point out to them that interesting shapes are formed by this 'walk'. Try to discourage them from making very thin shapes because these will be difficult to color. They can then paint the shapes or color them in with crayons. Not many colors are necessary.

\section{How to Make Paper Mache'}

Materials: used newspaper, large bowl, glue or wheat flour, water

- Cut some used newspaper into small bits and put them in a large container. The amount of paper to be cut depends upon the size of work to be done. Pour some water into the container and stir. Let the paper soak in the water for a few days. Take a heavy piece of wood and crush the paper into pulp. Add some glue or flour paste to the soft pulpy paper and stir till it turns thick. It is now ready to be used for modelling. 


\section{Texture Rubbings}

Materials: crayons, paper and pencils

- There are many surfaces that children can rub which make an attractive pattern. Here is a list of some of them but you will certainly find more. This activity gives children an awareness of texture.

- coins

- tree bark

- corn cobs
- walls

- stone

- woven surfaces (cloth, mats)

- The paper is placed on the surface to be rubbed. The child then rubs the surface with a crayon or a pencil, feeling the edges of the surface carefully so that he does not go over the edge. An interesting extension of this activity is for children to draw a simple picture first and then give the picture a textured effect by making rubbings for parts of the picture or the whole picture.

\section{Eggshell Mosaics}

Materials: eggshells, paper, paint, brushes and glue

- Collect any eggshells which are being thrown away after cooking. The children can paint the shells. When they are dry they can break them into small pieces and stick them on to paper to build up mosaic pictures and patterns. They can draw an outline of the picture first and then fill it in as if coloring. They can also paint the eggshells once they are glued onto the picture to make the activity easier for younger children.

\section{Clay Modelling}

- Clay is an excellent material with which children can model. It can sometimes be found locally, or can be bought from a shop selling art materials, or from a local pottery. They need to be given the opportunity to get the feel of it and find out for themselves its possibilities and limitations. You can show them pictures of animals and people familiar to them so that they get the idea of turning pictures and photographs into three dimensions. They can work individually or in groups in which case each group can make larger models.

- There are many interesting activities children can do with clay, for example:

- drawing on slabs of clay

- modelling simple animals, houses, people or vehicles

- making pinched or thumbed pots

\section{Stained Glass Windows}

Materials: paper, crayons and oil

- First let the children draw a pattern or picture of their own choice. They then rub the back of the pictures with oil, which makes the paper translucent. These pictures can be displayed on the classroom window to give a stained glass effect. 


\section{Picture Making}

- Drawing from observation: It is important that young children are encouraged early on to draw real things with objects in front of them rather than from pictures and photographs or memory.

- Free drawing and painting: Apart from drawing from observation it is also very important to encourage children to draw for pleasure and from imagination.

- Here are some suggested themes. You can add your own making sure the subject matter is within the child's experience: playing outside, animals, my family, my house, the market.

- Give the children the chance to express themselves by talking about their experiences first and getting as much information as possible on what they are going to draw.

\section{Collage}

Materials: paint, glue or flour and water paste, paper, scrap material (pieces of cloth), beads, colored paper, feathers etc.

- Collage is a way of making pictures by sticking small scraps of materials, paper, feathers etc. on to a backing. This technique produces colorful pictures with interesting textures. It would be a good idea to clivicle the class into groups so that each group can make their own collage on an interesting topic, such as, the market, our class, a holiday. It is worth encouraging them to choose a colorful topic, because the results will be more eye-catching. Paste some large sheets of strong paper together by overlapping the edges. The children can draw roughly the outline of the picture they want to make on to this backing. Then they stick on the materials they are using and builcl up the picture.

\section{Wall Stories}

Materials: paper, crayons, paints, scraps of material, glue

- This is a pleasant art activity to follow a story told to the class. It gives the children an opportunity to work in groups together, which encourages both social and creative skills.

- First you need to discuss with the class the four main evcnts of the story you have told. Then divide the class into groups. Each group will be responsible for making a picture of one of the events in the story.

- The pictures might be painted or drawn or made with scraps of paper or material to make a collage or mosaic. The pictures need to be large enough for the class to see them clearly from a distance when they are displayed on the wall.

- When the pictures are finished mount them on larger sheets of paper and write a short sentence describing the event that is illustrated. 


\section{Mixing Colors}

Materials: powder paint, colored transparent papers, brushes, water, containers

- Give the children primary colors - red, yellow and blue. Let the children mix the different colors freely in each of their groups. Each group should experience mixing all three colors if available to see what they get when they mix different colors together:

$$
\text { - red }+ \text { yellow }=\text { orange } \cdot \text { yellow }+ \text { blue }=\text { green } \cdot \text { blue }+ \text { red }=\text { purple }
$$

- By adding white or black to the mix it can change the shade of the colors. The teacher and children can then discuss the results and display paintings made with the paints.

\section{Crayon Etchings}

Materials: paper, wax crayons, black crayons or paint, a well sharpened pencil

- The children will need crayons. They can use several colors and try to cover the paper thickly and evenly all over. They then either put a layer of black crayon over the top of the colors or black ink, or a layer of black paint mixed with soap so that it sticks to the waxy surface. Let it dry.

- The children can use a pointed stick or any other instrument to scrape or etch a picture or a pattern in the black layer, revealing the colors underneath. They need to take care not to scrape holes in the paper.

\section{Spiral Mobiles}

Marerials: paper, scissors, thread and thin sticks

- The children will need circular pieces of paper. They can be different sizes but there must be at least two of each size to balance the mobile. The children can draw a spiral shape on their paper. You should have a sample for them to follow. After coloring or drawing a design on the spiral, the spiral is cut out very carefully. This may be difficult for many children, so you may need to help them. A piece of thread is then put through the center of the spiral and attach this to either end of a thin stick so that it balances and creates a mobile. The same idea can be followed to make mobiles of other kinds of geometric shapes, animals or birds etc.

- This activity is appropriate for older children, since drawing the spiral and cutting it out take good fine muscle control. If the children are not skilled enough for this activity they can color and draw patterns on a circle and you can complete the mobile. Alternatively, mobiles can be prepared by the teacher to brighten the pre-school . classroom. They are also very effective in the nursery.

From Primary Lleas: A Resonuce Book for Primary Teachers
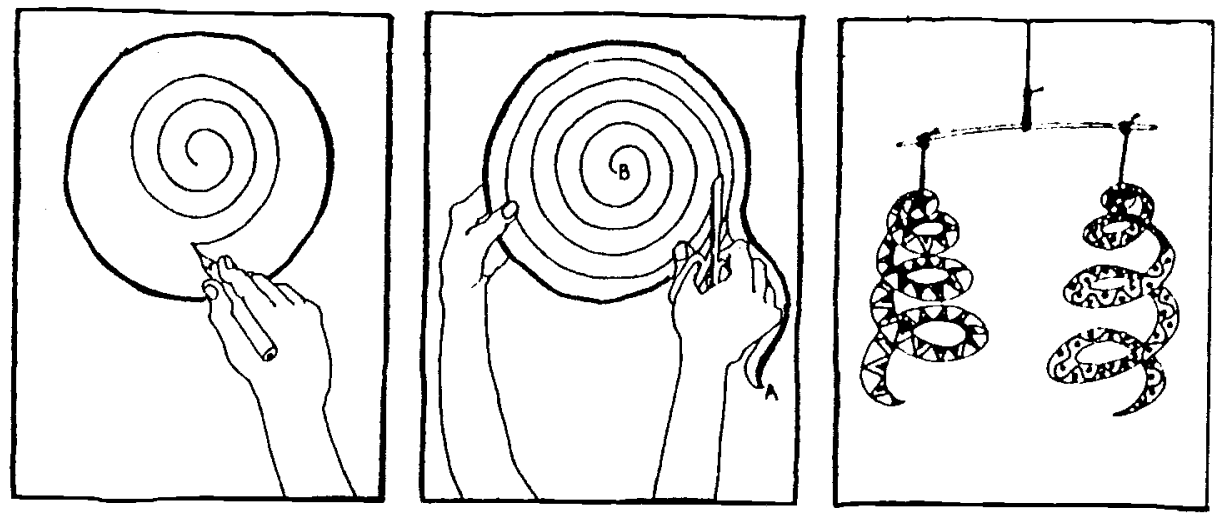


\section{Art and Craft Activities}

\section{Simple Cut Paper Designs}

Fold a piece of paper in half and then in half again, forming quarters. Randomly clip pieces from he corners and the edges of the folded sheet. Unfold the paper carefully to reveal the cutout design. Gluing the design to colored backgrounds enhances them.

A variation of this activity is "Paper Dyeing", see illustration.

\section{Paper Strip Sculpture}

Cut strips of various lengths from pieces of colored construction paper. Put a little glue on one end of a strip and attach that end to a sheet of paper, pressing. it with your finger for a few seconds before letting go. Form the strip into an arch, a pinched peak, accordion folds, or a twist and paste the other end to the sheet of paper. Repeat this process with other strips. Encourage the children to be as creative as possible to make their three dimensional designs.

\section{Crumpled Tissue Collage}

Using tissue paper (or other thin paper), which tears and crumples easily is an ideal medium for collage. Crumple $5 \mathrm{~cm}$ to $10 \mathrm{~cm}$ squares of colored tissue paper into balls. Dab one side of each ball with glue and stick it onto plain or colored paper. Children can make a picture with the different colored balls or an abstract design - let them use their imagination.

\section{Paper Bead Necklace}

You will need: paper, pencil, scissors, glue in a small bowl, liquid paint, paintbrush, woolen yarn and tape.

1. Begin by marking and then cutting out paper rectangles, approximately $4 \mathrm{~cm}$ by $13 \mathrm{~cm}$. A child's necklace takes ten or more rectangles.

2. Dip a rectangle into the glue covering it on both sides. Let the excess glue drip off into the bowl; or strip off the glue by using one hand to gently pull the paper up between two fingers of your free hand.

3. Lay a short end of the rectangle on a pencil and make a bead by rolling the paper around the pencil. Slip the beal off and set it, flap down on wax paper fo dry overnight. Repeat these steps for all of the rectangles.

4. After the beads have dried, paint them, let them dry and then use the beads to string the necklace. Wrap one end of the woolen yarn with tape to make it easier to string the beads. Remove the tape and tie the two ends together for the completed necklace

A simplified variation is described in the activity called "Making Jewelry". 


\section{Art and Craft Activities}

\section{Splatter Pictures}

Cover a table with newspapers. Mix different colored paint, quite thin, in empty yoghurt pots (or similar small plastic containers). Use old toothbrushes or other small brushes and dip each one into a different color. Rub your finger or thumb over the bristles and splatter the paint onto the paper. You can lay shapes (geometric, or figures or fruit) cut from paper or thin card, on your page and then splatter the paint to leave a silhouette.

\section{Snakes}

For a small snake use an old striped or colorful sock. For a long snake cut the leg from an old pair of tights. Stuff with crumpled pieces of newspaper and tie the end. Stick or sew on buttons for eyes and make a long forked tongue from card or material. You can paint on colored strips or a pattern on the snake.

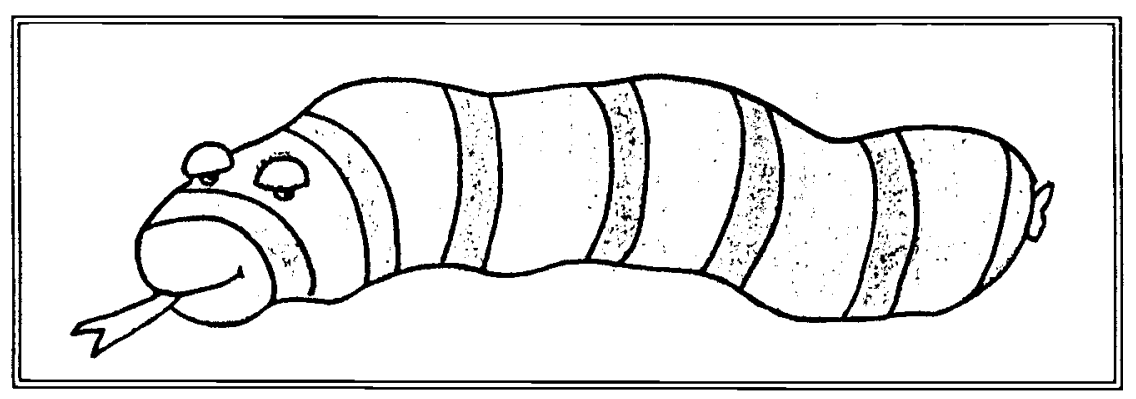

\section{Bubble Pictures}

Cover the table with newspapers. Mix thin watery paint of different colors in empty plastic tubs/containers. Add a little washing up liquid. Gently blow through a straw until the bubbles are coming over the tops of the tubs. Carefully place a piece of paper on top of the bubbles. When the picture dries, things can be added to the picture using crayons or pens. Be sure to warn the children to only blow into the straws - do not suck in!

\section{Straw Flowers}

Draw, color and cut out flowers. Use adhesive tape to stick the flowers to a stem made from a drinking straw. Several of these "straw flowers" can create a bouquet of flowers. The straws can be put into a clay, plasticine or mud base for display.

\section{Painting Stones}

Wash and dry some smooth, flattish stones, use thick poster paint and paint faces, fish, owls, ladybugs or anything else you like on the stones.

From Ladybird Leaming at Home Series

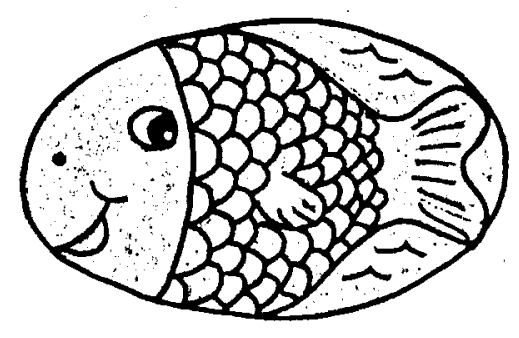




\section{Art and Craft Activities}

\section{Sock Puppets}

Use clean old socks and cut out eyes and a tongue from felt, cloth or paper. Cut up pieces of old material and stick on to make noses, ears or whiskers.

\section{Paper Dyeing}

Use paper napkins, paper towels, tissues or other thin absorbent paper. Fold the paper and cut in different ways. Then carefully dip the corners into pots of different colors of food coloring added to water (or thin, watery paint). Gently open out and leave to dry. The finished dyed "snowflake" designs can be hung from a string like a mobile or mounted on colored paper.

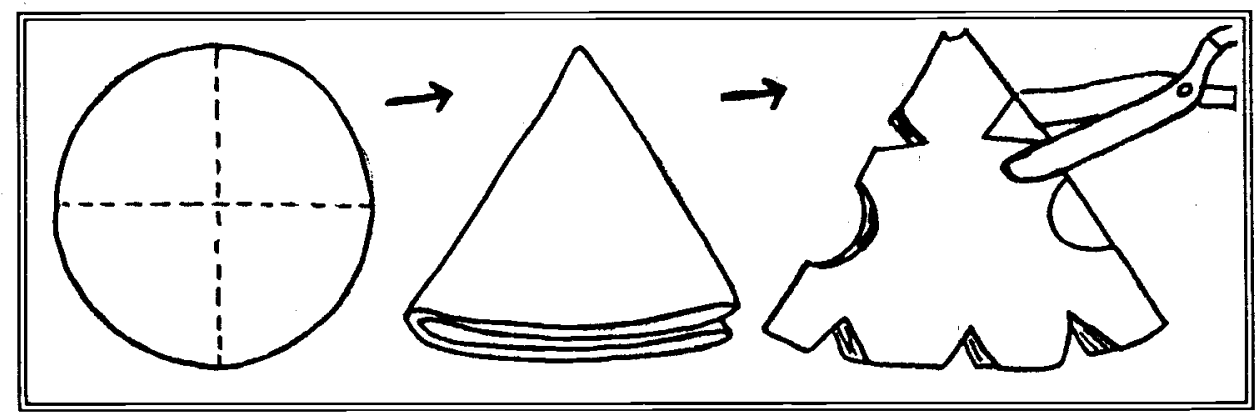

\section{Stringing Beads}

Collect colorful buttons, macaroni tubes, or cut drinking straws into pieces. Use a large blunt needle and some woolen yarn or a shoelace. Tie a knot at one end. Thread the 'beads' until the necklace is long enough to go over the child's head and then tie the two ends together. Alternatively, put these different kinds of beads in a box with strings for children to thread the beads and undo them again when they are finished.

\section{Make your Own Playdough}

You will need:
1 cup of plain flour
1 tablespoon of cooking oil
2 teaspoons of crean of tartar (optional) food coloring (optional)

\section{$1 / 2$ cup of salt \\ 1 cup of water}

Mix the ingredients together and warm them in a pan. Allow the mixture to cool and then knead the dough until smooth. Store the dough in the refrigerator or a cool place. You can add food coloring to the mixture to make the playdough more fun for children to play with.

\section{Marble Painting}

You will need to mix 3 or 4 pots of fairly thin, different colored paints. Find a shoe box or similar sized box with sides and lay a piece of paper on the bottom of the box. Put marbles into the pots of paint. Pick them up with a straining spoon if you have one - or simply drain the extra paint from the spoon. Gently roll the marbles around in the box so that they leave different colored trails. 
Printing

Cover a table with lots of newspaper. Mix different colored paints in saucers or lids from empty jars. Add a little wallpaper paste to the paint to make it thick and sticky for printing (but this is not essential). Cut up potatoes, carrots, turnips, and paint the flat surface. Then print onto paper using different colors and shapes to make patterns.

Next time you go out for a walk, collect different leaves. Paint one side of each leaf and press onto paper to make leaf print patterns.

Collect card tubes, cork, jam jar lids, tube caps or anything with an interesting shape and print different patterns with the collected items.

\section{Cardboard Cylinder People}

Use toilet rolls or other cardboard cylinders to make people. Use a variety of scrap materials and paper to decorate the rolls, by making clothes, drawing on faces, use cottonwool for hair or beards. Be creative.

\section{Rolling Animals}

Paint and decorate cardboard tubes lengthwise to look like animals. Stick a marble inside each tube and cover the ends with adhesive tape. Race the animals down a slope or across the floor.

\section{Recipe for Kitchen Clay}

You will need:

2 cups of plain flour

$1 / 2$ cup of salt

Mix with enough cold water to make a stiff dough.

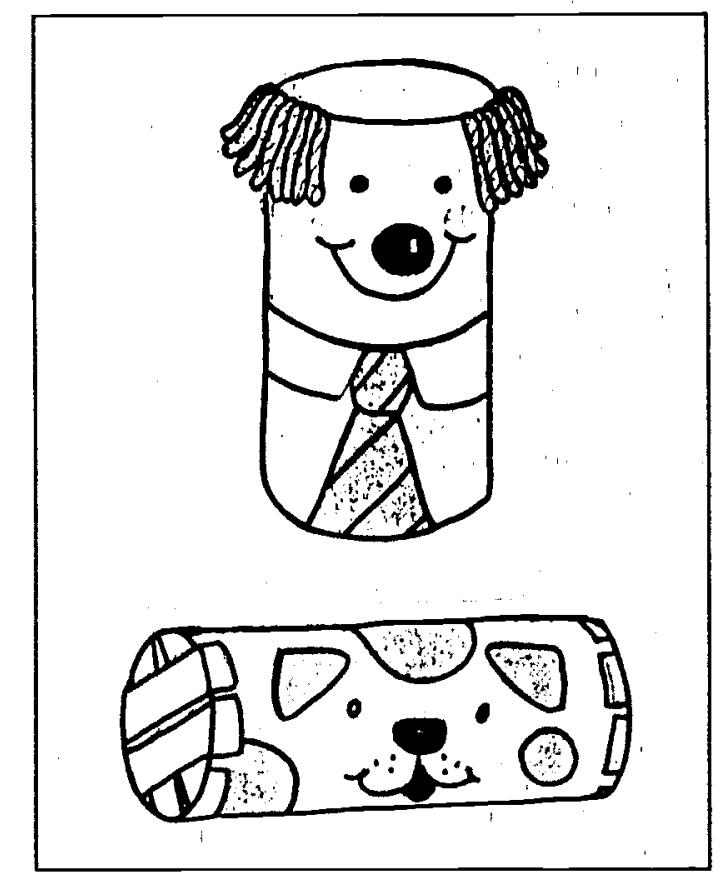

Knead this well. Shape it and bake it $\left(250^{\circ} \mathrm{F}\right)$.

The clay shapes will become hard and sound hollow when tapped. When the clay shapes are baked and cool, paint them using bright colors. You can have the children make many items that can be 'sold' in a store in the imaginative play area.

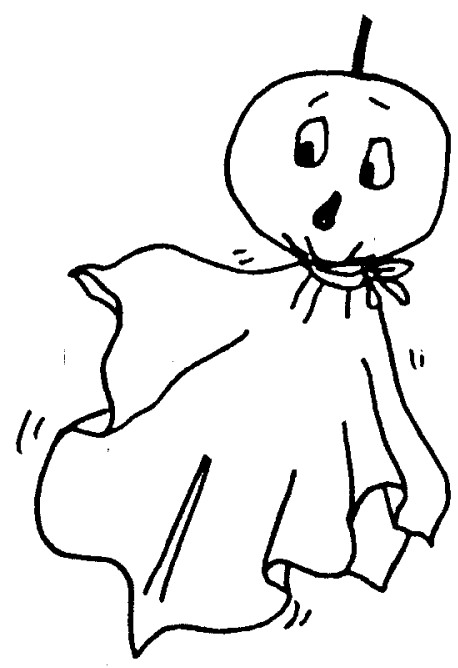

\section{Making Ghosts}

You will need pieces of paper towels, tissues or paper napkins, some woolen yarn or heavy thread and a felt tip pen. Crumple one piece of the tissue (or as many as necessary to make a small ball that can fit in your fist). Fold a second piece of tissue around the ball making sure that the ends hang free. Tie a string around the neck and draw on a face. You can hang these from the top of the head. Or, wrap the ball around a stick or straw and the 'ghost' will have a handle like a puppet. 


\section{Card Puzzles}

Collect old birthday and other cards to make a simple jigsaw puzzle. Cut the card into a few different pieces that must be put together. Smaller pieces can be cut for older children. Draw your own pictures or cut them from a magazine to make more puzzles.

\section{Weaving}

To make a simall flowerpot holder, pencil holder, holder for beads, buttons or anything else, make an odd number of holes around the top and bottom of a paper cup or an empty plastic yogurt pot. With a thick, blunt needle, thread woolen yarn from the top to bottom. You can either weave thin strips of colored paper in and out of the strands of wool or thread different colored wool in and out to make a pattern.

\section{Make Some Headphones}

You will need two paper cups or clean, empty yogurt pots and some string.

1. Make a small hole in the side of each cup near the top.

2. Measure the string so that it fits over the top of your head from ear to ear and then add a little extra for the knots.

3. Thread the string through each hole and secure it with a big knot at either end.

The headphone idea works well as a telephone. Just make the string longer and make the holes in the bottom of each cup instead of the sides. The string has to be pulled straight for it to work properly. You could also try this with empty tins.

\section{Roly Poly People}

Use clean, empty yogurt pots. Save empty cotton thread reels. Make a small hole in each side of the pot and push a piece of plastic drinking straw through one side, through the center of the reel and out the other side of the pot. To stop the straw from slipping out, fix the ends with adhesive tape. Make sure that the edge of the cotton reel is lower than the pot. Then decorate the pots with paper, string, woolen yarn and draw on them with permanent markers to make 'people' out of the yogurt pots.

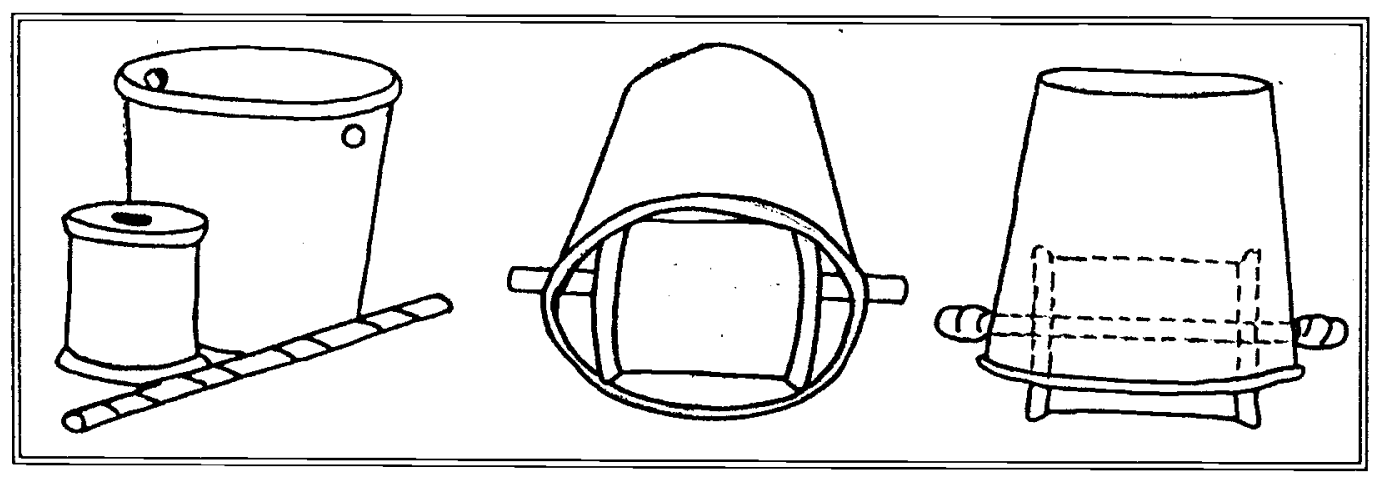


Play with Boxes

You will need large cardboard boxes. To make a car, just draw wheels, doors and lights on the outside of the box. Use thick felt tip pens, crayons or paint. Invent a number plate.

Make a train by sticking several large boxes together. You could stick on small boxes and cartons for funnels, paper plates or circles of colored paper for wheels, and cottonwool for steam. Make a bus, boat, fire engine, tuk-tuk, lorry and so on.

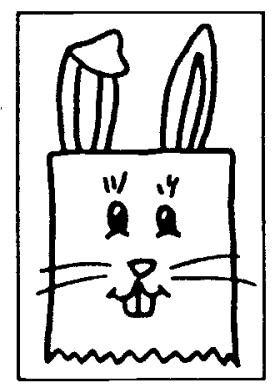

\section{Make a Bag Puppet}

Use paper bags to create simple puppets. You can secure the puppet on a child's hand using a piece of string, wool or an elastic band. Draw or paint different faces or make funny animals. Use colored paper or card for ears. String or wool for whiskers.

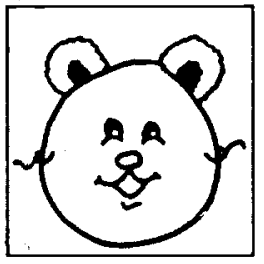

\section{Make a Mask}

Use paper plates or cut out cardboard circles. Make small holes in each side of the circle and thread pieces of string, elastic or thick wool through to tie the mask on. Cut holes for eyes and draw or paint different faces. Stick on cottonwool, string or woolen yarn for hair, beards and eyebrows. Make a pair of glasses from pipe cleaners or stiff card. Add scraps of ribbon, material or colored paper for bow's or bow ties.

\section{Make a Bangle}

To make a bangle, carefully cut rings of plastic from a clean, empty washing up liquid bottle. Wrap thick woolen yarn round and round one of the rings. Use a large blunt needle to weave other colored woolen yarn in and out to make your bangle.

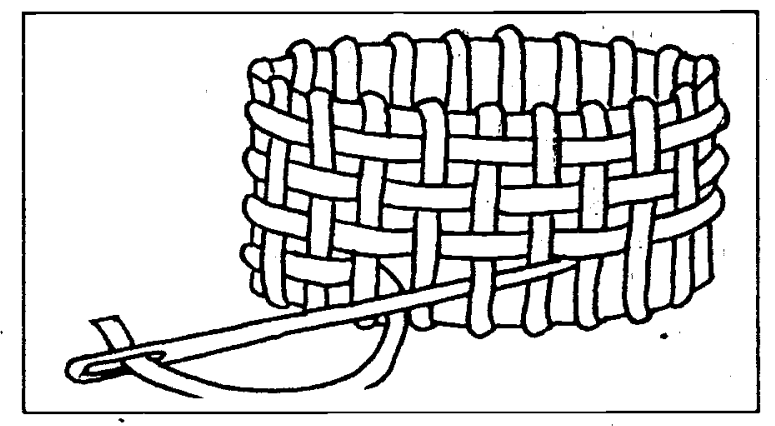

\section{Wool or String Pictures}

Draw some simple animal shapes on paper. Dip pieces of woolen yarn or string in some strong glue and then stick them onto the shape. Make loops and swirls until your shape is full. You can add material, paper and other scraps to decorate the animals.

\section{Hand Puppet}

Clench your fist with the thumb tucked inside. Draw a face with water based felt tip colors or washable paint. Wiggle your thumb up and down to make the puppet speak or tell rlyymes. You can wrap a handkerchief round your hand for a head scarf. 
Woolly caterpillar

Cut small squares from scrap material. Tie a knot at the end of some thick wool and thread on the squares. Make a card face for the other end and finish with a knot at the nose.

Knock Down the Wall

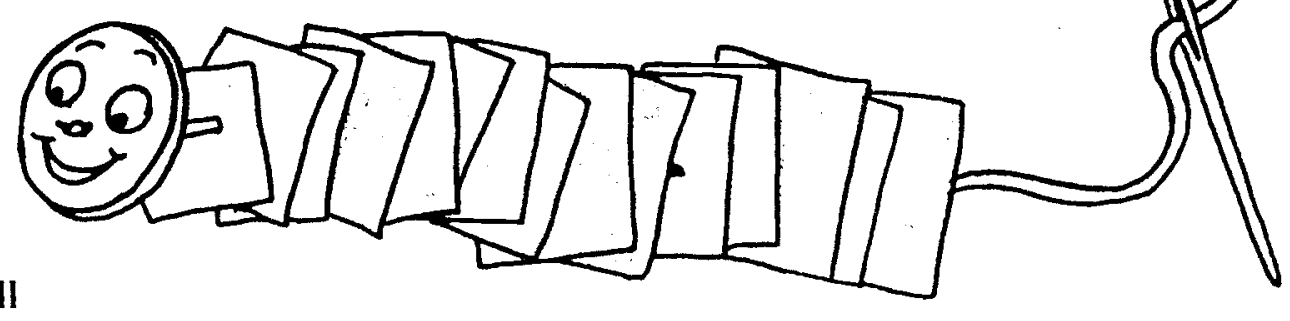

- Collect empty boxes all the same size, or you can use empty yogurt pots. Use paints, crayons or felt tips to make lots of different faces. Pile your people up (make a pyramid) on a low table and try to knock them down by throwing a small sponge or a ball made from crumpled newspaper. Instead of faces, just decorate the boxes and put numbers and corresponding dots on them.

- Paint an animal face on a large piece of thick card such as one side of a big cardboard box. Push pieces of thin round wooden sticks, or cane through the card in some key places on the face (eyes, mouth, ears). Make hoops by cutting sections from a big empty plastic bottle. Aim at the pegs. Keep score for the number ringed.

\section{Paper Folding}

- Dancing Dolls: Fold a long sheet of thick paper backwards and forwards (like accordion pleats). Draw half of a doll figure against the folded edge and cut around the outline (but not the folded edge!) Open out your row of dolls and draw faces on them and color them. In the same way you can make a row of houses, cars, flowers - use your imagination.

- Fold another piece of thinner paper in the same way, make small folds. Tie the center of the paper with a piece of string. Then take the edges of the paper and open out the folds to form a circle. Use glue or adhesive tape to stick the ends together. Use thick felt pens to draw facial features or glue on paper eyes, mouth etc. You can make animals, clown faces or anything you like.

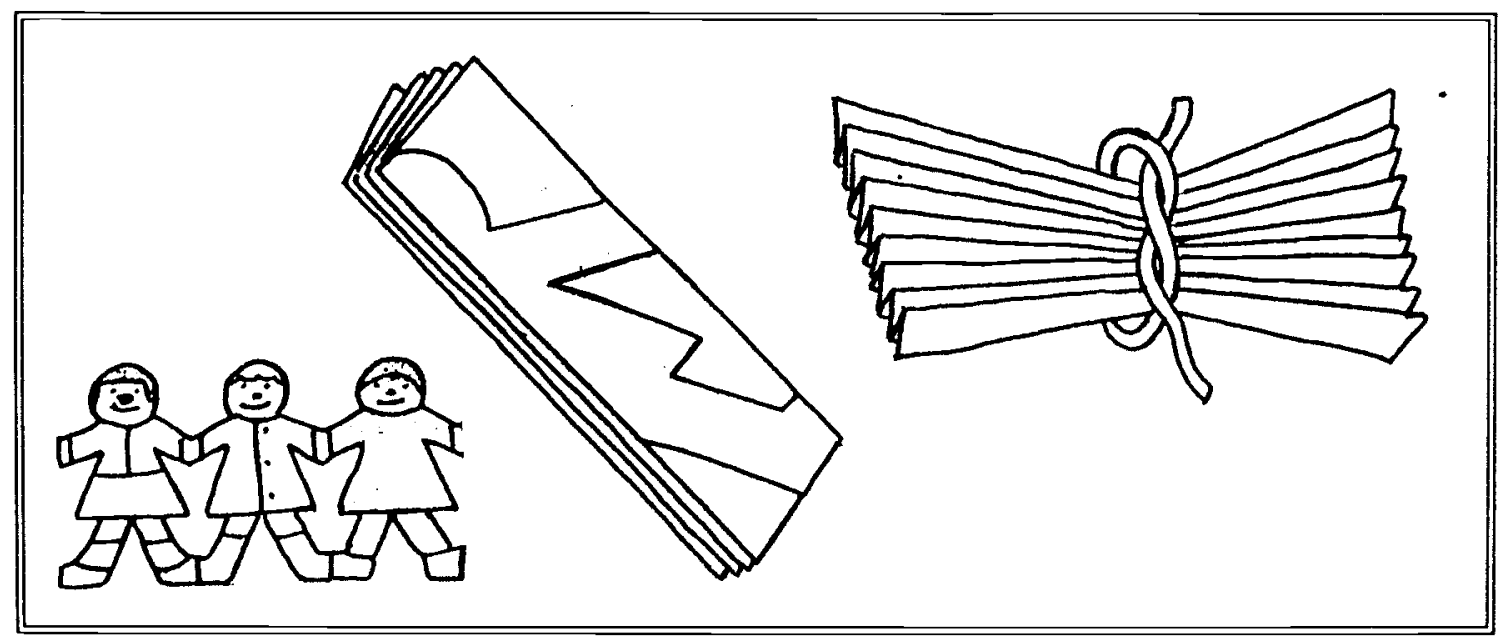




\section{Marionettes}

Cut a simple gingerbread man shape from card. Color it on both sides and stick on paper shapes or buttons for features. Stick thin elastic or wool to the top of the head and attach to a pencil. You can now make him dance and run away (See Story-telling Activities in this part of the Manual for the text of the story.) You make other characters from the story (or other stories) and have a puppet show. Another idea is to stick a cork to a small box for the head and make legs from pleated stiff paper.

\section{Making Jewelry}

Cut 20 of the shapes below from a magazine or colored paper. Curl the strip of paper around a pencil and glue the end down before removing. Use a large blunt needle and thick woolen yarn to thread the beads. Tie the ends together and wear as a necklace or make smaller beads and make a bracelet.

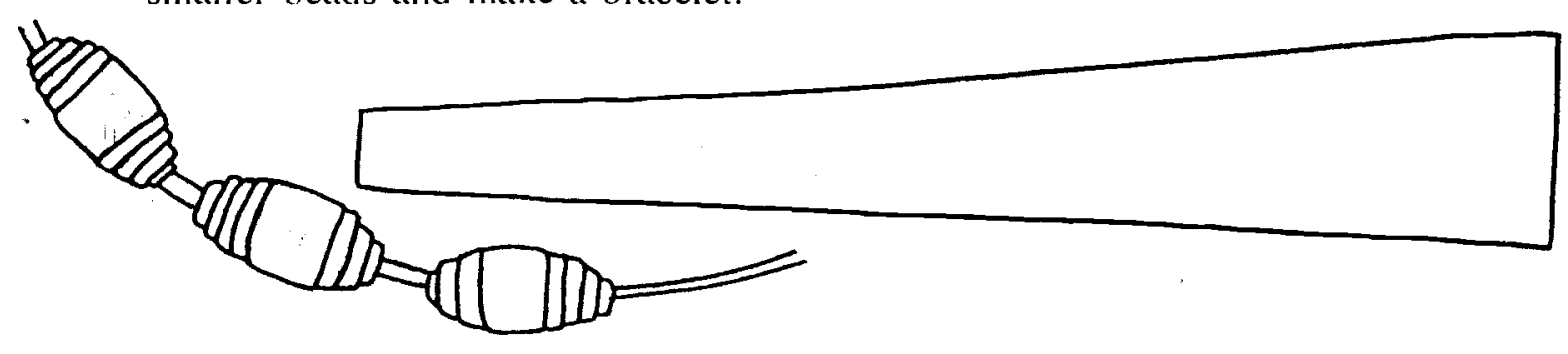

\section{Make-believe TV and Radio}

You will need old shoeboxes or empty cereal packets, cigarette packets or matchboxes, toothpaste tube caps, bottle tops, thin card, straws and pipe cleaners. Paint your box. Stick on the caps and bottle tops for knobs. Attach the pipe cleaner or straw for an antennae. Cut out a picture or draw one and paste it on the TV screen. Make a radio in a similar way, using a smaller box. Draw a row of numbers for wave bands. Cut a circle from card and draw a criss-cross pattern. Stick this on as the speaker.

\section{Other Ideas with Paint}

Cover the table with old newspaper. For each of the following, mix thin paint.

Blow Pictures With a paint brush, drip little puddles of different colored paints on your paper. Gently blow through a straw from all four sides of your paper and watch the different patterns and colors appear.

Invisible Pictures Draw your picture or pattern on a piece of white paper using a white wax candle (or a white crayon). Paint over the top and watch the picture appear.

Symmetrical Pictures Fold a large piece of paper in half. Then open it out. Drip different colored paints on one half or in the center. Fold over and gently smooth over with your hand. Carefully open it out again. What does the picture look like?

Painting without Paint On a sunny day, take a bucket of soapy water and different sizes of household paint brushes outside. Paint pictures on the cement or stones. How long does it take for the sun to make the pictures disappear? 


\section{Working with Shapes}

Use art and craft time to reinforce the concept of shape. Cut out the common shapes you are using in many different colors and sizes and allow the children to experiment with making pictures and patterns.

Using clay get the children to attempt to make shapes. Show them how to make spheres, cylinders, cubes, bowl shapes and any other odd shapes by simply squeezing the clay in their fist. Then ask them to see how these shapes move down a steep slope. Change the shapes by squeezing, flattening, stretching and rolling. See if they behave in the same way. Using sample shape blocks are ideal, or a ball, box, tin can and so on.

\section{From Science 5-7}

\section{Working with Clay}

Clay is a good and inexpensive material to be used in sculpture by the children. Wax can also be used though it gets very soft and adhesive, sticking to children's small hands in warm weather. Finished clay sculptures can be painted and wooden knives or comparable tools are very effective for carving on the sculptures and adding decorative designs.

Other materials for shaping are wheat flour with water to make dough, plasticine, rolling pin and board, cookie cutters, butter knife, fork, spoon, etc. Make slapes or things like animals, flowers, dishes and cups with hands. Roll out the clay mixture with the rolling pin." Use the cookie cutter to make shapes, use a butter knife to cut desired shapes. Press elbow or finger in the clay which has been rounded to make a hole. Use a few flowers and some leaves and press them on the dough to produce a decorative item.

\section{More Ideas for Painting and Working with Color}

- Finger Painting: Use the index finger. Dip the finger in the paint and then press it on a piece of paper. This will produce spots of color. Use various colors. Dip the tip of all the fingers into one color or each finger into a different color, then draw lines on the paper to produce different lines of various colors. Use different colors to produce the colors of a rainbow. Dip all four fingers into the colors and spread the fingers and place them on the paper. By pulling all the fingers towards the center the petals of a flower will form.

- Dripping Color: Dilute the colors and drip them onto a piece of paper. Move the paper from left to right and front to back so that the color will spread to several directions. Use several colors to produce a batik design.

- Squeezing color: Use a closed plastic bottle, punch some holes in the plastic. Put in the color into the bottle and then squeeze color onto the paper.

- Coloring on black or brown paper: Use white on a black or brown paper to produce an attractive result. 
- Pasting with Colored Paper: Paste on a piece of paper several cuttings from colored paper, drawing paper that has been colored, or use pictures from old magazines and calendars. Draw some simple shapes such as a circle, square, a flower, a house etc. on the paper. Cut out the shape. Use glue to stick the shapes on a piece of drawing paper. These can be decorated further or placed on backing paper to make an attractive border.

\section{Working with Things from the Enviromment}

There are many natural things such as wood, walnut shells, stones, seeds from fruits and others. Items from nature can be carefully studied before drawing, for example, plants, leaves and so on. Leaves and flowers can be pressed and dried and the children can put these things into their own book of "Leaves and Flowers". Printmaking can be done with a variety of things from nature: potatoes, leaves, lady's fingers, or from the children themselves: hands, palms, fingers, foot prints.

\section{-Using Stories as a Starting Point for Art Activities}

Story time can be a good starting point for many art activities. Children can illustrate a scene from a story they have just heard. The teacher can introduce children to characters and heros from literature and folk tales and art activities can be created around these.

From Malaysian Course of Childhood Development and Childrare, and

From the Afghanistan Pre-school Curriculum

\section{Connecting Art with other areas of the Curriculum}

Just as story-telling can be used as a starting point for art activities, art and craft can be used to complement other areas of the kodakistan curriculum. For the dramatic play comer, items to play "House" can be made during art: food items can be made from clay or paper mache', just as cups and plates can. These can then be painted to make them more attractive. Empty biscuit boxes, crisp bags and so on, can be stuffed with newspaper and sealed with adhesive tape. Other scrap materials can be used as well - for other areas of the kodakistan. Have the children be directly involved in planning and making a display. They can make kites for physical elucation or other PE equipment, and of course musical instruments for music and picture books for the book corner or story-telling. There are numerous possibilities. With careful planning the children can be an integral part of creating things for the kodakistan and making it a learning process. 


\section{Material Name: Non-spill Paint Container}

What you Need: Empty plastic bottle (750 $\mathrm{ml}$ - water bottle), scissors or a sharp knife

\section{How to Make It:}

1. Cut the bottle one-third of the way from the top.

2. Push the top section up-side down into the bottom section of the bottle.

Material Name: Paint Holder

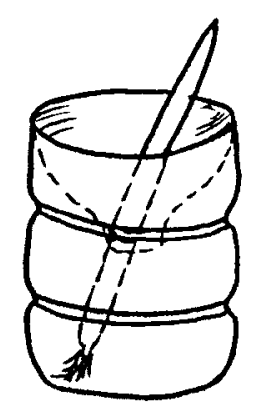

What you Need: Soap-powder (detergent) box, 3 small yoghurt cups (or similar small plastic cups), pencil, scissors or cutting knife, enamel paint and paintbrush

\section{How to Make It:}

1. Place the containers upside down on the box and trace a line around their opening onto the box.

2. Cut along the traced line.

3. Paint the box with enamel paint.

4. Once the box is dry, place the containers in the holes.

Material Name: Peg Paintbrush

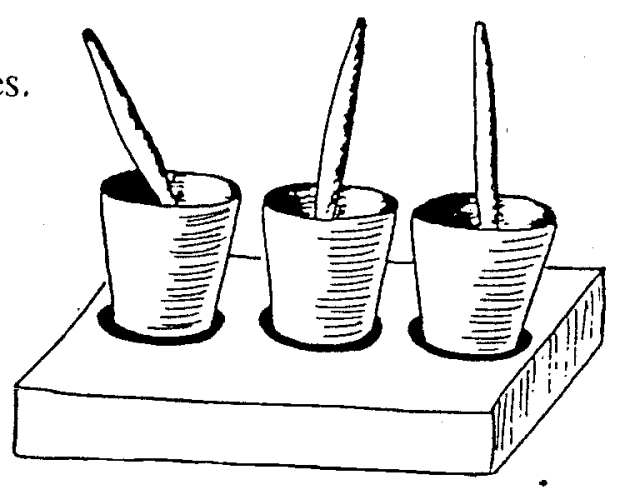

What you Need: Clothespin with a spring clasp (peg), pieces of sponge

How to Make It: Open the peg and place the sponge inside 
Material Name: Crayon Tins

What Children Learn: While this serves as storage containers for crayons, children also learn to match the crayons to the tins according to color.

What you Need: A tin for each color crayon, enamel paint and paintbrush

How to Make It:

1. Paint each tin a different color so that there is a tin for each color crayon.

2. Stock the crayons in the tins according to their colors.

Activity Name: Plastic Bag Apron

What you Need: A plastic shopping bag, scissors

How to Make It:

1. Cut the bottom end of the bag and open it out.

2. Adjust the size of the apron by tying knots in the handles.
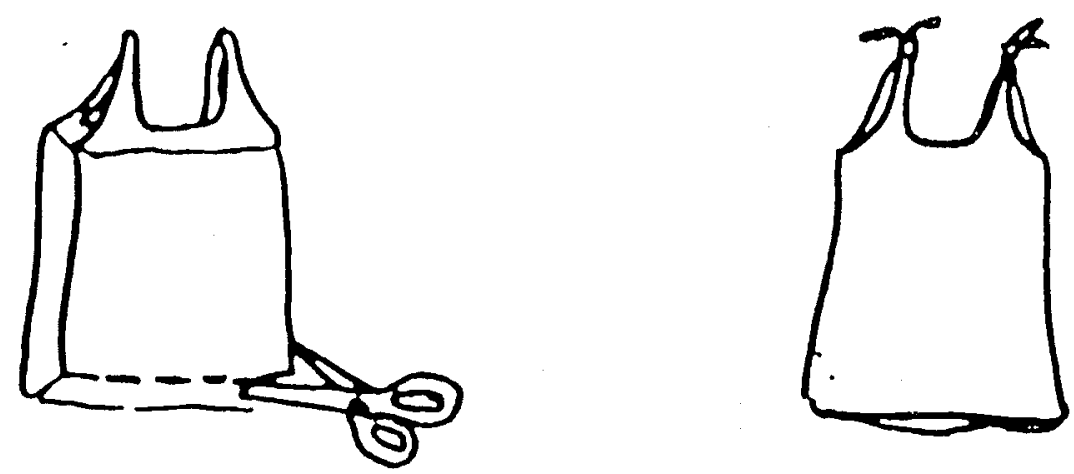

There ideas comes from Le'arning with Scrap 
Part V: Suggested Games, Activities and Learning Materials

\section{Physical Education Sand and Waterplay}




\section{Physical Education Activities}

The following pages include just a few suggested activities for Physical Education lessons. Much of the information serves to spark your own ideas, based on equipment, various movements and suggestions made below. To develop your own activities it is important to review the parts of a PE lesson and the elements that should be included:

A Physical Education lesson consists of the following parts:

- Warm-up: to loosen up muscles and get children ready for the activity.

- Game/Main activities

- Cool down: to calm children, let them cool off and relax before going back to class.

The teacher must incorporate the following important elements into the lesson:

- Participation

- Variety

- Creativity, Imagination

- Fun

- Skill Development

Some simple ideas for activities, warm-up or cooling down...

- Making ourselves small, big or tall; making lines or standing in a line; making circles or standing in a circle; making semi-circles or standing in a semi-circle.

- Walking in a line; walking in a circle; walking forwards and backwards; rolling forwards and backwards.

- Skipping in a line; skipping in a circle; skipping freely around.

- Jumping on the spot; jumping forwards and backwards; jumping on one foot.

- Running on the spot; running forward and everywhere; running in a line or a circle.

- Swinging; sliding; climbing; balancing on a log or bencl.

- Throwing and catching a ball or bean bag; bouncing and kicking a ball; skipping or jumping over a rope.

- Crawling under a bench or tunnel or between objects; crawl under chair or rope; to head the ball or other soft object.

- Walk or run swinging body to music and stop when music stops; to shake/turn head to left and right according to music.

- Dribble ball around bowling pins or sticks.

\section{Imitation Games:}

- Jump like a rabbit, frog; gallop like a horse etc.

- Flap hands and pretend to fly like a bird or move the body by gliding like a snake

- Imitate other animal movements: walk like a worm, stretch like cat, and so on. 


\section{Physical Education Activities}

\section{Physical Movements}

Ask the children to do different things which emphasize different parts of the body. These can include:

- Using the legs, when running, walking, skipping, jumping.

- Moving around the ball without using legs.

- Throwing and retrieving such small apparatus as balls and bags.

- Carrying a small apparatus without use of hands.

- Pushing small apparatus without using hands or feet.

- Moving parts of the body by: swinging, rocking, stretching, lifting, pulling, bending, pushing, twisting, kicking, digging or bouncing.

- Moving from place to place by hopping, galloping, sliding, rolling.

From Science 5-7

\section{Follow the Leader}

Teacher can lead a game of 'Follow the Leader' to music using every part of the body in turn. First the head: nod, shake, tilt, from side to side; roll clockwise and counter clockwise. Then the eyes: blink, wink, stare, etc.; then the shoulders, elbows, hands, fingers, hips, legs, knees, feet and toes.

\section{Action Songs}

Using music along with physical education lèssons is very effective. Collect action songs to use with the children or create some of your own.

\section{Movement Games}

Brainstorm movement games you played as a child and try them on the children. Ask others to contribute their ideas as well. Some ideas for games include:

- Play "Statues". The children run around and the teacher or another designated caller shouts "Statues!" They must freeze in place and hold their pose until the caller instructs them to run around again.

- Play "Musical Chairs". Set up a row of chairs, one less than the number of children playing. The chairs should alternate the direction they face. While the music is playing children walk around the chairs. When the music stops everyone must find a seat. The child who does not find a chair is out. One more chair is removed and the game continues until there is only one chair and one child left. If you do not have music, you can sing a song, clap a beat, or play an instrument.

- Play "Tag". One child is 'it'. The child who is it must run around and tag someone. The person who is tagged then become it.

- Play "Simon Says". The leader gives directions which children have to follow, e.g. "Simon says, Hop on one foot," or "Simon says, Scratch your knee." When the words "Simon says" are omitted, children must continue to perform the previous action. Those who perform the new action, when "Simon Says" is omitted are out. Continue until one child remains and is the winner. 


\section{Physical Education Activities}

- Relay races are always a good activity for a PE lesson. Form teams and children take turns doing a specific task. For example, each team member must balance a bean bag on their head to a chalk line marked on the ground. When one child accomplishes the task, she runs back to the next person on the team and hands them the bean bag. Then the next child takes their turn. This continues until all members on one team finish and they are the winners.

- Children race each other taking off one shoe and stocking and putting it back on.

\section{Physical Education Equipment}

- Suggested Outdoor Equipment: swings, see-saw, slide, big pipe for crawling, old tires which are hung for climbing and swinging, or arranged one next to each other for crawling through and climbing over, frame for climbing, logs which are cut up, stools, mobile toys with wheels such as bicycles and cars, punching bags, rubber plastic balls of various sizes, wooden horse, rattan hoops, mats, balance beam, jump ropes and so on.

- Equipment is Used For..

Climbing - ladders, ropes, trees, slides, tunnels, wooden barrels, balancing board, Jumping and skipping - ropes, hoops, tires and other small apparatus

Throwing and catching - balls and bean bags

Pounding - punch bags

Pushing and pulling - wagons, cars, tricycles and tires

Crawling - tunnels, tires, hoops

Rolling - balls, self on mats, sideways, backwards etc.

Kicking/Bouncing - balls

Hitting - ball with a stick

Balancing - balance beam or wooden board, bean bags on head while walking

Control - walking along a chalk line

- Sand box/Sandplay: children are able to scoop and shovel, build castles, roads, tunnels etc. Provide them with toys cars, small pails, plastic shovel, cuips and so on. Children can learn many concepts from sand in addition to pursuing a physical activity, such as weight, volume, different textures, use of a variety of containers and creation of shapes. Children also use language when playing with sand.

- Waterplay: Prepare a basin of water. Encourage the children to play with water in the following manner: hit the water in the basin, scoop the water and pour it into another container, play with water and sand together. If affordable, prepare a small children's pool so that they can swim. While playing with water the teacher must supervise the children with caution. As with sandplay many concepts are learned such as, weight, floating, sinking, bubbles, volume etc.

Remember Safety with all PE Activities: The area must be large enough to move and run; all equipment must be stable and strong; provide a safe surface such as a turf area for the climbing frame to ensure the children's safety; keep equipment well maintained; the playing area must always be safe and the children always supervised. 
Physical Education Activities

Activity Name: Tire Swing

Age Group: 2 - 6 year old

What you Need: An old motor car tire, strong rope, a sharp knife, a piece of chalk

How to Make It:

1. Draw a line as indicated in the picture on both sides of the tire.

2. Use a sharp knife to cut along the line drawn.

3. After cutting, turn the tire inside out.

4. Make a small hole in the seat so that rain water will run out.

5. Tie rope to the handles of the swing and hang it on a strong branch of a tree.

Variations: You can make a bouncing swing by using bicycle inner tubing instead of rope to attach the tire to the tree. A tire swing can also be made by hanging a sturdy rope from a tree and tying a tire to the end of the rope.

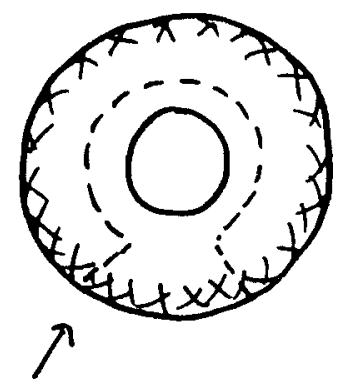

cut

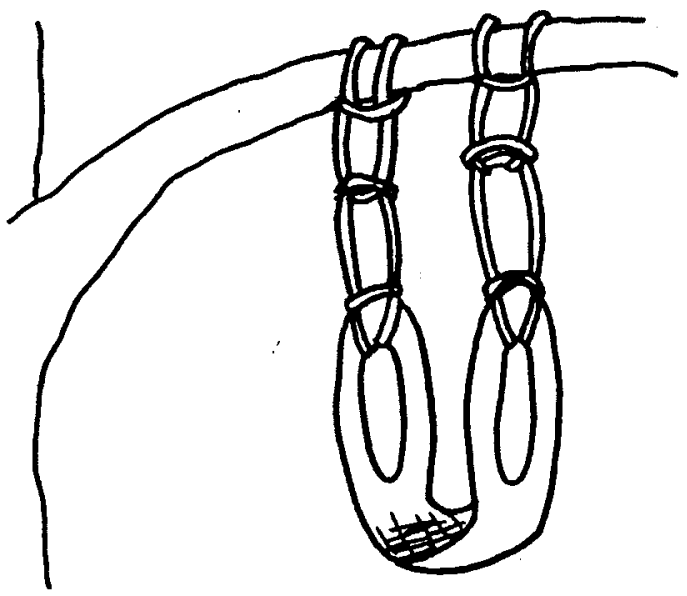

Activity Name: Tire Tunnel

What you Need: 3 or more old tires

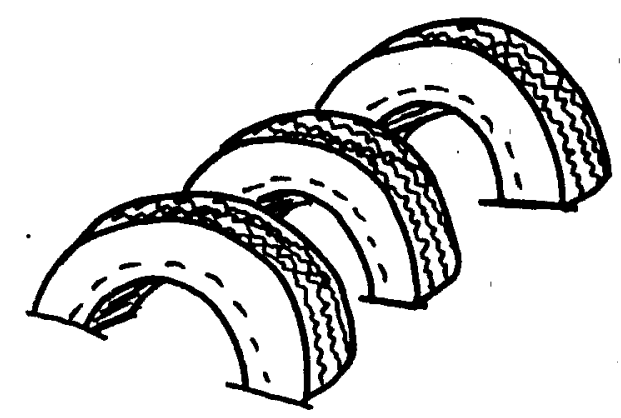

How to Make It: Stand large tires upright and bury them in the ground up to the middle of the hole. Children can crawl through the tunnel.

These ideas come fiom Leaming with Scrap 
Physical Education Activities

Activity Name: Tin Can Stilts

Age Group: 4 - 6 year old

How Children Play: The child stands on the tins and holds a string in each hand. By pulling up on one string at a time; the child can walk with the stilts.

What Children Learn: Children develop their large muscle skills. Children practice their balancing skills.

What you Need: 2 tins of the same height, a large nail, hammer, scissors, thick string; enamel paint and paint brush

\section{How to Make It:}

1. Paint the tins with enamel paints.

2. Using the hammer and nail, make 2 holes opposite one another on each tin. (Make sure that the outside of the tin hole is not sharp.)

3. Cut 2 pieces of string $-200 \mathrm{~cm}$ long for $5-6$ year old, and $180 \mathrm{~cm}$ long for 4 year old.

4. Push one end of each string through the holes of the tins toward the inside, and then pull it through the second hole toward the outside.

5. Tie the two loose ends tightly together.

This idea comes from Learning with Scrap

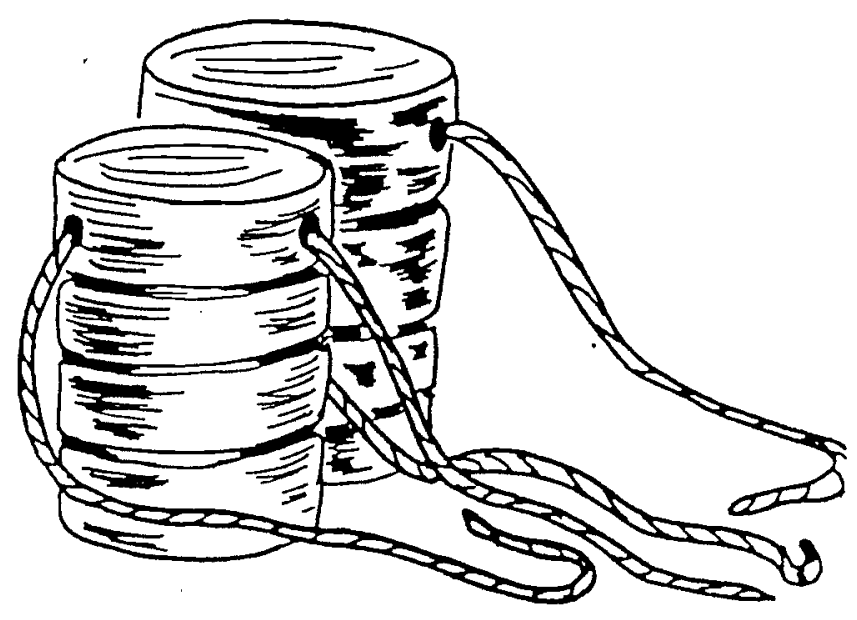


Physical Education Activities

Activity Name: Wastepaper Basket and Balls

Age Group: 4 - 6 year old

How Children Play: Child stands about 3 meters from a basket, \& tries to throw a ball in.

What Children Learn: Children practice their large muscle skills and develop their handeye coordination.

What you Need: Wastepaper basket, bucket/sturdy box, 5 tennis balls, or other small balls

Variations: Bean bags can be used also. Younger children can stand much closer to the basket. Make a line of 3 or more baskets in a row and have the child stand directly in front of the first basket. First he throws the ball into the first basket. If he is successful he tries the next, and so on. This gives him practice while increasing the difficulty of the task.

Activity Name: Bowling (Skittles)

Age Group: 3 - 6 year old

How Children Play: The bottles (bowling pins) are set up in the following way:

The child stands about 3 meters in front of the bottles and rolls the ball towards them, trying to knock them down.

What Children Learn: Children develop their large and small muscles skills and practice their hand-eye coordination. Children practice their number skills when counting how many bottles (bowling pins) have been knocked down.

What you Need: 6 bottles of the same size and their lids, enamel paint and paintbrush strong glue, tennis ball, sand

\section{How to Make It:}

1. Fill the bottles with sand.

2. Glue the lids on.

3. Paint the bottles with enamel paint.

Variations: One to six dots can be painted on each bottle to teach the children numbers. 
Physical Edlucation Activities

Activity Name: Number Rhythms

Age Group: 2 to 6 year old

How Children Play: This activity can be done individually with one child, or with a group of children outside. Explain that you will call out a number and that the children will respond with some special movements - clap, stamp, tap their head, jump up and down - the number of movements should equal the number called out. For example, if the teacher calls out the number ' 3 ' and demonstrates a movement, like stamping your foot, the children can stamp their feet three times, counting together aloud. Keep the actions simple, and let one of the children be the 'caller' - or let a pair of children do it - one can call the number, the other can select the movement. This is a good activity for outdoors, standing in a circle, or indoors if space allows. It touches on both the Mathematics and Physical Education Curriculum.

What Children Learn: To introduce the idea of counting the number of times a specific movement is performed. The activity requires physical control.

What you Need: A large space, depending on the size of the group of children.

From Ready for Maths

Age: $2-3$ years

Capability: To jump and climb.

Objective: To increase her ability to climb so that she is able to be involved in various games that require this skill. To strengthen the leg muscles and do long jumps.

Material: Large boxes and hoops

Method: Place the box in a spacious area. Place the hoop in front of the box. Teach the child how to climb and jump into the hoop. Praise her when she succeeds.

Note: Ensure that the box is not dented or fails when climbed on. Be prepared to avoid any injuries if the child falls. 


\section{Physical Education Activities}

Age: $3-4$ years

Capability: Jump on one foot.

Objective: Strengthen the leg muscles and to balance the body.

Material: A long rope

Method: Shape a figure 8 with a rope. Ask the child to jump from one circle to another.

Note: Ensure that there is nothing in fiont of the circle.

Age: $3-4$ years

Capability: Able to kick a ball.

Objective: Able to kick a ball to the desired direction and with the strength desired.

Material: Ball, small flag as a marker

Method: Go to an open space outdoors with the children. Ask the children to form a line. Place a ball in front of the first child and tell the others to wait. Place the flag at a distance from the ball. Tell the first child to try to kick the ball towards the flag. After kicking the ball, the first child will move aside to give the others a chance.

Note: Avoid shaming the child if he is unable to kick the ball in the desired direction, instead encourage him and find something to praise each child for.

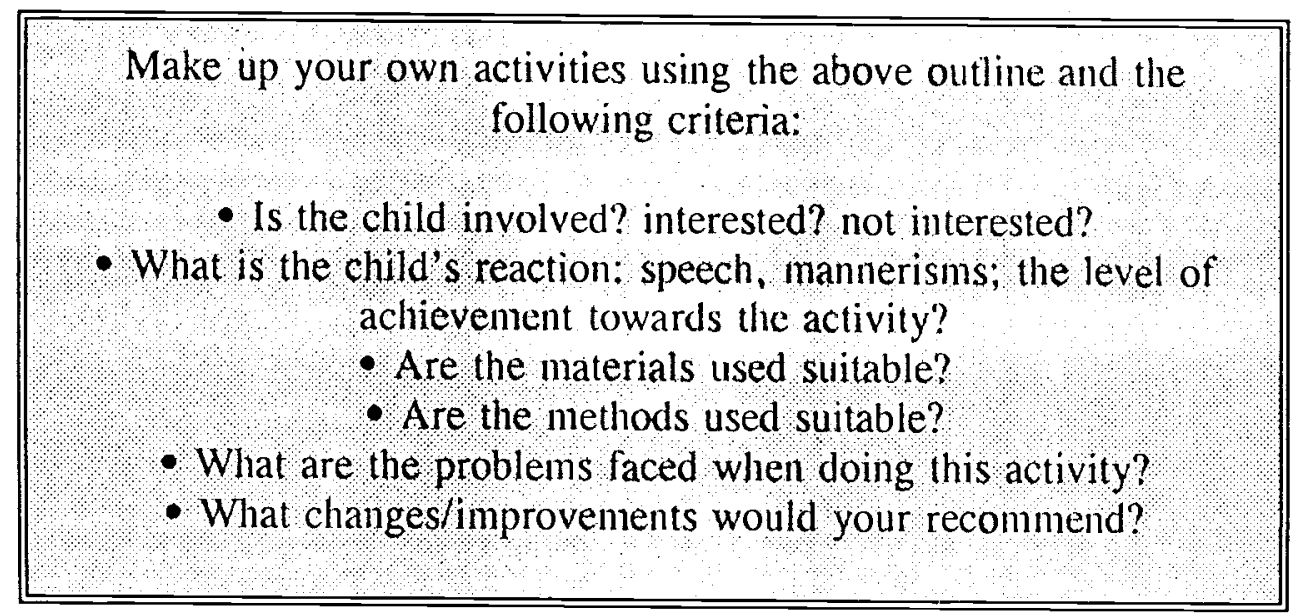

From Malaysian Course of Childhood Development and Childare 
Activity Name: Funnel (for Sand and Waterplay)

What you Need: A plastic bottle (for example, an oil or shampoo bottle), sharp knife

\section{How to Make It:}

1. Cut the bottle in half.

2. The top half is the funnel. Save the bottom half to use as a container.

Activity Name: Bottle with Holes (for Waterplay)

What you Need: A plastic bottle, nail, candle

How to Make It:

1. Heat the nail over the candle flame.

2. Make holes in the plastic bottle, using the nail (keep reheating the nail as necessary.)

Variations: Think of different places to punch holes in the bottles. Also, holes can differ in sizes. Plastic cups are ideal for this as well, as they have the added benefit of having a handle.

Activity Name: Sieve (for Sandplay)

What you Need: Plastic container (e.g., liter sized ice cream container), thick nail, candle

\section{How to Make It:}

1. Heat the nail over the candle flame.

2. Make holes in the bottom of the container using the nail.

Activity Name: Tins (for Sand and Waterplay)

What you Need: Tins of different sizes, enamel paint and paintbrush, tin-opener

\section{How to Make It:}

1. Remove any sharp edges from the tins with a tin-opener.

2. Paint the tins with bright enamel paint.

These ideas come from Learming with Scrap 
Materials for Sand and Water Play

Activity Name: Boat (for Waterplay)

Age Group: All ages

What you Need: Plastic bottle with lid, stiff paper, a stick, scissors

\section{How to Make It:}

1. Cut a hole in the bottom end of the bottle (through one side only).

2. Cut a triangle out of the paper for the sail.

3. Cut slits in the sail so you can insert the stick.

4. Cut a hole in the top half of the bottle just big enough for the stick. Place the stick with the sail in the hole.

Variations: Boats can be made out of many other things such as wood or sea shells. Think of other ways to make boats for waterplay.

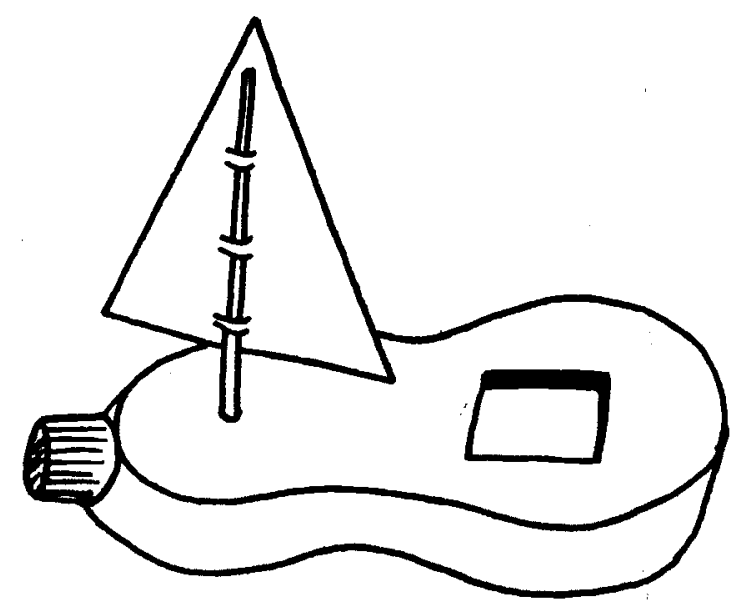

Activity Name: Scoop (for Sandplay)

What you Need: A large strong plastic bottle, a sharp knife, pencil

\section{How to Make It:}

1. Outline the scoop on the bottle.

2. Cut out along the drawn line.

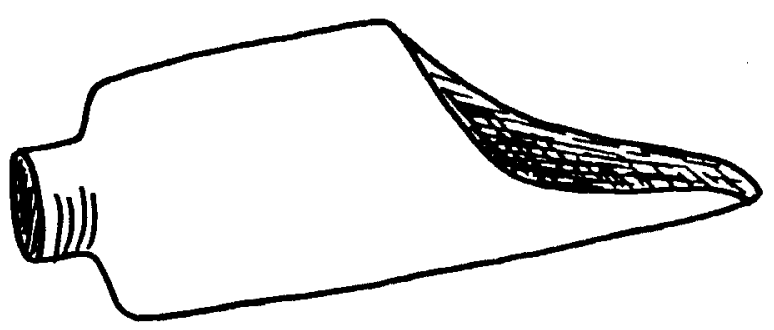

These ideas come from Learning with Scrap 
Part V: Suggested Games, Activities and Learning Materials

\section{Music Making Musical Instruments}




\section{Music Activities}

- Children stand in a circle. They step to the left and the right in time with a rhyme. (Make one up based on numbers). Make it progressively more complicated.

- Play a tape of different sounds. Children guess what they think they are.

- Body sounds: children experiment making different noises with their hands, faces, legs etć. - clicking fingers, clapping hands, patting knees, stamping feet, and so on.

- Play a game in a circle where each repeats all the previous sounds, then makes a new one. (Like "I went to market and I bought...")

- Teacher claps simple rhythms to children and they clap back. Clap progressively more complex rhythms. Allow children to have turns being the leader.

- Give each child a stick. They follow the teacher in banging the floor in $4 / 4$ time, then when they are good at it, half the group bangs in $3 / 4$ time.

- Stand in a circle and the teacher does alternating repetitive action, such as, tapping head 4 times, then face 4 times. Children join in. Make the sequence progressively harder.

- Discriminating high and low pitch: use milk bottles filled with water to different heights. You hit two of them and the children have to say which is higher or lower. Let children also test each other and play with the materials.

- Play different kinds of music. This is a good experience for children and extends their experience - classical, traditional, folk, modern etc.

- Children can develop a sense of underlying pulse in music by listening to records with a consistent pulsation, catchy melody and good instrumentation: folk songs, pop music, nursery rhymes, marches and waltzes.

- Play music for the children and discuss it with them. How cloes it make you feel? Let's see you move to the music.

- All children, or a small group, has instruments. Establish rules when children can play and not play, for example, they all stop when the leader puts their hand in the air.

- Put the bangers, shakers, and others in different groups. Get them to play rhythms back to you all together. When they do this well, get each group to play different rhythms.

- All the children have an instrument and they should move like their own instrument. Shakers, then bangers, then others, then all together.

- Sing songs using the instruments as percussion. Use them in different ways, for example, one time have all the shakers, another time all the bangers.

- Sometimes use the instruments in class singing time. One group can play the instruments, another group can sing, the third can move to the sound.

- Make instruments with small groups. Let them do as much as possible.

- Tell a short story with sound effects, or make up a poem with sound effects. You can do this as a whole group with the children making the sounds, or the teacher can make all the sounds. Use anything you want to make the sounds.

- Have a Sound Corner in the classroom with instruments the children can play with. This can be one of the activity areas that you rotate.

- Do simple mimes to the beat of the music such as cooking, gardening, sport etc.

- Imitate animal movements along with the sound of the music - all be mice (light sounds), all be elephants (heavy sounds), be an old man without music, and then with. 


\section{Music Activities}

- Ask the children to listen to the sounds made by some of the following things you have collected: stones, palms, leaves for rustling, wood and sticks to rub and bang together, dried reeds, newspapers to crumple, different types of grains and cereals to shake; various stalks to blow through, empty containers to tap.

Encourage them to describe the sounds they hear and what they think about them. For example, are the sounds hard or soft, sharp or dull, high or low, happy or sad, pleasant or unpleasant, loud or soft, long or short?

- Give the class a variety of home-made instruments. Suggest some words to them, one at a time, e.g. rain, wind, car, sweeping, etc. and ask them to decide which instrument best represents that word.

- Ask the children to listen carefully for about thirty seconds to the sound around them. Then invite them to tell you about what they heard, to describe the sound and how they felt about it. Make a chart on the blackboard or wall headed 'classroom sounds' and list the sounds. You could repeat this activity after taking the children out for a 'listening walk.'

- Ask the children to tell you different types of sounds they hear at home or elsewhere.

Some Questions to Ask:

- What sound did you wake to this morning?

- How did it make you feel?

- What sounds do you hear on the way to school?

- Which sounds do you like the most?

They can record this on paper - in words or pictures - and make a class book 'What I heard this morning'.

- Clap four steady beats loudly, followed by four steady beats softly. Ask the class to repeat the rhythm. Do the same thing, changing to tapping, knee slapping, etc. Ask the children to pick out the loud and soft sounds. Then ask them to name objects or animals which make a loud noise and those which make a quiet/soft noise. Make a chart of their suggestions and put it on the wall.

- Teach the children traditional songs or songs sung on special occasions using instruments you have made in class.

- Let the children show you musical games they play, e.g. skipping songs, ring games, clapping songs. Ask them to suggest sound accompaniments. 


\section{Music Activities}

- Musical Conversation: Clap a rhythm or sing a few notes and ask a child to repeat it. Repeat the activity with several other children. Then ask the class to take turns to do the same activity in pairs. Let the children clap their own names, one clap for each syllable. Ask children in the class to take turns clapping the syllables of the name of the town, area or province they come from. For older children, they can try to guess the name.

- Make some shaker instruments with the children, using tins, boxes or hollow containers. Fill them with bottle tops, grains, seeds, stones, sand or cereals. Now first shake one instrument, then another, and ask the children which sound is higher or lower, louder or softer etc. Use all the other instruments in turn. Work with the class to make rhythms using the instruments you have made.

See section on making musical instruments for more ideas.

- Ask the class to walk (clap, tap, nod their heads) with a steady rhythm. Then ask them to find out how they can take two quick steps (or clap, tap, etc.) to each ordinary step. You may illustrate this with the idea of a mother going to market with her three year old child. As the mother takes one stride, the child will need to take two short strides to keep up with her.

- Types of sounds we hear: Bring a tape of sounds or, if you do not have a tape, imitate the sounds of people, animals, instruments and movements.

- Listening to simple music: Play or sing simple songs, or get a group of children from the class, the school or community to perform.

Some Questions to Ask:

- Did you recognize the song?

- What was the name of the song?

- What did you hear?

- What did you like about the song?

- Which instruments were playing?

- Where do you think the song came from?

- What is it used for?

- Was it fast or slow?

- Was the sound loud or quiet?

- Was it a happy song or a sad song?

- How did it make you feel?

From Primary Ideas: A Resource Book for Primary Teachers

- Use music and movement lesson times to develop body awareness by asking the children to make different shapes with their bodies, for example: spiky, rounded, tall and thin, short and squat. Use suitable music to create a good atmosphere. 
Music Activities

\section{Singing}

- Singing includes nursery rhymes, finger plays, poems, actions and dramatizations. The more songs they sing, the more new words they learn and develop their oral skills. The rhythmic movements help children to develop physically and helps them acquire control of their body. Singing traditional and national songs also helps them gain an appreciation for Afghan culture.

\section{From the Islamic Pre-school Curriculum}

- Sing musical notes in ascending or descending order (do ray me..); sing musical notes (la la la or do do do etc.) while the teacher plays a musical instrument or tape. Dramatize while others are singing, or play a percussion instrument while others are singing.

- Suitable songs for children are happy songs with short repeated verses, simple melodies and clear rhythms. Children like songs about: colors, flowers, animals, numbers, the family, people, and other things they are familiar with. Songs can include both those we teach children and those that children make up themselves. Traditional songs are an important part of cultural heritage, as well as modern songs for pre-school children.

- One way to sing along with the children is to group the children in a circle. Explain the song to the children using pictures or drawings. The teacher can sing the whole song while the children listen. Then sing the first line and let the children follow. Continue in this way until the end of the song. Sing the whole song with the children once or twice and then let the children sing the song on their own.

- To help children enjoy singing more, let them act out the verses as they sing along. Do not force the child to sing when he or she doesn't want to. Do not force the child to memorize the verses.

\section{From Malaysian Course on Childhood Devolopment and Childare}

- Visitors: Ask older members of the community, especially those who grew up in rural areas, to teach children traditional songs.

- Action Songs: Sometimes children move their bodies in different ways while singing as they act out the words. These are action songs and they help children develop body awareness and large muscle coordination. When children use actions with words, they are developing their understanding of how to use signs and symbols, which helps them to prepare for reading and writing. 


\section{Music Activities}

- Moving to instrumental music: Children move to the beat of a drum, tambourine, rhythm sticks, music played on a record or tape:

Sometimes we can direct children's movements, For example:

Listen to the music or beat. Can you move on your tip toes as the music tells you? Now can you take giant steps?

We can encourage children to move in different ways:

March, walk, jump, skip, gallop, sway, run and trot to the thythm or beat of the music.

Other times we can ask them to move freely any way they wish.

Or, we can ask them to dramatize something:

Can you be a very small seed (soft music), and then grow and grow to become a very big flower (as the music gets louder)? Can you grow taller and raller?

Can you walk like a (name any animal); can you rock a baby to sleep; move like grass in the wind?

Encouraging children to pretend and move freely helps them to be creative.

- Listening Games: Help develop listening skills through a variety of activities.

- Have children identify sounds and/or musical instruments.

- Blind-fold the child and have them follow the teachers' voice around the room. Remember to consider safety issues if the child is blind-folded. Assure the activity is conducted in an open space where the child can not hurt themselves, and of course monitor their movements carefully.

- Make sounds from the enviromment from behind a screen, so that children can not see the source of the sound but must identify it. For example, leaves rustling, rocks banged together and so on. Record this session if possible and it can be used for other activities later.

- Play telephone.

- Fill different glasses with water and arrange in order from high to low, or low to high sounds.

- Make a paper megaphone and have the children use it and identify when the voice is louder and quieter.

From Learning Together 
Activity Name: Rhythm Sticks

Age Group: 2 to 6 years old

How Children Play: The child holds one stick against his hand and taps it with the other.

What Children Learn: Children practice their listening and rhythm skills. Children practice their muscle skills and develop hand-eye coordination.

What you Need: Pieces of round wooden sticks $(12 \mathrm{~mm}, 15 \mathrm{~mm}$ or $18 \mathrm{~mm}$ thick), sandpaper, saw

\section{How to Make It:}

1. Saw off 2 lengths of the wooden sticks, each $30 \mathrm{cms}$.

2. Round off the ends with sandpaper.

3. Hold one stick against a slightly closed hand and tap it with the other stick.

Variations: Drumstick: make as for rhythm sticks. Then on one end attach a ball of foam rubber covered with nylon stocking material. Fasten it with string.

Activity Name: Bongo Drums

Age Group: 2 to 6 year old

How Children Play: The child beats on the drum freely, or to singing or other musical instruments.

What Children Learn: Children practice their rhythm and listening skills. Children practice their muscle skills and develop hand-eye coordination.

What you Need: Large coffee can (or tin of comparable size), old inner tube, string, enamel paint and paintbrush, scissors, wooden spoon or rhythm sticks or drumstick from above

\section{How to Make It:}

1. Paint the can.

2. Cut a circle out of the inner tube so that it is slightly larger than the rim of the can.

3. Place the circle of tubing over the open end of the can. Fasten firmly to the can with string.

4. Make sure that the wooden spoon or drumstick is smooth and without splinters. 
Activity Name: Bottle-top Rattle

Age Group: 2 to 6 year old

How Children Play: The child holds the rattle and shakes it freely, or to singing or other musical instruments.

What Children Learn: Children practice their rhythm and listening skills. Children practice their muscle skills and develop their hand-eye coordination.

What you Need: 12 cold drink bottle tops, coat hanger wire, a thick nail, hammer, pliers, enamel paint and paintbrush

\section{How to Make It:}

1. Remove paper from the bottle tops. Pierce holes through the centers with the nail and hammer.

2. Paint the bottle tops with enamel paint.

3. Cut the wire to thread the bottle tops onto the wire.

4. Using the pliers, twist the two ends of the wire around each other. Make sure there are no sharp ends.

Activity Name: Cymbals

Age Group: 3 to 6 year old

How Children Play: The child holds one cymbal in each hand and clashes the cymbals together.

What Children Learn: Children practice their large muscle skills and develop their eyehand coordination.

What you Need: 2 large tin lids, 2 small wooden blocks (for handles on the lids), strong glue and brush, enamel paint and paintbrush

\section{How to Make It:}

1. Paint the tin lids with enamel paint.

2. Glue a wooden block to the outside of each lid.

Variations: Screw or glue wooden handles onto blocks; saucepan lids of the same size may be used. 
Music Activities: Making Instruments

Activity Name: Clappers

Age Group: 2 to 6 year old

How Children Play: The child shakes the clapper freely, or to singing or other musical instruments.

What Children Learn: Children practice their rhythm and listening skills. Children practice their muscle skills and develop their hand-eye coordination.

What you Need: Scraps of wood, string, hammer and nail to make holes (or a drill), sandpaper, saw, pencil and ruler, paint and paintbrush

\section{How to Make It:}

1. Measure and draw these three shapes onto the wood. Cut them out with a saw.

2. Sandpaper the wood so there are no splinters.

3. Drill two holes through each piece of wood as pictured, make sure that each hole is in the same place on each piece.

4. Paint each piece of wood with enamel paint.

5. Attach pieces $A$ and $C$ loosely together to either side of $B$ with string.

This idea comes from Learning with Scrap
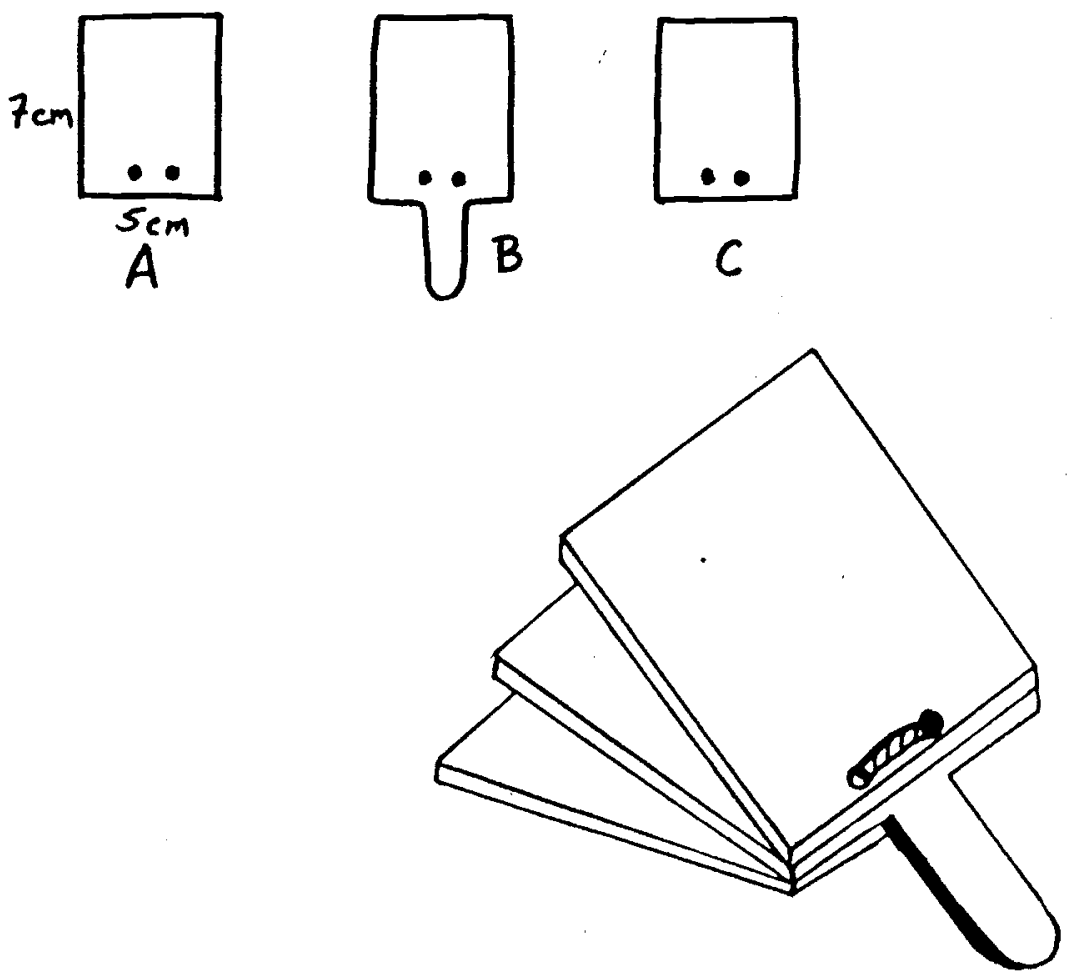
Music Activities: Making Instruments

Ideas for Making Musical Instruments

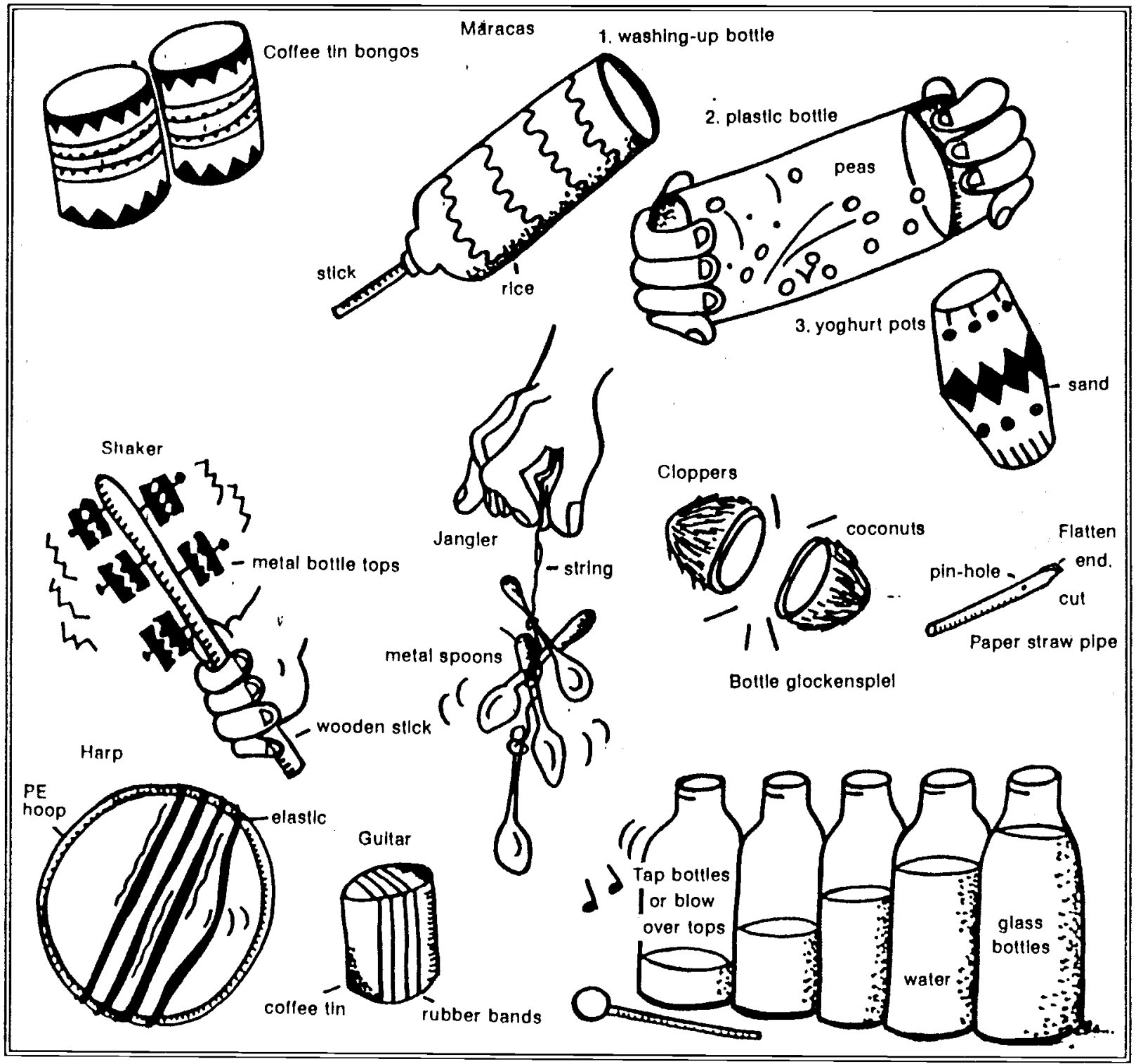

Frem Science 5-7 
- Rhythm or Percussion Instruments: these produce sound by striking, shaking or hitting:

- dried fruits and seed pods from certain trees, and other wild fruits

- sticks struck together

- gourds filled with dried seeds

- small tins with small stones, beads or seeds inside

- a wire bent in a circle with bottle caps strung on it

- clappers made out of the halves of coconut shells struck together

- tambourines made of tins and rubber tubes.

- drums made of barrels, tins, etc.

- jingles made of bottle caps or old shoe polish tins

- water bottles tuned to different pitches by filling them with water to various levels

- rhythm sticks struck together.

- Simple Wind Instruments: these produce sound when air is blown into them:

- palm leaves

- maize (sweet corn) stalks

- bamboo stalks (or other hollow reeds)

- rice stalks

- small coconut shells or scooped unripe guavas

- Let the class experiment with waste materials - for example - tins, plastic lids, empty matchboxes, newspaper and so on - to make their own instruments.

From Primary Idests: A Resource Book for Primary Teachers

\section{Ilanging Xylophones}

You can use many ordinary everyday objects to make musical instruments. Try some of these: Use a wire coat hanger and hang up cardboard cylinders (toilet roll, silver foil roll etc.) of different lengths. A collection of different plastic containers. Different metal objects. Tap all of these with either a wooden or metal spoon and listen to the sounds.

Ladybird Leaming at Home Series

More ideas for Musical Instruments from Available Materials

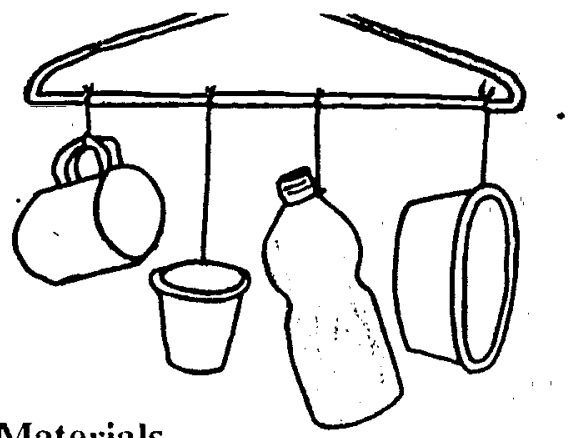

Make shakers: Put dried beans, lentils, peas, macaroni, salt or buttons into an empty container (tins, matcliboxes, plastic bottles, paper bag tied to a stick) and seal the lid tightly. Drumls: A saucepan, a cake tin, tin with a plastic lid, a biscuit tin, plastic bucket or bowls, plastic trays - all make good drums when hit with a wooden or metal spoon.

Scrapers: Stick sandpaper onto two boxes and rub together. Corrugated paper works well too. Cut some notches in a piece of wood and scrape a pencil or ruler along side of it. 
Part V: Suggested Games, Activities and Learning Materials

\section{Science}




\section{Science Activities}

Below are briefly stated science activities and themes to spark ideas and help you think of activities that you want to do in the kodakistan. Some of the themes and activities are further developed in this section. Before looking at the suggested activities that follow these lists, review the lists to help you develop your own ideas of how to teach science concepts. Imagine that these ideas are the start of brainstorming lists put together by preschool teachers: -what would you like to add? -develop? -change? -delete?

Be creative and have fun!

\section{ACTIVITY IdeaS}

- keep pets, look after an aquarium and do gardening

- visit the zoo, botanical gardens, padi fields and other places

- explore the environment to collect things which are found there, describe these things, make records (drawing and keeping them in albums), or just displaying them in the appropriate learning corners

- hold, feel and smell materials of different textures

- trace surfaces of different textures

- taste and differentiate various kinds of foodstuffs, drinks and fruits

- play games of naming objects, animals and plants found in the environment

- play the guessing game "Who am I?" or "What am I" using one of the senses

- play with water to find out:

some objects float, while others sink; some dissolve in water and others cannot; some absorb water and others cannot; water can be mixed with colors and so on

- play with sand to find out:

that sand can be used to build certain shapes; sand has certain characteristics such as wet, dry, fine, coarse and so on

- visit places such as the market, the fire brigade, police station, a health clinic or hospital to learn about people's work 


\section{SCIENCE THEMES}

- The Variety of Life: living and non-living things, looking at the variety of life and the variety of people

- Processes of Life: identifying parts of the human body, using the body, plants

- Genetics and Evolution: differences in people, faces and variety of human skills

- Human Influences on Earth: waste in the environment - what are waste products and how are they produced?

- Types and Uses of Materials: looking at shape, looking at color, looking at texture

- Earth and Atmosphere: weather - different kinds of weather, changes in weather, recording changes

- Forces: body power, air power, water power

- Electricity and Magnetism: what is electricity - using and mis-using electricity

- Energy: careful eating, food for energy, food for life

- Sound and Music: making sounds with your voice, making sounds with instruments, sounds in the environment

- Using Light and Electromagnetic Radiation: where does light come from? identifying and mixing colors, colors in the environment

- The Earth in Space: seasons, plants and animals, shadows

From Science 5-7

\section{Please Note:}

For more Science activities, in addition to the ones which follow, refer to the Science section of Part II: Highlights of the KEP Training Course Curriculum. While generally all activities are included in Part V: Suggested Games, Activities and Learning Materials of the Resource Manual, teaching Science is essentially involving the children in discovery and exploratory activities. Therefore, it is difficult to discuss teaching Science in Part II, without discussing some of the activities involved. The areas of cooking, ecology, animals and plants receive special focus in the previous section. 


\section{Exploring Around Us - to develop observing and communicating skills}

- Hold a listening game in the classroom. Blindfold six children at once and let the others take turns making a noise in the room for the blindfolded children to guess what it is. For example, scrape a chair along the floor, open a cupboard, shake a pencil box and so on.

- Have a sound quiz. Play a tape of common sounds that two teams have to guess the correct answers. The team with the most correct answers wins. If you do not have a tape player, the teacher can imitate sounds for the teams to guess.

From Science 5-7

- Take the children for a discovery walk near the school. Choose a route which includes interesting things to see. Stop occasionally to look at things the children find interesting and ask them to tell you about the things they see. Encourage them to look upwards to the sky and downwards to the ground. Do they see the clouds, birds, insects? What do they hear? Let them bring some objects back to the classroom to display them, talking about them first to the rest of the class.

Some Questions to Ask:

- What can you see in the sky?

- What can you see on the ground?

- Which sounds can you hear?

- What can you smell?

- Take the children around the school compound. Encourage them to look downwards.

Some Questions to Ask:

- What can you see?

- Can you see the plants?

- Can you see flowers?

- Can you see seeds?

- Can you see animals including birds and insects?

- What color are the insects you see?

- Do they fly or crawl?

- What other things can you see apart from plants and animals?

- Do you see holes?

- What makes the holes?

Ask the children to make a collection of things collected outside to display in the classroom. Let them sort out their collection into animals, plants and others. Label everything clearly. 


\section{Science Activities}

- Take the children out for a listening walk. Ask them to be very quiet while walking. Encourage them to listen to sounds.

Some Questions to Ask:

- Can you hear the sounds of traffic - a moving lorry, bus or car?

- Can you tell the difference between the sound of a moving car and a moving bus?

- Can you hear a moving train?

- Can you imitate the sounds of moving vehicles?

- Can you hear horns in the traffic?

- Can you hear animal sounds, e.g. cows, donkeys, goats, chickens, dogs?

- Can you hear the sound of birds and insects?

- Can you imitate these sounds?

- Can you name any of these animals?

The children can experiment to see if they can hear better using a cone of newspaper in their ears. They can listen to a small sound such as a clock ticking or a child whispering to find out if it helps them to hear better.

- Take the children outside. Ask them to lie down on the ground and look up.

Some Questions to Ask:

- What can you see in the sky?

- Can you see the clouds?

- What shape are they?

- Are they moving?

- Can you see different kinds of clouds?

- Can you see birds?

- Are the birds low or high?

- Are they big or small?

- Can you see insects?

- What kinds of insects?

- Can see the tops of trees?

- Are they moving?

- Can you see the moon?

- What shape is it?

- Can you describe its position in the sky?

- What happens when you move around and change your position?

- Does anything in the sky change its position?

Let the children make drawings of what they have seen in the sky and display them. 


\section{Science Activities}

\section{Air, Water and Weather - to develop observing and experimenting skills}

- Ask the children to blow on the backs of their hands.

Some Questions to Ask:

- What do you feel?

- What causes the feeling?

- Does the air feel hot or cold?

- Does it feel wet or dry?

- Does it make a difference how you blow?

- Can you use a book as a fan?

- Can you feel the moving air?

- Have the children play a game of 'Blow Football.' They will need to make a ball from waste paper and blow tubes from hollow stalks or rolled up paper. Goal posts could be made from piles of books or sticks fixed to the edge of the table. Players try to blow the ball through each other's goal posts. Let the children play the game before you discuss it with them. At the end ask them questions about what happened.

Some Questions to Ask:

- What moves the ball?

- What happens if two players blow at the ball from opposite directions?

- Is a narrow tube better than a wide one? Why?

- Why does paper make a good ball?

- What other materials could be used?

- Cut some cheap soap into pieces, or get some soap powder. Put it in a bottle with water. Shake it up. Take the children outside and let them work in groups. Give each group a little of the soapy water in a tin or dish. Let them use straws or hollow reeds to blow bubbles. Who can make the biggest bubble?

Some Questions to Ask:

- How do the bubbles behave?

- What colors can you see in the bubbles?

- How long do the bubbles last?

- What happens to a bubble when the wind catches it?

- What do you think is inside the bubble?

- Where did the air come from?

- Can you draw pictures of your experiment?

- Provide the children with a wide variety of containers: tins, jars, bottles, sieves, funnels, plastic bowls, saucers, plastic tubing, cups. Let them pour the water from one container to another. Can they use a tube as a siphon from one tin to another? Make a hole in the bottom of a tin and in the lid. Do they see that the water stops coming out? 


\section{Science Activities}

- A Weather Chart: The class can keep a weather chart for a month. Choose one of the rainy season months, when the weather changes. Select simple symbols for sunny, cloudy, rainy and use words, for example, calm, clear, dry for other kinds of weather. A different child can record the weather on the chart each day using a marker or colored pencils/crayons. At the end of the month, the class can discuss the information on the chart. They could make bar charts to illustrate some of the findings, for example, number of sunny days, number of rainy days each week. Were there more rainy or sunny days?

- The Vanishing Water Drops: Sprinkle a few drops of water on the concrete path or veranda outside your classroom on a dry day. Ask the children to predict what will happen to the water. Explain how the sun drys the water.

\section{From Primary Ideas: A Resource Book for Primary Teachers}

- Talk about the way the seasons affect our bodies. How do we keep warm? Talk about clothes we use to protect ourselves from the seasons, e.g. adding extra clothes or wearing cool thin clothes in the heat, or waterproof things to help keep us dry in the rain.

- Do activities that demonstrate that water can move things:

- Hold a race using small plastic containers/tubs and liquid soap bottles as the propellant. This is a good activity to do outside.

- Using an assortment of heavy/light and large/small objects let the children experiment with pushing them with water. The objects can be propelled by jets of water from plastic soap bottles or from waves of water from a small bucket poured out along the ground.

- Let the children take turns to move rubber balls using the water hose. See who can push the different balls the farthest.

Some Questions to Ask

- What happens if the water squirts quickly, slowly?

- Can you make the balls move to where you want them?

- Read poems and stories and discuss the children's experience of different types of weather. Some may not have had any experience of snow whereas others may have. Discuss the children's favorite weather.

- Seasons: Look at seasonal pictures (collected from magazines etc.) and compare similarities and differences, drawing upon the children's own memories of things they have done at different times of the year. More activities include:

- Put the pictures in order, starting at the beginning of the year.

- Make a seasonal clock using some of the pictures stuck to the appropriate quadrant.

- Talk about jobs which are done at different times of the year: especially agricultural activities and holidays that are always on the same day each year.

- Extend this to a discussion about the moon, its affect on months and relation to holidays such as Eid.

- Light: Identify sources of light: the Sun, electricity, fire. Take a look around the room and try to find the light sources. 


\section{Science Activities}

- Make a Windmill

1. Use a heavy piece of square paper $-15 \mathrm{~cm}$ and from each corner, make an $8 \mathrm{~cm}$ cut towards a point in the center.

2. Fold in alternate corners to the center. Pierce the center with a thin nail or strait pin with a head. Approximately $1 \mathrm{~cm}$ from the head make a stop with some clay.
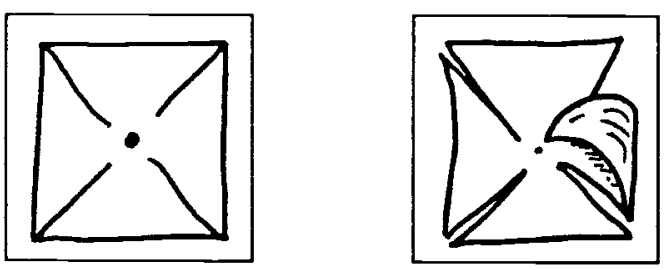

3. Make a windmill for the race game. Number the wings and folds as follows: $\begin{array}{lllllllll}0 & 1 & 2 & 3 & 0 & 1 & 2 & 3\end{array}$

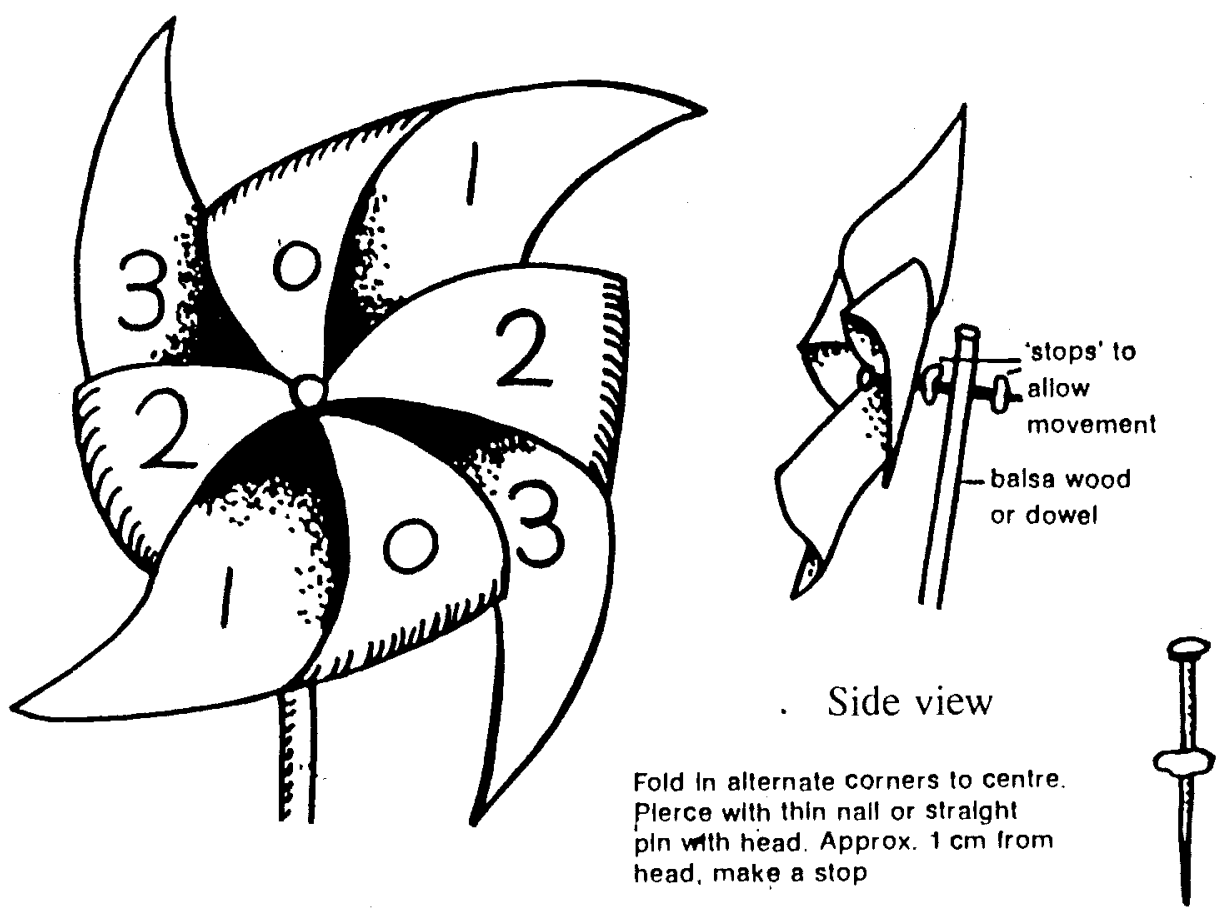




\section{Materials - to develop classifying and observing skills}

- Sinking and Floating: Have a bowl or bucket of water ready. Arrange the children in a circle around it so that they can all see. Test a variety of objects to see whether they float or sink. Let the children make a prediction first before the object is tested.

- Stir it Up: Fill up a jar with water. Put in a teaspoon of salt. Stir the salt and water slowly. How many stirs does it take for the salt to dissolve. Try the same experiment with sugar.

- I see...you see: Get the children to bring to school a small object which they particularly like. Put the objects in the middle of the floor with the children sitting around them. Play the game 'I see... you see'. Choose an object in your mind but don't tell the children what it is. Think of two of its properties, for example, its shape and its color. So for a ball the properties might be round and blue. Say out loud: "I see an object which is round and blue. What object do you see which is round and blue?" The children then have to identify the object. Let one of the children be the question-master and describe two properties of one of the objects. The other children have to guess which object the question-master is describing. Children could play the game in groups. They could talk about why they like the objects. Help them to think about the properties of the objects.

- An Object Box: Make up an object box for each group in the class. Into each put the following objects:

- a rubber band

- a seed, like a bean

- a stone

- a short piece of string

- a button

- a matchstick

- a stone

You do not need to use these exact items, select objects with interesting properties. Give out the boxes but tell the children not to open them. Get them to think about the contents of the box by shaking it. Encourage them to use their ears and to feel the box very carefully so that they gain as much evidence as possible about what the box contains before it is opened. Let them open the box and examine the objects inside to see if they can identify them. Ask them to tell you about their properties, for example, their size, color, shape, texture, rigidity or flexibility, smell. Can they tell you where they could be bought? Ask the questions the other way round, for example, 'Does anyone have an object which will grow?' It is important to let the children play with objects like buttons, paper clips and rubber bands in a less structural way as well, so that they get used to them. 


\section{Science Activities}

- Have an initial discussion about texture using the children's clothes and objects in the classroom as examples.

- Make a 'Feely Box' from a cardboard box with a closable lid. Cut a hand-sized hole at one end so that a child can put their hand inside and feel the mystery object. The teacher or another child can put about six small objects into the box unseen by the 'player', who then has to guess the contents of the box by feeling. Change the contents for each player and include objects such as small plastic toys, stones, an apple, a rubberband - be creative. $A$ variation of the 'Feely Box' described in the Educational Toys and Games section.

From Science 5-7

\section{Beginning Measurement - to develop skills for measuring length}

- Bring to class:

- pairs of objects which differ in length

- pairs of objects which are the same length

Pin two pieces of string of different length on the board. Ask the clildren about the string.

Some Questions to Ask:

- Are the pieces of string the same length?

- Which one is longer?

- Which one is shorter?

Do this with the other objects which you have brought using the same line of questioning as above.

Now put up on the board your two pieces of string which are the same length (pencils or rulers). Teach the children the term 'is the same length as'. Make sure the children understand the three relationships: 'is longer than', 'is shorter than', 'is the same length as'. Use the other objects which you have brought and things in the classroom to develop and extend the idea. The children could work in groups using their own objects and making appropriate sentences.

- Play a game with the class to find out who is tallest. Divide the class into groups of six. Each child in the group measures himself/herself against another child by standing back to back, with the back of their heels touching. In each case they say: I am taller than....,or, I am shorter than...., or, I am the same height as....

In each group there should be one child who is taller than the others. Now take the tallest children from each group and put them in order. The other children will see which child is the tallest. If you have time you can put the whole class in order by height. The information can all be recorded on a bar chart for the wall. 


\section{Living Things - to develop observing, classifying and counting skills}

- Take the children out to observe the different kinds of animals, including insects and birds, in their immediate environment. Make a chart using children's drawings of animals on the ground and birds and insects found in the trees and air. Display the chart or simply the pictures.

- Ask the children to bring different kinds of fruits and seeds to the next lesson. With your help the children should be able to name and label fruits and seeds they have collected and also know which plant they came from. Working in groups, they can sort the fruits and seeds into those which you can eat - such as maize (sweet corn), beans, rice - and those which you can not eat - such as fruits and seeds from flowers and decorative shrubs. Encourage them to tell you more about the fruits and seeds you can eat.

Some Questions to Ask:

- Which plant/tree do they come from?

- Where are they grown?

- What do they look like (color, shape, texture)?

- Which need to be cooked before they can be eaten?

- Do the fruits and seeds taste different from each other?

- Catch a butterfly or moth and put it in a glass jar with leaves for food and holes punched in the lid for air. Encourage the children to look at it closely, working in groups and describing it to the rest of the group.

Some Questions to Ask:

- How many wings does it have?

- How many legs does it have?

- How does it move?

- What color are its wings and body?

- What do butterflies live on?

- What eats butterflies?

Now let the class make their own butterflies based on what they observed. This can be done by using sheets of waste paper folded in half. Children should place their hand on the fold (just below their thumb) and draw around the hand, but do not trace individual fingers. Tear the paper very carefully along the line that was drawn. When you open the paper out, the shape should look like a butterfly or moth. The children can color the butterflies for display in the classroom.
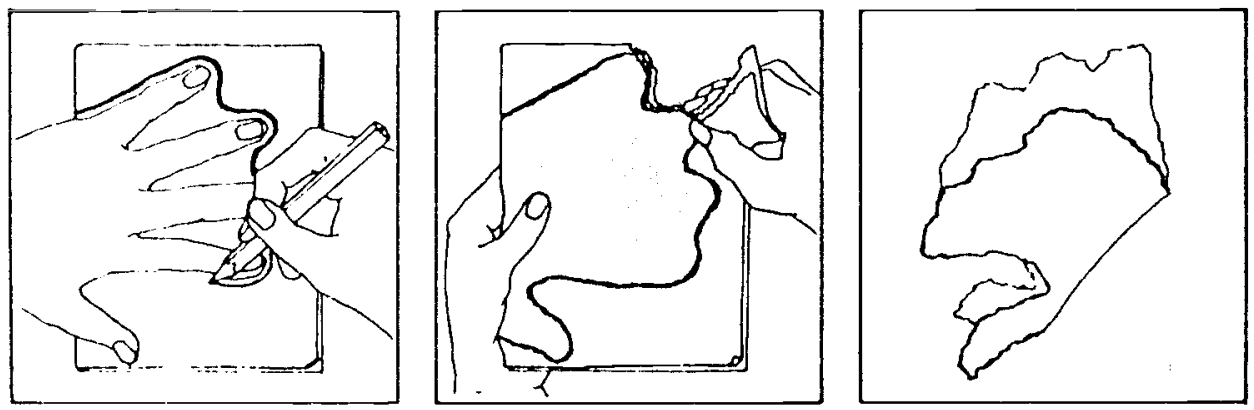


\section{Science Activities}

- Ask the children to bring different kinds of fruit to school. Pass around the fruits one at a time for the children to look at. They should feel each one with their fingers and talk about the color and the feel of each. Ask the children to tell you the colors of all the fruits they know (when unripe and when ripe). Keep unripe fruit for a few days and then let the class look at it again.

Some Questions to Ask:

- How has it changed?

- Has the color changed?

- Does it smell different?

Divide the class into two or three groups. Give each group a green tomato. Ask them whether they think these will change color or not. Now give each group a piece of paper. The tomatoes should be placed on the paper. The children then put the date and the teacher can write a sentence about what the tomato is like, based on what the children say, for example, green and hard. They can check it daily and write about any changes which happen. They can compare what happened with the other groups.

- Visit a farm with the class to see how milk comes from cows and goats, and eggs from hens. Back at school you can discuss the uses of milk and eggs.

Some Questions to Ask:

- What else do animals give us?

- Which animals are helpful?

- Which animals are harmful?

They can record their experiences by drawing. Using the children's pictures or collected pictures of animals they can make a class book about domestic animals.

- Bring a leather shoe, some small pieces of leather, some raw wool, socks, milk and if possible a little butter or cheese to the classroom. Pass round the shoe and other things made of leather for the children to feel, smell and look at. Ask them where leather comes from (cows and goats). Show them socks and other things made of wool, and the raw pieces of wool. Pass them around as before. Ask them where the wool comes from.

Do the same with milk or butter. Get the children to tell you more about domestic animals such as cows and sheep. How do we use these animals?

Some Questions to Ask:

- Which products do we get from domestic animals?

- How do we use these products?

- Ask the children to make a collection of leaves with different colors and shapes and let them paste an example of each on a chart. Label them clearly. The others may be used to make leaf rubbings with charcoal or crayon. Make a display of these. 
Activity Name: Sorting Animals

How Children Play: You can first use pictures of animals to talk about the different animals and to name them. The animal pictures can then be sorted into different categories:

1. Wild Animals and Domestic Animals

2. Found in our city/village and Not found in our city/village.

3. Animals which live on land, in the air, or in the water.

The children can take turns sorting the collection of animal pictures into each of these categories: first wild and domestic. Then reshuffle the picture cards and sort according to which animals live in your city/village and which do not. Last, sort the animals by their habitat - land, air or water - that is, where they live most of the time.

What Children Learn: Learning concepts of animal life; classifying animals ways.

How Teacher Can Help: The teacher can ask thinking questions, such as:

- Can you name an animal which is very small?

- An animal which is very big?

- Why did you put all these animals in this particular pile?

- Which of these animals have you seen? Where?

- In what ways is this animal useful?

- Can you find one which can by useful in some ways, and harmful in others?

What you Need: Pictures of animals, heavy paper or cardboard, pencils and markers, glue, container for the cards

How to Make It: Collect or make pictures of many different animals. Glue the collected pictures onto cards, approximately $15 \mathrm{~cm} \times 5 \mathrm{~cm}$ (or you can draw directly onto the cards). Prepare cardboard strips $46 \mathrm{~cm} \times 15 \mathrm{~cm}$ and divide these into 3 equal portions. Each one of these strips will correspond to the three sorting categories identified above. The chart below illustrates each of the headings on the strips. Add a simple picture for children who can not read. For example, a goat lives in the village, an elephant does not; a cow is a domestic animal and a tiger is a wild one; finally, clouds can illustrate air, waves for water and mountains for land. The animal cards can be placed under the strips for sorting.

\begin{tabular}{|c||c|c||}
\hline WILD ANIMAL & SORTING ANIMALS & DOMESTIC ANIMAL \\
\hline LIVES IN OUR VILLAGE & SORTING ANIMALS & NOT IN OUR VILLAGE \\
\hline LAND & AIR & WATER \\
\hline
\end{tabular}




\section{Science Acrivities}

- Go for a plant spotting walk around the school. Look for cultivated and wild plants and look for any unusual places where plants grow. Try to find small plants such as mosses, fungi and algae as well as observing larger ones such as trees. After explaining what weeds are, pull one up to examine the root system. For recording work, children can draw or paint from their observations.

- Take cuttings of quick growing plants and watch the root growth start in a jar of water. Note the day you took the cutting and count the number of days until root growth starts.

- Grow flower seeds and/or vegetables in a garden patch outside the classroom if the space is available or in a window box.

- Grow bean seeds in glass jars using cottonwool, paper napkins or newspaper to keep them in place against the jar. Keep them constantly moist and in the sun. The children can prepare their own seeds and observe the seeds sprouting and then plant some in soil.

From Science 5-7

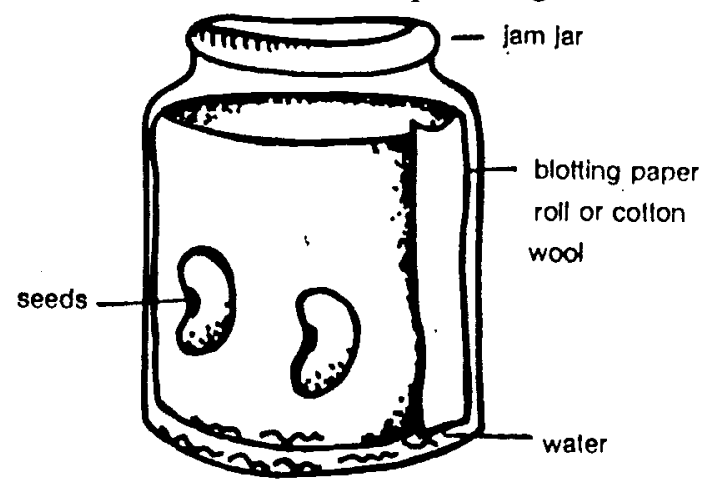

You and Your Health - to develop counting, classifying, communicating and observing skills

- Draw some children's faces on the board, very simply. Give them different expressions: happy, sad, frightened, angry and so on. Can the children say which emotion each face shows? Talk to them about how our faces often show how we are feeling inside.
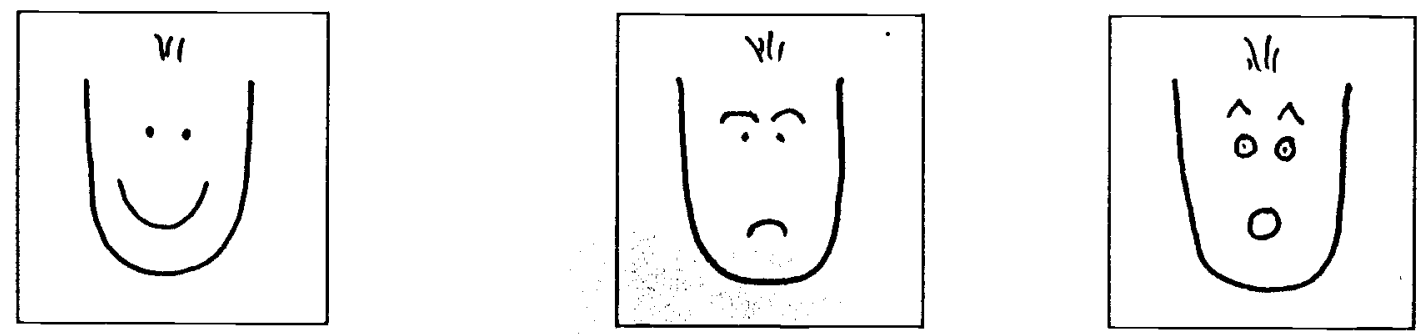


\section{Science Activities}

- What are our bodies like? With adhesive tape or glue, stick several sheets of newspapers together. Ask a child to lie down on the big sheet of paper. Get two children to draw a line around his body. Ask the children to tell you the names of the parts of the body. Write them in clearly and display the paper. Talk about the parts which are labelled.

Some Questions to Ask:

- How do you move the parts of your body?

- What happens to your chest when you breathe deeply?

- Can you feel your heart beating?

- Can you move your eyes, your ears, your nose, your toes?

- How many joints can you find in your body?

- Where are they?

- What is the smallest thing you can pick up with your toes?

- Looking at feet: Children can make footprints in the dust of the school compound. Or they could wet their feet and walk over smooth concrete. Let them examine the different shapes their footprints make.

Some Questions to Ask:

- How are footprints different?

- Are footprints different when children are walking or running?

- Can you tell which way a person was going from the footprints?

You could relate this work to tracks left by animals. Encourage children to be detectives and find out things for themselves.

- Learn to be kind! Blindfold a normal child. Lead her to the front of the class. Turn her around several times so that she does not know which way she is pointing. Ask her to find her way to the door of the classroom. (Make sure she does not hurt herself!) Ask the rest of the children to watch what happens to her. Take the blindfold off and let another child try. Talk with the class about what happened.

Some Questions to Ask:

- Did you laugh at the person who was blindfolded?

- How did the blindfolded person feel?

- Does this help you to understand what it is like to be blind?

- Would you like to be blind?

- Why not?

- Do you like to be laughed at?

How is that disabled persons can do some things very well? (For example blind children often have very sensitive hearing.) 
- Growing Older: Look at photographs of people in different age groups and discuss growing up and growing older. List differences between babies and grown-ups and grandparents.

- Moving the Body and Following Directions: Gather the clildren together and play a game such as Simon Says. Simon gives directions for moving parts of the body, sometimes in amusing ways. Children should only follow the instruction if prefaced by the words "Simon Says", otherwise they are out. Picture flash cards can be used instead of words for identifying different parts of the body.

- Differences in People: Look at differences in people - their size, skin colors, facial features, age and so on. As part of your discussion, get the children themselves to take a closer look at the different sizes among the children in the kodakistan. Group the class in order of height. You can extend this activity by making a bar graph of children's heights. Comparing size is also an important part of math lessons.

- Faces: Discuss the shape of human faces generally and draw one yourself pointing out the positions of different features - eyes, ears, nose mouth, chin etc. Get the children to do self-portraits (they can use hand mirrors to remind themselves of important features such as skin color, hair color etc) and then portraits of friends either in paints or crayons. A useful follow-up discussion would include consideration of what makes faces individual: features such as skin color, hair color and style and eye color. Have a guessing game using the finished portraits to see if the children can identify characteristic features of classmates.

From Science 5-7

\section{- Ideas for Activities Using Senses:}

Sight: Put a letter or number card at some distance in the classroom or outside and have children try reading the letters/numbers with one eye at a time.

Smell: Put ginger, garlic, and cardamon on small plates. Have the children close their eyes and smell the different aromas. Can they identify any of the smells? What do they smell like?

Hearing: Use 3 different materials, e.g., a drum, a table, and a tin. Have the children close their eyes and guess which object made the sound? Was the sound high or low? Taste: Repeat the exercise described for smell, using three different kinds of food. For example, an apple, banana, and orange. Stress the importance of safety with the children. Never put something in your mouth if it isn't food, or you don't know what it is.

Touch: Use a 'Feely bag' with classroom items in it. The child feels the item without looking at it, describes it and then takes it out of the bag and opens their eyes. The teacher helps introduce new vocabulary words and gives opposites to choose from (hard or soft) for children with limited vocabulary. 
Shadows

Before this activity talk about the danger of looking directly at the Sun.

- Look around the classroom and observe through which window the Sun is shining, which parts of the classroom are in sunshine and which are in shade. Do this several times during the day from a spot marked on the floor. Plot the movement of the Sun by painting a tiny Sun on the window at key times of the day.

- Cast a child's shadow on paper. The teacher can draw around it with chalk and the children can help to cut it out. Choose two children, one large and one small for comparison.

- Make a shadow clock. Mark an "X" on a suitable place outside where no other shadows fall. A child can stand on the same spot and the teacher draws round the shadow at several times during the day - morning, playtime, lunchtime and before going home. Discuss why the length of the shadow changes.

- Ask the children to make some observations at home. Let them find out which side of the house the Sun shines on in the morning, at lunch and in the afternoon and evening. Ask them to discover the sunniest room in the house and at what time in the day it is at its sunniest.

- Take the children outside to play with their shadows. Ask them to make the biggest shadow they can with their body. Make the smallest shadow. Make the longest shadow. Make the shortest shadow. Stand so that your shadow is behind you. Stand so that the shadow is in front of you. Touch your shadow. Jump on each others shadows. Escape from your shadow. Shake hands with your shadow. Can you move without your shadow moving? Can you jump on your shadow? Work in groups of four and make a shadow with four arms, four legs, six arms, six legs. Play a game of shadow 'tag'.

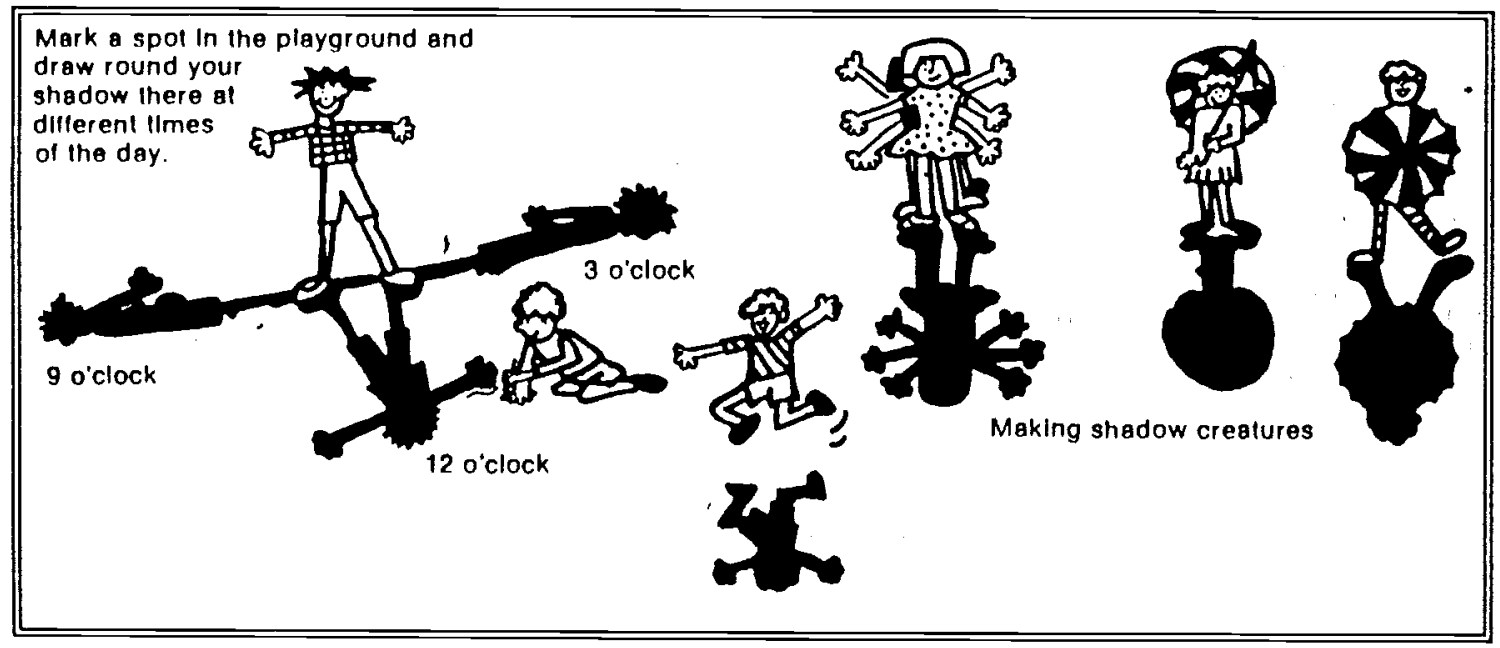

From Science 5-7 


\section{Science Activities}

\section{Colors}

- Talk about color used for display or attraction. Plants have beautifully colored flowers to attract insects. Some animals such as peacocks are very brightly colored to attract other animals.

- Look at pictures of road signs and traffic lights: red for danger or stop, green for go.

- Talk about colors used for warnings, e.g. on certain poisonous plants and creatures. Sometimes nature uses trickery and gives an animal a 'danger color' when it is not poisonous so that coloring becomes a safety feature for that animal.

- Make a color corner each week from the start of the school year. Include the children's own toys, household items and other familiar objects in the displays.

- Bring in a shopping bag of fruits and vegetables which can form the subject of a useful color sorting activity. Sharing out some of the fruit to be eaten may serve to fix the learning experience.

- Make a Spinner: Cut a circle of card and make two holes in it. Thread wool or embroidery cotton through the holes and tie in a loop. Color the card with sections of different colors to show, when the card is spun, that these colors blend together to make white. If two colors are used then these two will mix, i.e. red and blue to make purple.

The two loops are held in each hand and the spinner tossed over and over until the wool on each side is tightly twisted. Pull each hand apart gently to make the spinner spin and blend the colors.
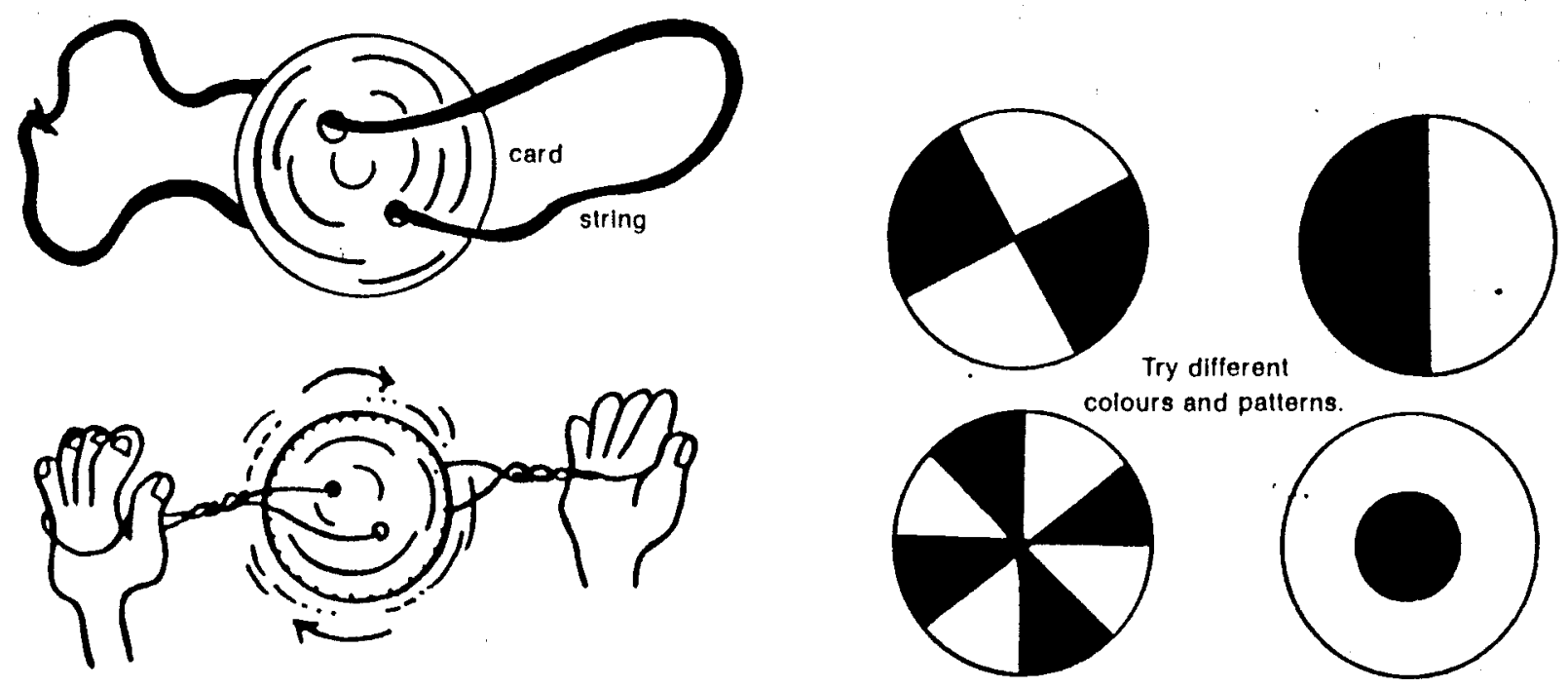

From Science 5-7 


\section{Science Activities}

- Mirrors and Reflections: Children can look at a variety of reflecting materials (water, car bumper, silver foil paper, a window, mirror, drop water on mirror). Ask the children questions and encourage them to try different things.

- Animal Sounds: Have the children imitate different animal sounds they know. Introduce them to some new animal sounds they might not be familiar with. Have a quiz or contest between two teams in the class in which they must identify animal sounds - use a recording, have the teacher imitate the sounds, or other children. Follow-up with activity with picture drawing of animals with the sounds they make. It is interesting to observe how children represent sounds on paper.

- Producing Waste: Select 10 children with the dirtiest hands after playtime. After discussing the state of these hands, get five to wash their hands in a bowl and dry them with paper towels or napkins. Get the remainder to wash and then dry their hands on the cloth towel. You can then discuss where the dirt from the hands has gone and what will happen to the three waste products: the water, the paper and dirt on the cloth.

- Looking at Shape: Once the children are beginning to be familiar with the twodimensional shapes have a game of 'I Spy Shapes in the Classroom' with clues such as: "it has 3 sides and 3 corners", or more simply, "I spy a square". The children then have to identify the specific shape that has been 'spied' - a triangle on the clisplay board, or a square window etc.

From Science 5-7 


\section{Downy Duckling's Walk}

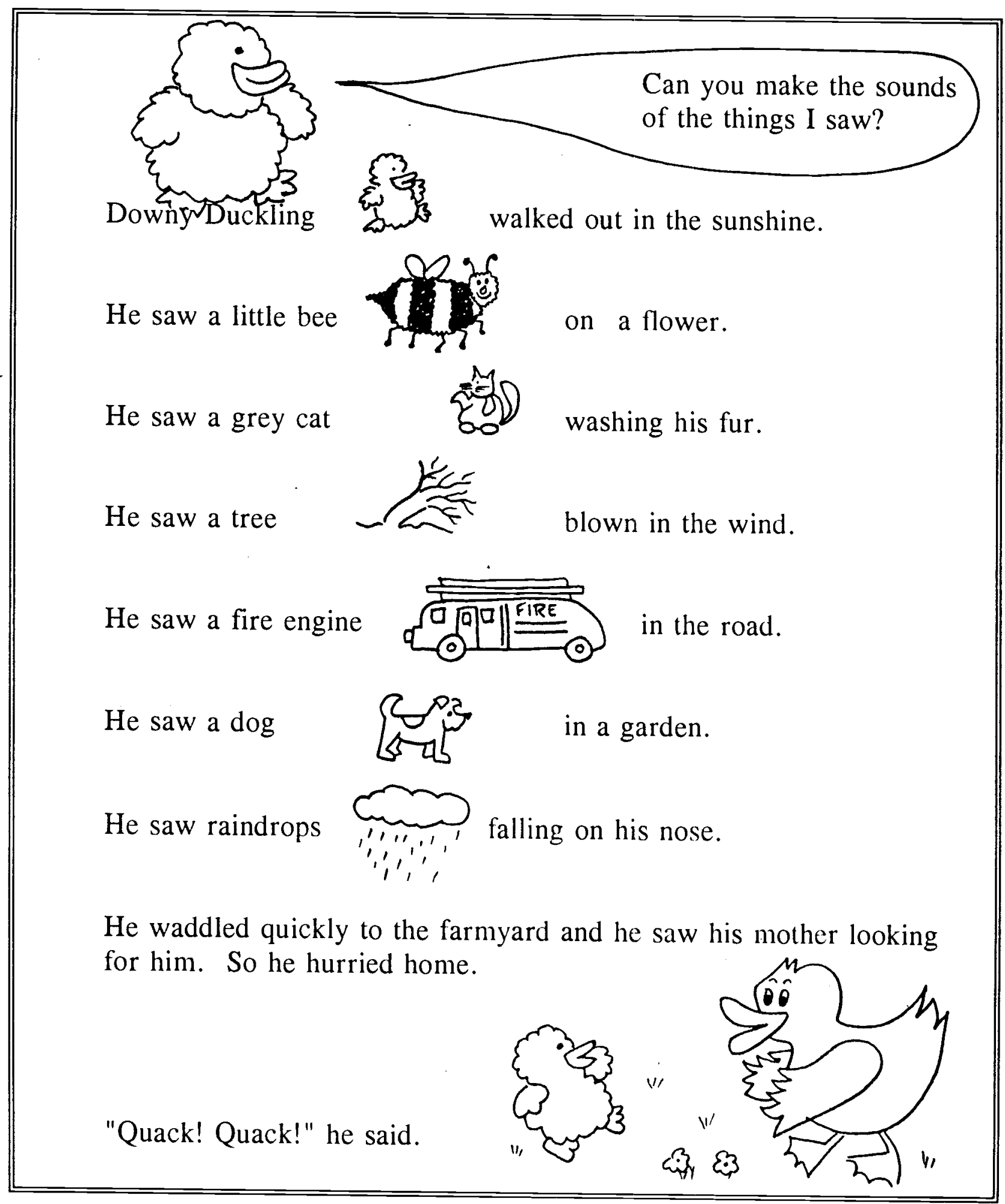

From Science 5-7 
Part V: Suggested Games, Activities and Learning Materials

\section{Islamiat}




\section{THE SACRIfice}

As the sun began to set, the prophet Ibrahim, Hajar and Ismail left the field of Arafah and made their way towards Mecca. The burning heal of the day slowly changed to the cool of night as shadows fell over the desert. It was late, so they stopped for the night at Muzdalifah.

While he slept, the prophet Ibrahim dreamt that Allah commanded him to sacrifice his beloved son, Ismail. He woke with a start and looked at Ismail asleep nearby. As he looked at the boy's face, he understood that his dream really was a command from Allah.

The next morning they woke and prayed to Allah. Then Ibrahim put his hands on Ismail's shoulders and gazed into his eyes. The boy's eyes shone with love for the father he had missed for so long. Ibrahim found it difficult to speak. "I had a dream last night," he said softly. "It makes me very sad to tell you about it."

"Please tell me father. I am ready to hear," said Ismail calmly. Ismail's words helped Ibrahim face his duty and carry out the will of Allah.

"Oh my son, I dreamt that Allah commanded me to sacrifice you," said the prophet.

When he heard his father's words, Ismail said calmly, "Father, carry out Allah's command. I have the courage to obey His will." (Al Quran, Surah al-Saffat, verse 102) Ismail already showed the great faith and loyalty to Allah of a future prophet and messenger of Allah. This was not the first test which Ibrahim and his family had faced. Ibrahim would obey Allah's command because his loyalty to Allah was even stronger than his great love for his son.

The prophet Ibrahim and his son set out for the Hill of Angels, in Mina. This was where they would carry out Allah's command for the greatest of sacrifices - the sacrifice of human life. Their courage and their faith were so great that they did not hesitate once.

At a crossroads they met a man who asked them where they were going. When the prophet Ibrahim explained, the man tried to dissuade him.

"Do not kill your only son," he said. "Just think how long you waited for him and how you nearly lost him. His life cannot be replaced."

But the man's words did not make Ibrahim and Ismail doubt what they had to do. They knew that this man was Iblis, hoping to tempt them. They picked up stones and threw them at the man until he fell to the ground. Then they left the place, which is now called Jamrah al-Ula, and went on their way. 


\section{The SaCrifice continued}

As they walked on, they met another man who tried to persuade them to forget Allah's command. Again they ignored his words, and stoned him to the ground. That man was also Iblis in disguise and the place is now called Jamrah al-Wusta. It is 156 meters from Jamrah al-Ula.

They walked on and they were tempted a third time by another man who was really Iblis in disguise. This was at the place now known as Jamral al-Aqabah, which is about 156 meters from Jamral al-Wusta, and they stoned this man too.

At last they arrived at the foot of the Hill of Angels at Mina. They got ready to carry out the sacrifice.

"Now, father, you must carry out Allah's command," said Ismail. "I will obey anything you say. But first, may I ask something of you? Please tie me tightly so I won't move and make it difficult for you. Take off my clothes, then my blood won't stain them and grieve my mother when she sees it. Sharpen your sword and kill me quickly so I do not suffer too much. Remember me to my mother and give her my clothes. They may comfort her in her grief, as a remembrance of her son."

The prophet Ibrahim was deeply moved by his son's brave words. He embraced him and kissed him.

"Allah has blessed me with a son who is loyal, respectful and has the goodness in his heart to obey Allah's will without hesitation."

Ibrahim gripped his sharpened sword in his hand. Ismail lay in front of him, tightly bound. They said their farewells and prayed to Allah. Then, as the prophet put the point of his sword to Ismail's throat, he heard a voice from the hilltop.

Ibrahim turned round and saw a healthy and fat sheep. The voice continued. "Ibrahim, take this sheep in place of Ismail," said the voice. "Kill the sheep and eat its meat. This shall be a day of celebration for you. Give some of the meat to the poor as part of your sacrifice." The angel left the sheep and disappeared.

The prophet Ibrahim killed the sheep. Its blood soaked into the earth. Ibrahim and Ismail ate some of the meat and gave the rest to others.

With this sacrifice of the sheep, Allah saved Ismail and blessed the family of Ibrahim. The Celebration Day of the Sacrifice, when Muslims all over the world kill a sheep, even today, is in memory of Ibrahim and Ismail's sacrifice of the sheep. The things we do during the Haj follow the things that were done by Hajar, the prophet Ibrahim, and their son, Ismail. 


\section{NUI's ARK}

For years Nuh tried to recall the people to Allah, but he was only laughed at and scorned. Even his own son, Kana'an and his wife Wafilah would not listen to Nuh's message. The prophet Nuh told Allah of his sorrow at his failure and Allah comforted him.

"...truly you will find no others of your people who will worship Me, save those who have already done so. Therefore do not despair at their evil deeds." (Al Quran, Surah Hud, verse 36)

Nuh realized only Allah had the power to move the people.

"O My God!" Do not allow these profane men to remain upon the Earth. Truly if You allow this to continue, in the end they will destroy your faithful servants.

"O My God, have mercy on me, on my father and mother, and on all people of the faith..." (Al Quran, Surah Nuh, verse 26-27)

Allah listened, then He told Nuh to build an ark.

Nuh found four carpenters to help him. Nuh's boat-building attracted a lot of interest. The godless took the opportunity to taunt him.

"Nuh! You've been telling us all this time that you are a prophet and a messenger of Allah. Now you have become a carpenter. Are you bored with being a prophet?"

"Have you gone mad, Nuh?" yelled one of the headmen as he passed the spot where Nuh was building the ark. "What good is a boal here?" There is no sea nor rivers. Are you going to drag it along with oxen? Or maybe you will use it to fly in the air?" he added, laughing.

The prophet Nuh replied calmly, "Today you laugh, but soon you will see the wrath of Allah."

At last, the ark was finished, and the prophet gave thanks to Allah. The people were amazed at the huge size of the ark, but they still despised the prophet Nuh. 


\section{NUH'S ARK CONTINUED}

Storm clouds gathered, a gale blew up and torrential rain began to pour. Water came up out of the Earth too. As the prophet Nulı's ark sailed with the blessings of Allah, the godless ran to and fro, trying to save themselves from the flood.

Nuh saw his son, Kana'an, running towards a hill and his heart went out to him.

"My son! My son! Come with us! Do not follow those men of sin!" his voice battled with the wind and rain.

"No!" replied his son, stubbornly. "I will climb this hill and save myself from the flood."

"Today nothing can save you but Allah, the God of Love," said the prophet Nuh. (Al Quran, Surah Hud, verse 43)

The water began to cover the houses and the trees. Nuh saw his son swallowed by the raging flood waters.

"O Allah, is not my son included in the salvation of my family?" pleaded Nuh.

Allah replied, "Nuh! Truly he is not included among those of your family who are saved. He has done evil, therefore do not speak concerning that of which you know nothing." (Al Quran, Surah Hud, verse 46)

Nuh realized that loving mankind too much could make man forget the promise and might of Allah, and he asked forgiveness.

"I seek Your protection, O Allah, for I have spoken without true understanding. If You do not forgive me than surely I am lost." (Al Quran, Surah Hud, verse 47)

At the command of Allah the rain and the storm subsided. The flood water ran into the Earth and Nuh's ark came to rest on a hillside. The prophet Nuh and the Islamic people began a new life. 


\section{WATER! WATER!}

A group of travellers were camping in a barren valley on their way to Mecca. They were very thirsty and knew there was no water nearby, Then, to their surprise, one of the travellers help up his water jar and shouted. "Water! Water!" He passed the jar round and everyone drank thankfully.

"Where did you get this water from?" asked one of the men.

"From the Zam-zam well," he replied. The people were astonished at the strange name of the well.

"It's between the two hills: the hills of Safa and Marwa, "explained the man.

"I have never seen a well there," said one of the travellers.

"How could there be a well there?" said another. "No one lives there."

"There is a well there, and there are people there," replied the man.

The others were astonished. They did not think anyone could live in such a place.

"A mother and her child live there, continued the man. "The woman is not just any women. She has great faith in Allah. She is good and patient. Her name is Hajar and her son's name is lsmail." The man had known of Hajar and Ismail in Palestine. "She is the wife of a prophet called lhrahim," he added.

"Did he leave the mother and child there, without shelter or water?" asked one of the people. They all wanted to know more about Hajar and Ismail, so the man told them what had happened when lbrahim rode away:

Soon Hajar had no food and water left, and no one passed by. She was hungry and thirsty but lbrahim had told her it was Allah's will she should be left there, and she bore the buming sun and the loneliness with patience. Ismail suffered too. When he hegan to cry. Hajar tried to comfort him but she could not help him. She searched and searched for water until she could hardly stand. Then Hajar thought she heard someone call her name. She ran between the hills of Safa and Marwa, but there was no one there. She was in despair.

Ismail was crying more and more, his heels stamping the ground. Hajar prayed for Allah's protection and Allah sent the angel Jibril.

Then Hajar saw water springing from a crack in the ground beneath Ismail's heel. She could hardly believe her eyes. She dug at the san around the spring. She cupped the water in her hands and lifting it carefully, let lsmail drink. He was quiet now and Hajar was no longer atraid.

"The water continued to flow until it became a well," said the man.

"So the water we drank came from that well?" asked the travellers.

"Yes," said the man. "It was water from the Zam-zam well; a well crealted from sorrow, patience, and a mother's faith in Allah." 


\section{AL-AMIN, TIIE WISE JUDGE}

The walls of the Ka'abah had been rebuilt. The people had worked for months, bringing the heavy stones from the mountains in the hurning heat. The old walls that Al-Walid had torn down were now repaired and the Ka'abah looked like new again.

The people were proud of their work. They came from four great clans, but they had worked together peacefully. Now the heads of the four clans were meeting together to decide who would have the honor of laying the Hajar Aswad. The Hajar was the stone which Ismail had placed in the Ka'abah. When Ibrahim and Ismail kissed the stone, the light of Allah's love shone from it. Only a very great man could lay the Hajar Aswad in the rebuilt Ka'abah,

There was one problem. The head of each clan though his own clan was the greatest, and only a member of his own clan was worthy to lay the stone. The good will when the people of the four clans worked together rebuilding the Ka'abah disappeared. For four days the heads of the clans argued. Each man was too proud to let a member of one of the other clans be chosen.

The heads of the clans went back to their people and told them to hate the other clans. They forgot the friendship there had been between them and thought of war instead.

The heads of the clans met again but now there were no smiles and no cooperation. Each threatened to kill any man who tried to lay the stone from his own clan.

The leaders of Mecca were becoming worried. They feared the argument would end with the spilling of blood. But they could not solve the problem themselves, because they were all members of the clans, too. Then one of the leaders had an idea. he went to talk to the heads of the clans.

"I want you to find a peaceful solution to this problem, he said. "We must find a judge who will be fair, a judge whose decision everyone will accept. I suggest that we choose as the judge the first man who enters the Forbidden Ground from the direction of Safat today."

Everyone agreed and they sat and waited. After a while. Muhammad came along from the direction of Safa. He was then thirty-five years old and known as Al-Amin, "he who is trusted'. Everyone was pleased to see Muhammad. "We will accept his decision." they said.

Muhammad was very surprised because he knew nothing about the argument. He sat and listened as they explained the problem to him. He though for a moment, then he said calmly, "Give me a large
piece of cloth."

Someone brought a piece of cloth and Muhammad spread it out in front of him. Then he lifted the Hajar Aswad and put it on the cloth. He told the people of the four clans to take hold of one corner each. Then together the four clans lifted the Hajar Aswad and put it in its place.

Everyone was delighted. They praised Muhammad. His wisdom was sharper than the sword. If it hadn't been for him blood would have heen spilt on the ground of Mecca.

Muhammad would become the savior of mankind. 
Part V: Suggested Games, Activities and Learning Materials

\section{Health Education}


- Keeping clean: Let children work in pairs to look at their skin. Look at the palm of the hand, an arm, a finger, a nail, the scalp, the sole of the foot. Children can compare their skin colors.

Some Questions to Ask:

- Is the surface of the skin the same in all these places?

- Does hair grow on all parts of the body?

- Is the skin always the same color?

Discuss with them the functions of skin. Explain the importance of keeping the skin clean. Children should take responsibility for looking after their partner, checking that hair, face, clothes, hands and nails are kept clean and tidy.

Make sure that children know how to wash themselves with soap and water. They should learn to wash their hands before eating and after going to the toilet.

From Primary ldeas: A Resource Book for Primary Teachers

- Tell a story to the whole group about germs, how little they are, but how they can make us sick. Look under each other's nails for dirt. Teacher can demonstrate how to use a scrub brush for cleaning nails and children can practice.

This story and demonstration method can be done with any other aspect of health and hygiene: treating a wound, brushing teeth, washing hands and face, preparing ORS or Wheat Water etc.

Simple visual aids - flip charts and health education materials for a health center - or pictures you have prepared on your own, can be a good starting point for a story. Ask the children what they think the picture is about and build the story around their interpretation. This can be supplemented with asking the children what happens in their house when someone cuts themselves, or has diarrhea - relate your lesson to what is happening in the households al ready.

\section{From KEP Training Course Curriculum}

- Invite a doctor, nurse, and/or health worker to the class to talk about their work as a way inform the children about people's jobs and a means to improve health, prevent accidents.

- Act out the role of a doctor, nurse, or health worker. Set up a clinic in the dramatic play/imaginative play corner for a short time.

- Visit a clinic, doctor's office, hospital or health center with the children to see and talk about the work that is done there and its importance for health.

From Science 5-7 
- Practice the habit of keeping the kodakistan and surroundings clean with the children:

- Sing songs/act out dramas on good practices related to cleanliness/the environment.

- Play games involving collecting rubbish around the kodakistan, arranging books, and looking after the orderliness/cleanliness of the classroom and grounds.

- Ensure the safety of the children by teaching them how to look after their own safety:

- Talk about situations/actions which are dangerous, such as, playing near ponds/wells, playing with matches, playing with sharp objects etc.

- Discuss traffic rules and role play safe behavior on roads.

- Practice doing things which ensure safety, such as, closing the gate, throwing away broken glass, nails and rubbish etc.

- Sing songs and act out dramas related to safety.

From Malaysian Course of Childhood Developmen and Childcare

\section{- Road Safety}

Draw a large map of the area around the school. Mark the paths or road by which children come to school. Let the children mark on it or tell you where they cross the road, places where accidents have happened, places such as crossroads which need special care.

Discuss road safety rules with the children and learn a safely code: stop, look, listen, before you cross the road. Explain the dangers of crossing the road close to a stationary velicle such as a lorry. Let two or three children pretend to be a parked vehicle. Can the others say where it is safe to cross?

\section{From Science 5-7}

\section{- Some Practical Ideas for Health}

1. Meet with parents to discuss healthy balanced meals and provide examples during the meeting; make up different menus during the meeting; the emphasis should be on food that is readily available.

2. Money spent on sweets and so on, should be spent on healthy things like fruit and nuts.

3. Make up posters on the different food groups showing examples of each: energy, growth and protection foods for the children and adults. Make or cut out pictures of healthy foods.

4. Plan ways to get children to understand the importance of being clean, for example, make up a story about how microbes can be washed away; or draw or cut and paste pictures of times when hands should be washed.

5. Ask a dentist or person from a clinic to give a talk to children and parents about good dental care and its importance.

6. Liaise with parents regarding immunizations, weight/growth progress and proper functioning of the five senses. 
Part V: Suggested Games, Activities and Learning Materials

\section{Nursery}




\section{Nursery Activities}

\section{IDEAS FOR THE NURSERY ClaSS}

- See the chart "What's It Like to Be..." Part II - Curriculum Highlights of the Nursery section for more activities. The column/section entitled "Ilow to Help Me Learn" has many good ideas for activities and things to do in the infant class.

- Hang pictures on the wall for the babies to look at and change these every few weeks.

- Hang mobiles on the cribs and from the ceilings.

- Make simple puzzles. For example, cut a picture in half and the children can put the two halves together to complete the picture.

- Collect things babies can practice "picking up" and keep them in a bag or box.

- Make a simple posting box. Use a cardboard box and cul a slit in the side or top. Cut out colored cardboard disks for babies to put through the slit in the box.

- Make a clothespin peg-box for babies to clip on and off. Store the pegs in the box.

- Give spoons to the baby to play with and practice using.

- Make some thick paint and let children do finger painting.

- Provide scraps of paper for scribbling.

- Encourage tearing paper and sticking - you can use newspaper for this.

- Make playdough and let children play freely.

- Provicle water in bowl with cups and jugs to pour. Sometimes put food coloring in the water or washing up liquid to make bubbles.

- Encourage fantasy play with old teapot, cups. Pretend to make tea and give to the baby.

- Sing songs. Sing your favorite songs about washing when giving the baby a bath. Sing lullabies when laying the babies down for a nap.

- Make musical instruments with plastic pots and beans or pebbles that children can use.

- Make a book for babies from cloth, or cover with plastic using only pictures.

- Make a collection of things with different smells (make sure none of them are poisonous for babies) Put on low table that babies can reach and experiment with.

- Make a collection things that feel different. Put on low table as above.

- Provide infants with opportunities to find out properties of objects. For example, a ball is round, it bounces, it can be thrown or bounced, etc.

- Make a collection of common objects (fruit, clothes, toys etc.) A lot are the same in some way, others are different. Teach while playing, explaining the object, talk to them, saying "give me all the apples", for example.

- Encourage crawling by putting movable toys (a ball, toy car etc.) in front of the infant, a short distance away. Sometimes during crawling, a rolled pillow should be put between the infant and toy so that the infant will have to crawl over the pillow to reach the toy.

- Play "peek-a-boo" with infants. Hide your face behind your hands or some other object. Or a small stuffed toy can be hidden and reappear. Babies seldom tire of this game.

- Play "hide and seek" with older infants. Let the child see you put a small toy under a blanket or pillow. They will look for it there. 


\section{SUITABLE TOYS FOR TIIE NEWBORN TO 18 MONTIIS}

\section{Below 3 Months}

- Encourage the movements of the limbs by providing such toys as teething rings made from rubber/plastic of various shapes, sizes and colors.

- For listening and hearing provide toys that produce sounds such as bells, a music box, clocks, rattles etc.

- Provide toys that hang and move, such as mobiles and plastic chains of various colors, shapes and sizes. Hang bright and large pictures on the wall. Provide soft stuffed toys.

\section{3 to 6 Months}

- At this stage, the baby is able to grasp and is interested in the surroundings. The baby likes to feel things with different textures like soft/hard, smooth/rough, etc. Provide toys for this purpose and for holding.

- Continue to use the baby toys described above and add more toys at five months, such as plastic blocks of various colors, shapes and sizes. plastic balls, cars that can be moved by hand, large picture book, dolls, and rattles of various shapes and sounds.

- Bond with the baby by playing the following game. Walk your fingers gently from the end of the baby's feet to his head. Tickle the baby under the chin, armpit and palm. Touch and name the baby's nose, mouth, eye and other parts of the bocly.

\section{6 to 12 Months}

- At this stage, the baby likes to look at things, throw and drop things and insert them into boxes. Continue to give the baby the above toys and then add the following kinds of toys: pictorial blocks, toy phone, simple jigsaw puzzles, toys that can be built and removed, animal cut-outs from materials, average size box for the baby to insert or take out toys, toys that have comparison shapes and colors, and toys that concentrate on movement.

\section{Months to Walking}

- At this stage, the baby needs toys that encourage hand and leg muscle movements. Give the baby the following toys: blocks with various colors and shapes with numbers or alphabets, toys that can be pulled with strings, a mattress to roll and jump on, paper and pencil for sketching, other toys that can be built and dismantled as well as can be compared with various colors, sizes and shapes. 


\section{Activities for Physical Develophent}

Age: Birth-3 montlis

Capability: Able to move the head from left to right without assistance.

Objective: Train the baby to move his head to one direction towards an object.

Material: Toys that attract the baby's attention such as rattle, vehicle, doll etc.

Method: Lay the baby on a flat surface; get the baby's attention; show the baby a toy (about $20 \mathrm{~cm}$ from his face); wait until the baby pays attention to the toy; follow the movement of the toy slowly from the left to the right.

Note: Get the baby's attention in a pleasant mamner. Avoid doing the activity too long.

Age: $0-3$ months

Capability: Able to move the head from left to right without assistance.

Objective: Train the baby to move her head towards sound and strengthen neck muscles.

Material: Sound-producing objects such as wood, bamboo, bottle filled with water, etc.

Method: Make a noise with the object within the baby's hearing clistance; when the baby moves her head towards the source of the sound slowly direct the sound to the other ear.

Note: Avoid using objects which produce loud moises such as a bell and avoid moving the object too close to the baby's face. Avoid performing the activity too long. 
Nursery Activities

Age: 1-3 months

Capability: Holding

Objective: To train in using and strengthening the hand muscles and reacting to touch.

Material: Can be done without materials or use object that the baby is able to hold on to.

Method: Let the baby hold a finger or an object; if he is slow to react to the touch of his palm, be closer to him and talk to him while you tickle his palm; when the baby grasps your finger, shake and gently pull it according to the strength of his grasp; may begin with the little finger and change to the third linger until the thumb; a damp or dry finger enables the baby to feel the difference.

Note: Your hand must be clean; objecrs used must be suitable for grasping/holding.

Age: $3-4$ months

Capability: Try to hold out hands to reach for something given to her.

Objective: To train the movement of her hands and to strengthen her hand muscles.

Material: A toy, such as a rattle

Method: Hand her the toy within the baby's reach; shake the toy so that she is able to hear and see the toy used; attract her attention and hand her the toys so that she can reach for it; assist her to produce sound from the toy she is holding by shaking her hand.

Note: Use clean and safe toys. 
Nursery Activities

Age: $4-5$ months

Capability: Able to roll over to his stomach when lying down.

Objective: To train the baby to roll over on his stomach; strengthen his neck muscles, backbone, hands and legs.

Material: Baby blanket and mattress

Method: Spread a baby blanket on a mattress; tie the baby on the blanket; hold one end of the blanket when the baby is lying down; gently pull and observe the baby roll over with his hands straight and close to the body.

Note: This activity is not suitable to perform on rough surface such as on a wooden or cemented floor.

Age: $6-7$ months

Capability: To reach for something.

Objective: Strengthen the hand and leg muscles.

Material: Bright colored toys

Method: Place the toy in front of the baby; bring the baby's attention towards the toy; change the distance of the toy so that the baby will follow.

Note: Ensure that the toy is clean and safe; do not perform this activity too long to prevent the baby from tiring. 
Nursery Activities

Age: $8-9$ months

Capability: Crawl towards an object or person.

Objective: Encouraging the baby to move in order to reach for something. To strengthen the leg and hand muscles, and to balance.

Material: Any toy that is tied to a string and moves when pulled.

Method: Place the toy about $60 \mathrm{~cm}$ in front of the baby; pull the toy gently in front and encourage the baby to follow it.

Note: The toy must be sturable and not have sharp edges and sides. Ensure that the floor is clean. When the baby succeeds in reaching the object, let her hold and feel the toy. Do not pull the toy to anorher direction immediately. Do not perform this acrivity for long periods.

Age: $9-12$ months

Capability: Able to stand for a while.

Objective: Strengthen the leg muscles so that the baby is able to stand without holding on to something.

Material: Mat

Method: Hold the baby under the armpits to support the baby when he stands. When the baby is standing, let go of him once in a while. Hold on to him when he is about to fall.

Note: You must be carefinl so that the baby does not fall. 


\section{Nursery Activities}

Age: $12-18$ months

Capability: Able to walk a few steps, without assistance.

Objective: To train the child to balance herself by encouraging her to walk to a certain place to get an object.

Material: No specific objects as long as they are suitable.

Method: Ask the child to get a toy. Tell her to put back the toy she took. Praise her after she has done so.

Note: Ensure that the object that is taken by the child is easy to reach fort.

Age: $18-20$ months

Capability: Able to climb stairs with support/assistance.

Objective: Train the child to coordinate hands and legs and body when climbing on stairs.

Material: Large, hard and stable boxes

Method: Arrange the boxes like stairs. Ask the child to climb up and clown. Observe him when he climbs up and down. Praise him when he succeeds.

Note: Ensure that the boxes are secure and do not fall when climbed on. Be prepared in case the child falls and make sure he does mot his his head if he does fall.

Make up your own activities using the above ourline and the following crireria:

- Is the child involved? interested? not incrested?

- What is the child's reaction: speech, mannerisms; the level of achievement towards the activity?

- Are the materials usced suitable?

- Are the methods used suirable?

- What are the problems faced when doing this activity?

- What changes/improvements would your recommend 
Nursery Activities

Activity Name: Knotted Doll

What you Need: A piece of material (about $40 \mathrm{~cm} \times 40 \mathrm{~cm}$ ), stuffing (wool, soft material, foam chips), string or strong cord, needle and thread, scraps of material and wool, scissors, markers, glue

\section{How to Make It:}

1. Hem the material on all sides.

2. Put a ball of stuffing in the center of the material.

3. Pull the material closely round the stuffing for the head. Tie securely at the neck with string.

4. Knot the two corners for the hands.

5. Draw a face with the markers.

6. Using wool and scraps of material, glue on the hair, hat or scarf etc.

The doll can be used both in the nursery and for imaginative play in the "home corner".

This idea comes fiom Learming with Serap 
Part V: Suggested Games, Activities and Learning Materials

\section{Citizenship Education}




\section{Citizenship EduCation}

The following has been adapted firom the Malaysian Course of Childhood Development and Childcare. It provides both objectives and ideas for activities that aim to promote pride in one's country and principles of good citizenship and national identity.

\section{Love for Afghanistan - Activities and Objectives}

To know and sing songs about Afghanistan.

To listen and tell stories about Afghanistan through simple storics, (lrawings and pictures.

To look at pictures of historical and famous places in Afghanistan and to visit such places.

\section{Respect for Symbols of Afghanistan}

To recite or sing the National Anthem of Alghanistan

To recognize and respect the flag of Afghanistan and provincial tlags.

To listen to stories about the flag, to color pictures of the nag; use paper to make the flag.

\section{Respect for the Mosque}

To recognize pictures of the Mosque and other religious places.

To talk about and tell stories about the mosque and religious places.

\section{Cooperation and Teamwork}

To practice the spirit of teamwork and neighborliness in and outside of the kodakistan.

To listen to stories about solidarity among Afghans.

To play games in teams and do activities in groups.

To act out dramas, recite and sing songs in groups.

To celebrate Afghan festivals at the kodakistan.

To respect the customs/cultural practices of the various ethnic groups in Afghanistan.

\section{Importance of Following Rules}

To know and practice the rules at the kodakistan.

To take turns/wait in line when playing, washing, having meals etc.

To make dolls, puppets and act out stories about observing rules.

To tell stories/talk about pictures showing scenes where rules are followed and problems that can happen when rules are disobeyed.

To help children understand why rules are important.

\section{Sense of Community}

To help one another at the kodakistan and be considerate of others.

To talk about and tell stories about communal togetherness by using pictures, books, etc.

To practice games about give and take and to dramatize ways of being neighborly.

To celebrate birthdays of friends at the kodakistan.

\section{Respect for Leadership}

To know Afghan leaders through pictures and show respect for them.

To follow the instructions of the team/group leader when playing in teams.

To act out the role of leaders. 


\section{Bibliographic information for sources cited in Pant $\mathrm{V}$ only}

Afghanistan Pre-school Curriculum. Ministry of Education, Department of Kindergarten Authority: Kabul, Afghanistan. Please nore: Bibliographic information incomplete.

Berman, Denise and Susan Connolly. Leaming with Scrap: Ideas for Making Preschool Equipment and Educational Toys, Cape Town: Early Learning Resource Unit, 1987.

Brown. One, Two, Buckle My Shoe: Math Activities for Young Children, Mt. Rainier: Gryphon House Inc. Please note: Bibliographic information incomplete.

Creative Ideas from Low Cost Materials: The Joy of Making..

Please nore: Bibliographic information incomplete.

Early Childhood Education Project Committee. The Is/amic Pre-School Curriculum, Nairobi, Kenya. Please note: Bibliographic information incomplete.

Fitsimmons, Jim and Rhona Whiteford. Blueprints: Science 5-7 Teacher's Resource Book \& Copymasters, Cheltenham: Stanley Thornes (Publishers) Ltd., 1990.

Heald, Chris and Val Eustice. Ready for Maths, Warwickshire: Scholastic Publications Ltd., 1988.

Hohmann, Mary. A Study Guide to Young Children in Action, Ypsilanti: The High/Scope Press, 1983.

Kerry, Trevor and Janice Tollitt. Teaching Infamts, Oxford: Basil Blackwell Ltd., 1987.

Knight, Gill. Primary Ideas: A Resource Book for Primary Teachers, London: The British Council with Macnillan Publishers Ltd., 1987.

Kurrien, Zakia. Helping Childen Leam, Bombay: Orient Longman Lud., 1988.

Lockyer, Val. Ladybird Learning at Home Series: Frog, Rabbit. Teddy and Panda Books, illustrated by Sara Silcock, Auburn: Ladybird Books, 1987.

Malaysian Course of Childhood Development and Childcare: Childcare Unit, Ministry of Welfare Services Malaysia with the Cooperation of Bernard van Leer Foundation, 1987. Malaysian Curriculum Books: Series of 12 books and 3 Modules. Unit Taska: Kementerian Kebajikan Masyarakat, Malaysia.

Matthews, Julia. Bright Ideas: Maths Activities, illustrated by Ken Stott, Leamington Spa: Scholastic Publications Ltd., 1987. 
Montgomery, Diane and Anne Rawlings. Bright Ideas: Classroom Managemem, illustrated by Sue Lines, Leamington Spa: Scholastic Publications Ltd., 1987.

Mort, Linda and Janet Morris. Bright Ideas for Early Years: Getting Started, Warwickshire: Scholastic Publications Ltd., 1989.

van der Merwe, Karen. Learming Together, Cape Town: Early Learning Resource Unit, 1990.

How Children Develop and Learn: An Introduction to Early Childhond Education, Cape Town: Early Learning Resource Unit, 1988. 